UNIVERSIDADE DE BRASÍLIA

FACULDADE DE TECNOLOGIA

DEPARTAMENTO DE ENGENHARIA ELÉTRICA

\title{
PROJETO, CONSTRUÇÃO E ENSAIOS DE UM PROTÓTIPO DE TRANSDUTOR DE CORRENTE DO TIPO BOBINA DE ROGOWSKI
}

BRUNO DA SILVA XAVIER e FÁBIO DOS SANTOS SILVA

ORIENTADOR: FRANCISCO DAMASCENO FREITAS

MONOGRAFIA DE GRADUAÇÃO EM ENGENHARIA ELÉTRICA

PUBLICAÇÃO: ENE - 02/2006.

BRASÍLIA/DF: DEZEMBRO - 2006. 
UNIVERSIDADE DE BRASÍLIA

FACULDADE DE TECNOLOGIA

DEPARTAMENTO DE ENGENHARIA ELÉTRICA

PROJETO, CONSTRUÇÃO E ENSAIOS DE UM PROTÓTIPO DE TRANSDUTOR DE CORRENTE DO TIPO BOBINA DE ROGOWSKI

BRUNO DA SILVA XAVIER e

FÁBIO DOS SANTOS SILVA

MONOGRAFIA SUBMETIDA AO DEPARTAMENTO DE ENGENHARIA ELÉTRICA DA FACULDADE DE TECNOLOGIA DA UNIVERSIDADE DE BRASÍLIA COMO PARTE DOS REQUISITOS NECESSÁRIOS PARA A OBTENÇÃO DO GRAU DE ENGENHEIRO ELETRICISTA.

APROVADA POR:

Prof. Francisco Damasceno Freitas, Doutor (ENE-UnB)

(Orientador)

Prof. Alcides Leandro, Mestre (ENE-UnB)

(Examinador Interno)

Prof. Mauro Moura Severino, Mestre (ENE-UnB)

(Examinador Interno)

BRASÍLIA/DF, 19 DE DEZEMBRO DE 2006. 


\section{FICHA CATALOGRÁFICA}

\begin{tabular}{l} 
XAVIER, BRUNO DA SILVA \& SILVA, FÁBIO DOS SANTOS \\
Projeto, Construção e Ensaios de um Protótipo de Transdutor de Corrente do tipo Bobina \\
de Rogowski [Distrito Federal] 2006. \\
xi, 74 p., 297 mm (ENE/FT/UnB, Engenheiro Eletricista, 2006). Monografia de \\
Graduação - Universidade de Brasília. Faculdade de Tecnologia. Departamento de \\
Engenharia Elétrica. \\
$\begin{array}{ll}\text { 1. Bobina de Rogowski } & \text { 2. Transdutor de corrente } \\
\text { 3. Indutância mútua } & \text { 4. Fluxo magnético } \\
\text { I. ENE/FT/UnB } & \text { II. Título (série) }\end{array}$ \\
\hline
\end{tabular}

\section{REFERÊNCIA BIBLIOGRÁFICA}

XAVIER, BRUNO DA SILVA \& SILVA, FÁBIO DOS SANTOS (2006). Projeto, Construção e Ensaios de um Protótipo de Transdutor de Corrente do tipo Bobina de Rogowski. Monografia de Graduação, Publicação ENE 02/2006, Departamento de Engenharia Elétrica, Universidade de Brasília, Brasília, DF, 74p.

\section{CESSÃO DE DIREITOS}

AUTORES: Bruno da Silva Xavier e Fábio dos Santos Silva.

TÍTULO: Projeto, Construção e Ensaios de um Protótipo de Transdutor de Corrente do tipo Bobina de Rogowski.

\section{GRAU: Engenheiro Eletricista}

ANO: 2006

É concedida à Universidade de Brasília permissão para reproduzir cópias desta monografia de graduação e para emprestar ou vender tais cópias somente para propósitos acadêmicos e científicos. Os autores reservam outros direitos de publicação e nenhuma parte dessa monografia de graduação pode ser reproduzida sem autorização por escrito dos autores.

Bruno da Silva Xavier

SHIS, QI 21, conjunto 7, casa 14, Lago

Sul.

71.655-270 Brasília - DF - Brasil.
Fábio dos Santos Silva

Quadra 04, casa 05, Rua Piauí, Vila Vicentina.

73320-040 Planaltina - DF - Brasil 


\section{AGRADECIMENTOS}

Agradecemos, em primeiro lugar, a Deus, fonte de vida, fé, força e perseverança.

Agradecemos especialmente aos nossos pais, Helena e Antônio, Edeilma e Hélio, pois eles foram quem formaram nossas personalidades e caráter, e a nossas respectivas namoradas, que sempre nos deram apoio e estiveram do nosso lado nos momentos difíceis.

Agradecemos também ao nosso orientador, professor doutor Francisco Damasceno Freitas, pela oportunidade deste trabalho e ao professor doutor Franklin da Costa Silva, pela orientação a respeito do estudo dos campos eletromagnéticos.

Agradecemos ainda aos técnicos dos laboratórios Silmar Alves de Oliveira, Célio Matos da Silva e Valter Costa de Oliveira, que nos deram apoio técnico para a realização dos ensaios. 


\title{
RESUMO
}

PROJETO, CONSTRUÇÃO E ENSAIOS DE UM PROTÓTIPO DE TRANSDUTOR DE CORRENTE DO TIPO BOBINA DE ROGOWSKI.

\author{
Autores: Bruno da Silva Xavier e Fábio dos Santos Silva \\ Orientador: Francisco Damasceno Freitas
}

Palavras-chave: Bobina de Rogowski, transdutor de corrente, indutância mútua, fluxo magnético.

Brasília, 19 de dezembro de 2006.

A Bobina de Rogowski é um transdutor de corrente, semelhante a um transformador de corrente, porém não possui núcleo ferromagnético, cujo enrolamento primário é o próprio condutor ou barramento onde circula a corrente que se deseja medir. Possui um enrolamento secundário que é mantido em aberto, ou conectado a uma alta impedância.

A partir do principio de funcionamento da Bobina de Rogowski, que é baseado na Lei de Faraday-Lenz, apresentou-se um modelo matemático, observando o acoplamento magnético entre seus enrolamentos, para se encontrar a relação entre a tensão no secundário e a corrente elétrica no primário.

O principal objetivo deste trabalho é projetar, construir e ensaiar um protótipo da Bobina de Rogowski. Foram desenvolvidos métodos de ensaio com objetivo de aperfeiçoar a medição para baixas correntes. A cada etapa de desenvolvimento foram encontradas dificuldades nas formas de medição, todavia, os erros foram identificados e corrigidos. 


\section{SUMÁRIO}

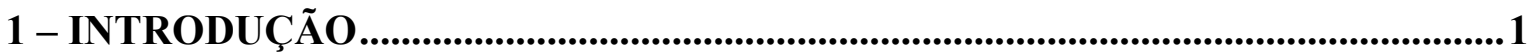

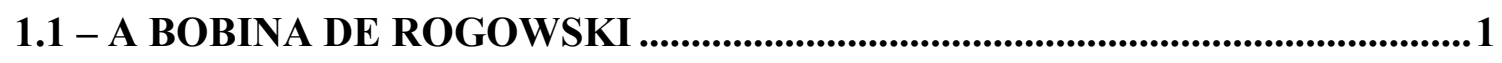

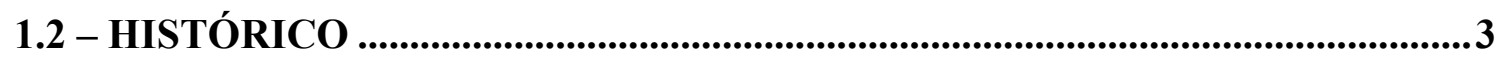

1.3 - MOTIVAÇÃO DESTE TRABALHO................................................................. 4

1.4 - OBJETIVO .........................................................................................................................5

2 - METODOLOGIA................................................................................................................6

2.1 - ASPECTOS CONTRUTIVOS DA BOBINA DE ROGOWSKI ......................6

2.2 - PRINCÍPIO DE FUNCIONAMENTO DA BOBINA DE ROGOWSKI............ 7

2.2.1 - Modelo matemático................................................................................................7

2.2.2 - Desenvolvimento a partir da Lei Circuital de Ampère .....................................9

2.2.3 - Desenvolvimento a partir da Lei de Biot-Savart ........................................13

2.2.4 - A relação entre a tensão no enrolamento secundário da Bobina de

Rogowski e a corrente elétrica no enrolamento primário ........................................16

3 - PROJETO DA BOBINA DE ROGOWSKI ........................................................19

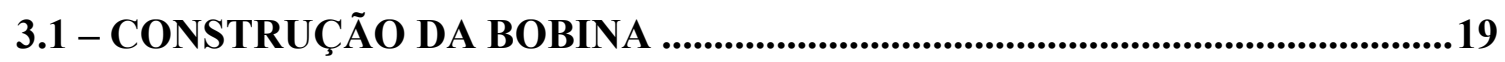

3.2 - ETAPAS DE DESENVOLVIMENTO DA BOBINA ...................................22

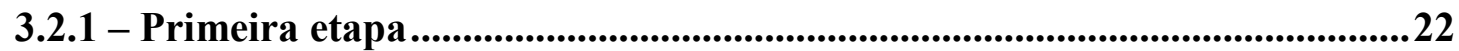

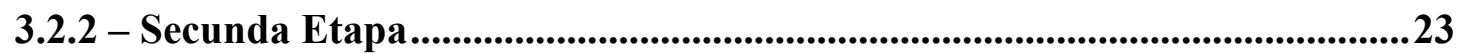

3.2.3 - Terceira Etapa..............................................................................................25

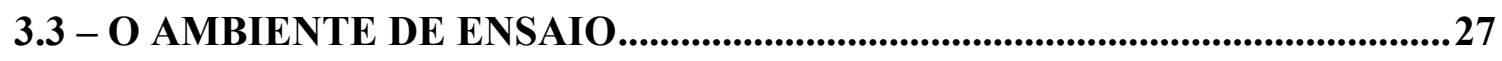

3.4 - MÉTODOS DE ENSAIO ................................................................................28

3.4.1 - Primeiro método ..............................................................................................................30

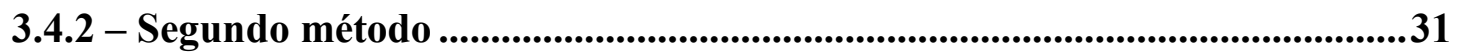

3.4.3 - Terceiro método ......................................................................................31

3.4.4 - Quarto método .............................................................................................32

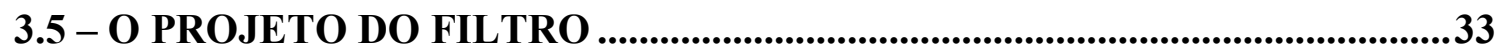

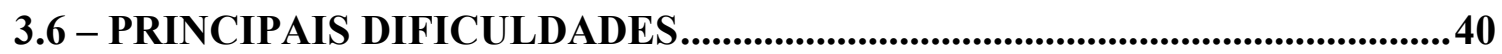

3.6.1 - Baixas correntes .........................................................................................................40 


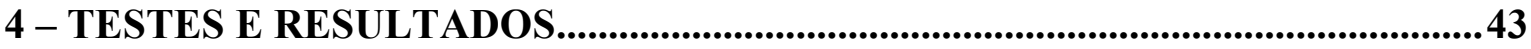

4.1 - TESTES E RESULTADOS DA PRIMEIRA BOBINA ...................................44

4.1.1 - Resultados obtidos .........................................................................................46

4.2 - TESTES E RESULTADOS DA SEGUNDA BOBINA ......................................49

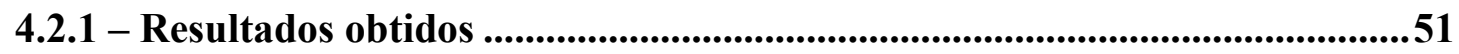

4.3 - TESTES E RESULTADOS DA TERCEIRA BOBINA …...............................54

4.3.1 - Resultados obtidos .......................................................................................55

4.4 - TESTES E RESULTADOS COM CORRENTES MAIORES.......................67

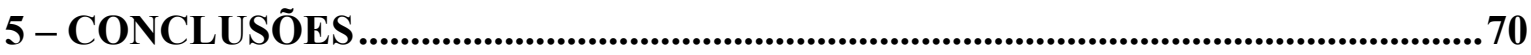

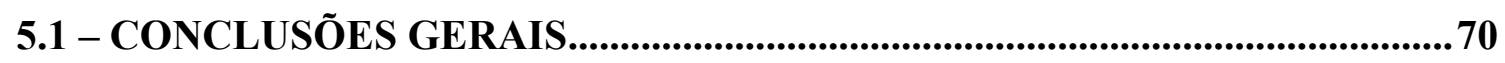

5.2 - SUGESTÕES PARA TRABALHOS FUTUROS .............................................71

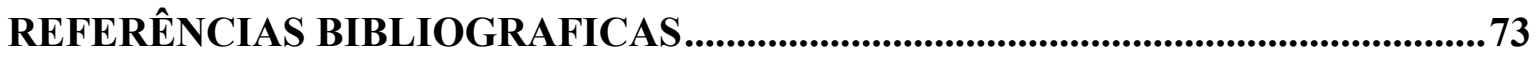




\section{LISTA DE TABELAS}

Tabela 3.1 - Aspectos construtivos do núcleo da bobina................................................ 19

Tabela 3.2 - Aspectos construtivos do primeiro secundário. .............................................22

Tabela 3.3 - Aspectos construtivos do segundo secundário..............................................24

Tabela 3.4 - Possíveis valores para corrente, considerando uma tensão de 220 V .............29

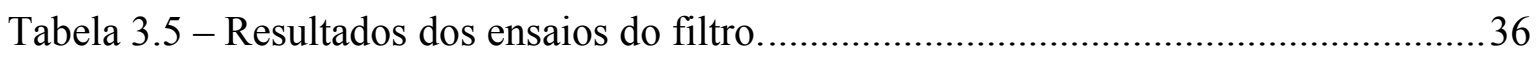

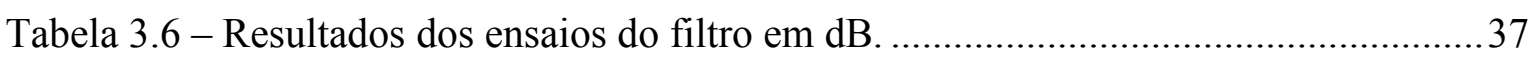

Tabela 4.1 - Valores de tensão obtidos com a primeira bobina e o primeiro método..........46

Tabela 4.2 - Valores de tensão obtidos com a primeira bobina e o segundo método......... 47

Tabela 4.3 - Valores esperados de tensão variando o valor de $l$........................................50

Tabela 4.4 - Valores obtidos com a segunda bobina e o segundo método..........................51

Tabela 4.5 - Valores de tensão obtidos com o terceiro método. ..........................................52

Tabela 4.6 - Valores de tensão obtidos com a terceira bobina e o terceiro método.............55

Tabela 4.7 - Valores de tensão obtidos com a terceira bobina, o terceiro método e o filtro.

Tabela 4.8 - Valores de tensão obtidos com a terceira bobina, o terceiro método filtro e condutor centralizado 59

Tabela 4.9 - Valores de tensão obtidos com a terceira bobina e o quarto método 62

Tabela 4.10 - Valores de tensão obtidos com a terceira bobina, o quarto método e filtro..65

Tabela 4.11 - Valores de tensão obtidos com a terceira bobina e o terceiro método. 69

Tabela 4.12 - Valores de tensão obtidos com a terceira bobina, o quarto método e o filtro. 


\section{LISTA DE FIGURAS}

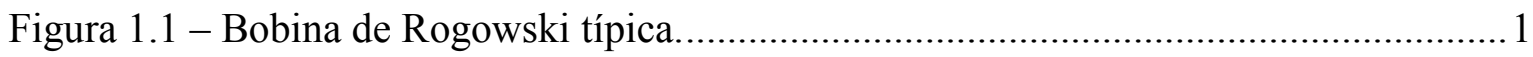

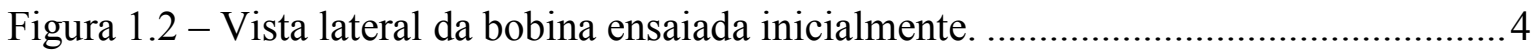

Figura 1.3 - Vista superior da bobina ensaiada inicialmente. .......................................... 5

Figura 2.1 - Modelo da Bobina de Rogowski. ..................................................................... 6

Figura 2.2 - Modelo de acoplamento magnético............................................................. 8

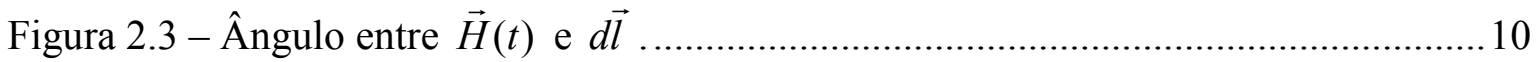

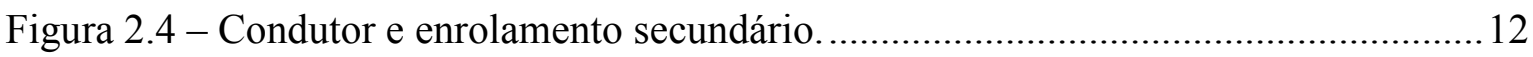

Figura 2.5 - Condutor no espaço (coordenadas retangulares).......................................... 14

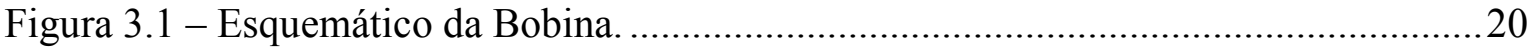

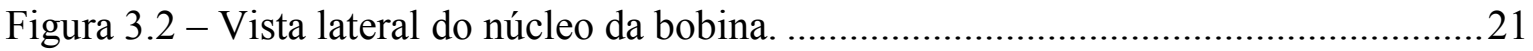

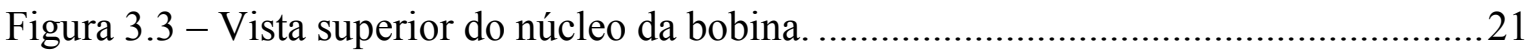

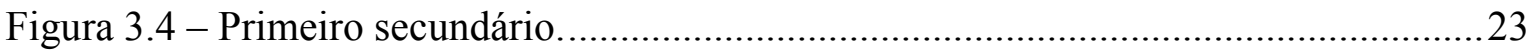

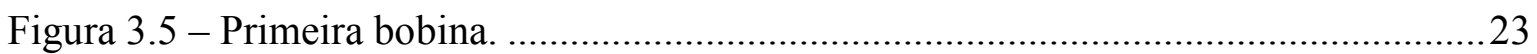

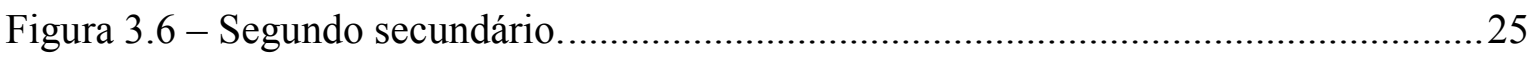

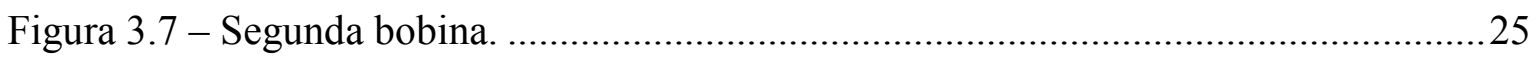

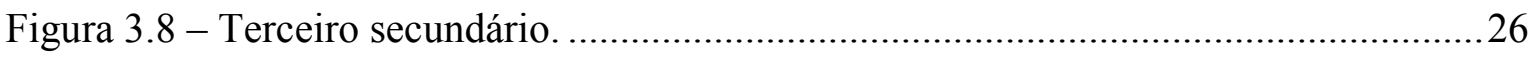

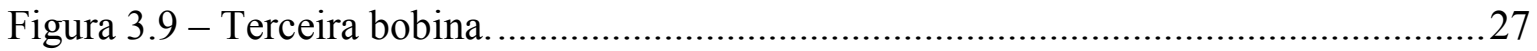

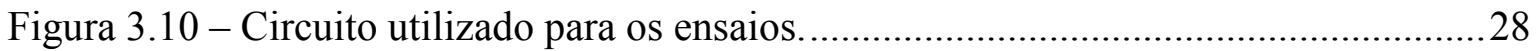

Figura 3.11 - Corrente em função da carga...................................................................29

Figura 3.12 - Primeiro método de medição; (a) Vista superior; (b) Vista lateral. ............... 30

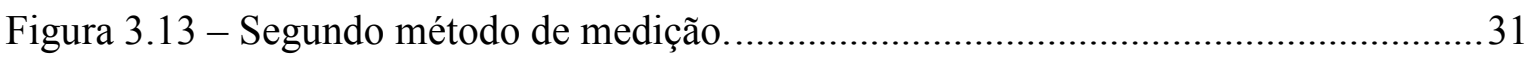

Figura 3.14 - Terceiro método de medição. ……............................................................... 32

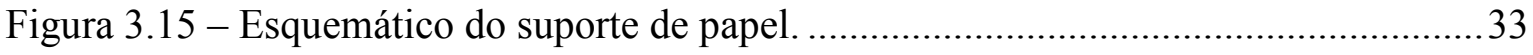

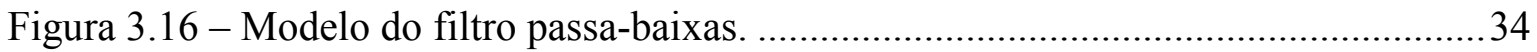

Figura 3.17 - Tensões de saída esperada e obtida, em $\mathrm{mV}$, em função da freqüência.........36

Figura 3.18 - Tensões de saída esperada e obtida, em dB, em função da freqüência.........37

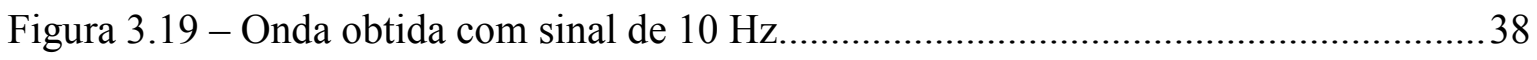

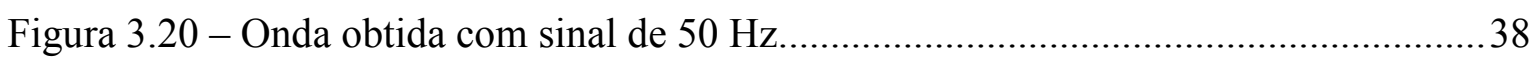

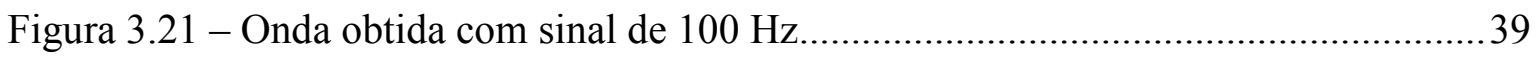

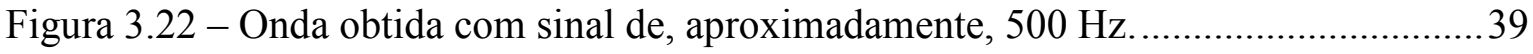

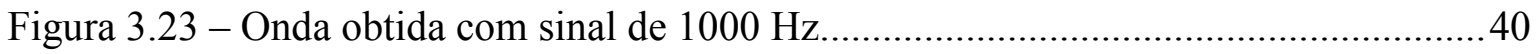


Figura 4.1 - Forma de onda capturada utilizando o primeiro método.

Figura 4.2 - Forma de onda capturada utilizando o segundo método.

Figura 4.3 - Forma de onda capturada com 44,3 A e com o segundo método.....................51

Figura 4.4 - Forma de onda obtida com a 45,4 A e o terceiro método. ...............................53

Figura 4.5 - Forma de onda obtida com a 38,4 A e o terceiro método. ................................53

Figura 4.6 - Forma de onda obtida com 45,4 A e o terceiro método. ...................................56

Figura 4.7 - Forma de onda obtida 38,4 A e o terceiro método. .........................................56

Figura 4.8 - Forma de onda obtida 34,1 A e o terceiro método. .........................................57

Figura 4.9 - Forma de onda obtida com 45,4 A, terceiro método e o filtro. ........................58

Figura 4.10 - Forma de onda obtida com 38,5 A, terceiro método e o filtro. ......................58

Figura 4.11 - Forma de onda obtida com 34,2 A, terceiro método e o filtro......................59

Figura 4.12 - Tensões esperada e medida com a terceira bobina, o terceiro método,

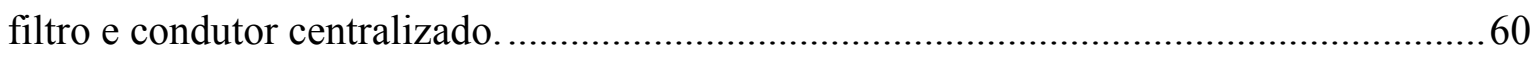

Figura 4.13 - Forma de onda obtida com 45,4 A, terceiro método, filtro e o condutor centralizado.

Figura 4.14 - Forma de onda obtida com 38,5 A, terceiro método, filtro e condutor centralizado.

Figura 4.15 - Forma de onda obtida com 34,2 A, terceiro método, filtro e condutor centralizado.

Figura 4.16 - Forma de onda obtida com 45,4 A e o quarto método.

Figura 4.17 - Forma de onda obtida com 38,5 A e o quarto método.

Figura 4.18 - Forma de onda obtida com 34,2 A e o quarto método.

Figura 4.19 - Tensões esperada e medida com a terceira bobina, o quarto método e filtro. 65

Figura 4.20 - Forma de onda obtida com 45,4 A, o quarto método e filtro. .66

Figura 4.21 - Forma de onda obtida com 38,5 A, quarto método e filtro. 66

Figura 4.22 - Forma de onda obtida com 34,2 A, quarto método e filtro. 67 


\section{LISTA DE SÍMBOLOS, NOMENCLATURA E ABREVIAÇÕES}

TC

ENE

$H(t)$

fem

$\frac{d}{d t}$

$\Phi(t)$

$e(t)$

$i(t)$

$L$

$M$

$d \vec{l}$

$\vec{J}$

$d \vec{S}$

$d \theta$

$\mu_{0}$

$B(t)$

$S$

$\lambda(t)$

DTE
- transformador de corrente.

- Departamento de Engenharia Elétrica.

- intensidade do campo magnético (unidade: A.m ${ }^{-1}$ ).

- força eletromotriz (unidade: V).

- taxa de variação no tempo (unidade: $\mathrm{s}^{-1}$ ).

- fluxo magnético (unidade: $\mathrm{Wb}$ ).

- tensão elétrica (unidade: V).

- corrente elétrica (unidade: A).

- indutância própria (unidade: H).

- indutância mútua (unidade: H).

- vetor elemento diferencial de comprimento (unidade: $\mathrm{m}$ ).

- vetor densidade de corrente elétrica (unidade: A.m ${ }^{-2}$ ).

- elemento diferencial de superfície (unidade: $\mathrm{m}^{2}$ ).

- elemento diferencial de ângulo (unidade: rad - radianos, ou ${ }^{\circ}$ - graus).

- permeabilidade magnética do espaço livre.

- densidade de fluxo magnético (unidade: $\mathrm{Wb} . \mathrm{m}^{-2}$ ).

- área (unidade: $\mathrm{m}^{2}$ ).

- fluxo magnético concatenado (unidade: Wb.espira).

- Divisão Técnica Laboratorial. 


\section{1 - INTRODUÇÃO}

\section{1 - A BOBINA DE ROGOWSKI}

Uma Bobina de Rogowski [1], [2] [3], [4] e [5] é um transdutor de corrente no qual o enrolamento primário é o próprio condutor onde circula a corrente que se quer medir e que possui um enrolamento secundário como um transformador de corrente (TC), porém seu secundário é mantido em aberto ou conectado a uma alta impedância, além de também não possui material ferromagnético em seu núcleo.

A Figura 1.1 mostra uma Bobina de Rogowski típica. Nela podem ser vistos o condutor ou enrolamento primário, o enrolamento secundário mantido em aberto e o núcleo, observando a ausência de material ferromagnético.

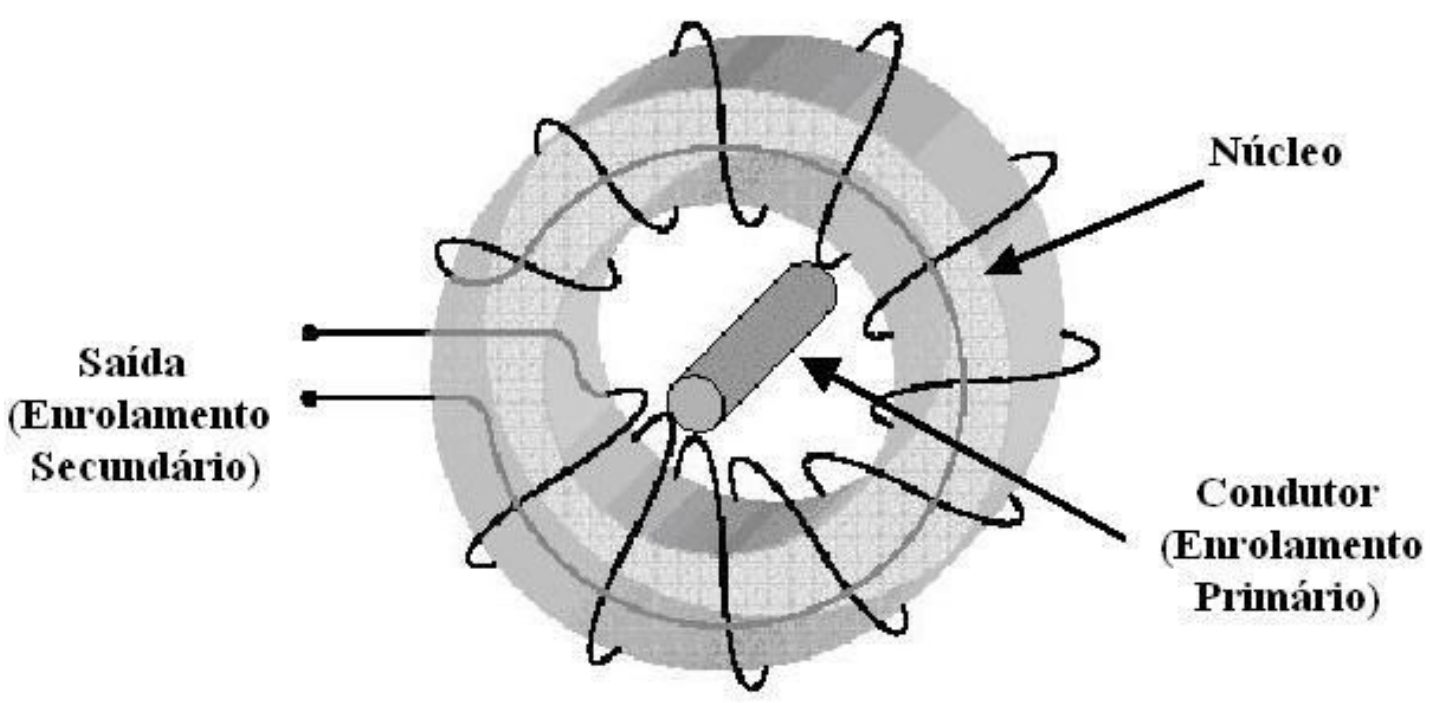

Figura 1.1 - Bobina de Rogowski típica.

Ela é projetada para ser utilizada na medição de correntes alternadas ou transientes de correntes numa faixa bastante considerável de correntes. Quando uma Bobina de Rogowski é acoplada a um condutor de corrente carregado, uma tensão é gerada no secundário da bobina proporcional à indutância mútua da bobina e à taxa de variação da corrente no tempo. 
Uma considerável vantagem que pode ser mencionada a respeito da Bobina de Rogowski é que, devido à ausência de um núcleo ferromagnético, ela não sofre saturação magnética [1] e [2]. A não ocorrência da saturação magnética leva a uma característica de magnetização extremamente linear. Assim, a calibração da bobina pode ser feita em correntes relativamente baixas (tipicamente alguns quilo-ampères ou menos), e ser usada com confiança em correntes muito elevadas (centenas de quiloampères), eliminando a necessidade realizar a calibração usando correntes muito elevadas, que é um processo difícil e caro de se executar.

Do mesmo modo, devido não possuir um núcleo ferromagnético, a Bobina de Rogowski pode ser construída de forma a ser aberta e instalada em pontos de difícil acesso [2] e [3]. Ela também possibilita a medição de corrente elétrica mesmo onde exista uma elevada diferença de potencial, como em usinas, subestações e linhas de transmissão e distribuição [1].

Outras vantagens apresentadas pela Bobina de Rogowski são: sua baixa inserção de perdas e seu tamanho reduzido comparado a um transformador de corrente equivalente, além de baixos peso e custo, baixa sensibilidade a variações de parâmetros de construção e também sua elevada precisão e grande largura de banda [3].

Como desvantagem, pode-se fazer referência à necessidade do enrolamento secundário da Bobina de Rogowski ser simétrico [2]. A saída da bobina dependente do formato do secundário. O tamanho de todas as voltas individuais deste enrolamento deve ser o mais idêntico quanto possível. A distribuição do enrolamento secundário em torno do núcleo também deve ser perfeitamente uniforme. Esta simetria é bastante difícil de ser conseguida na prática. As voltas individuais do enrolamento não são idênticas e sua distribuição em torno do núcleo não é perfeitamente uniforme, o que leva a erros na saída da bobina.

Outra desvantagem se refere ao fato da saída no enrolamento secundário da bobina ser dependente da posição relativa do condutor no interior da bobina [2], ou seja, depende da distribuição do fluxo concatenado pela bobina. Conseqüentemente, a bobina terá um erro de posição relativa, cujo valor na maioria das vezes pode ser reduzido. O erro mínimo resultará quando todas as voltas são de uma área exatamente idêntica à seção 
transversal e são distribuídas de forma perfeitamente uniforme em torno de um caminho realmente circular.

Todo fluxo magnético perpendicular ao caminho formado pelo enrolamento secundário induz uma tensão do erro na saída da bobina [2]. Na prática, existem outros gradientes de campo magnético em torno da bobina, além do gerado pelo enrolamento primário (condutor). As fontes do fluxo magnético perpendicular podem ser originadas da geometria do condutor primário, dos condutores de retorno próximos, de outros condutores de corrente carregados, de fluxo do escapamento dos transformadores, ou dos campos devido à presença de materiais ferromagnéticos.

Pode-se também mencionar como desvantagem da Bobina de Rogowski a limitação da corrente mensurável [2]. Na prática, o nível superior da corrente a ser medida é limitado pela tensão de entrada máxima de um instrumento de medição, ou pelos limites de variação da tensão da bobina ou de outros elementos do circuito. O nível o mais baixo da corrente que pode ser medido é limitado pela sensibilidade do instrumento de medição da tensão e do ruído do sistema. Assim, podem ser encontradas dificuldades ao medir correntes com pequenas amplitudes (menores que $100 \mathrm{~A}$ ) [4] usando uma Bobina de Rogowski uma vez que a ela tem melhores respostas quando submetidas a correntes mais elevadas. Isto porque a tensão induzida na bobina é muito pequena, podendo ser confundida com o ruído do sistema.

\section{2 - HISTÓRICO}

Rogowski foi, em 1912, um dos autores de um artigo intitulado "The Measurement of Magneto Motive Force”. Neste artigo, os autores demonstraram que a tensão nos terminais de uma bobina ao redor de um condutor elétrico carregado dará uma medida da intensidade de campo magnético $H(t)$ como definida na primeira equação de Maxwell, independentemente de o formato da bobina ser um anel ou uma elipse [5].

Desde então, este dispositivo tem despertado uma curiosidade maior nos físicos do que nos engenheiros eletricistas. Rogowski propôs um sistema onde, a indutância mútua entre uma bobina e um condutor elétrico carregado fornecesse uma tensão proporcional à taxa de variação no tempo da corrente nesse condutor. Em seu artigo Rogowski 
descreve uma bobina composta por um tubo flexível que possa ser colocado em torno do primário. A partir disto, observou-se dois aspectos importantes. $\mathrm{O}$ primeiro foi que a Bobina de Rogowski é equivalente a um transformador de corrente (TC), porém com um núcleo composto por um material dielétrico. O segundo, foi que a bobina precisa ficar envolvendo o condutor, que funciona como o enrolamento primário do TC.

\section{3 - MOTIVAÇÃO DESTE TRABALHO}

Inicialmente, os testes com a bobina de Rogowski foram feitos com quatro bobinas prontas obtidas no próprio Departamento de Engenharia Elétrica - ENE. Foram realizados vários ensaios com essas bobinas, porém não foi possível obter um sinal em regime permanente. Visto que essas bobinas eram lacradas com um material epóxi, seus aspectos construtivos internos como número de espiras do secundário, distância do centro da bobina até o centro do secundário e o raio do secundário não eram conhecidos. Como esses parâmetros são essenciais para o cálculo da tensão no secundário decidiu-se por construir outras bobinas, das quais se conheceria os aspectos construtivos. As Figuras 1.2 e 1.3 mostram as vistas lateral e superior, respectivamente, das bobinas obtidas no departamento.

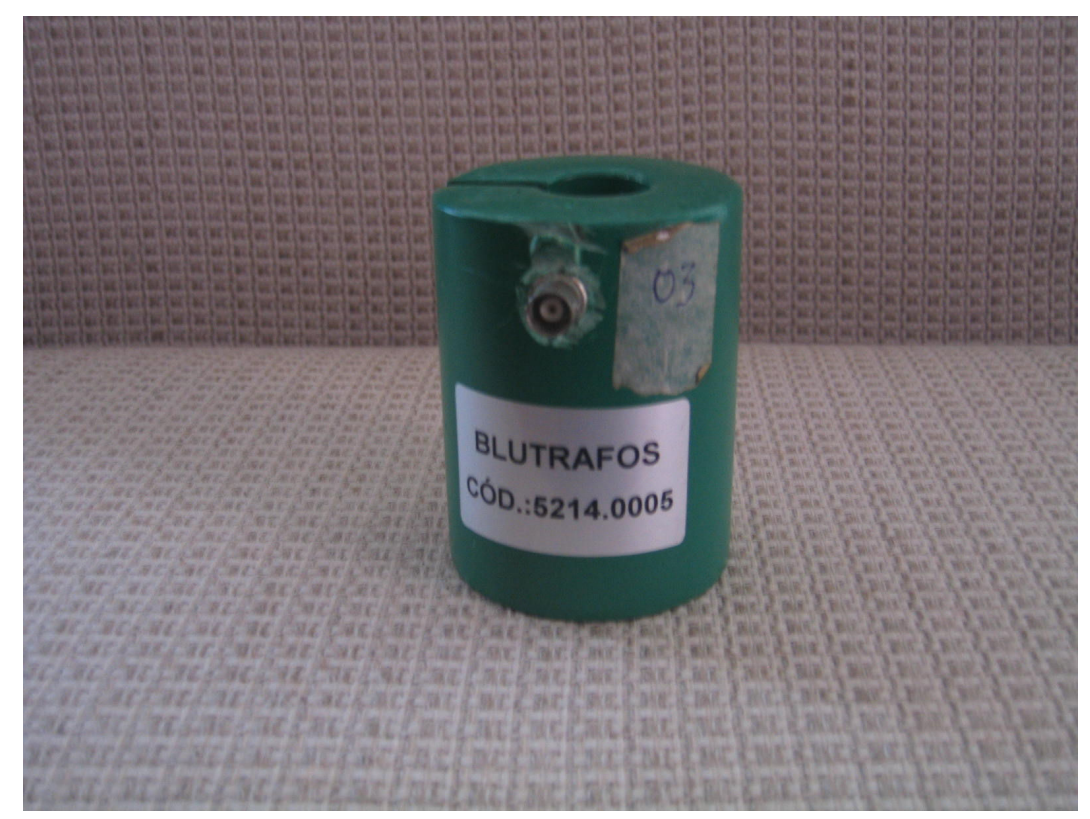

Figura 1.2 - Vista lateral da bobina ensaiada inicialmente. 


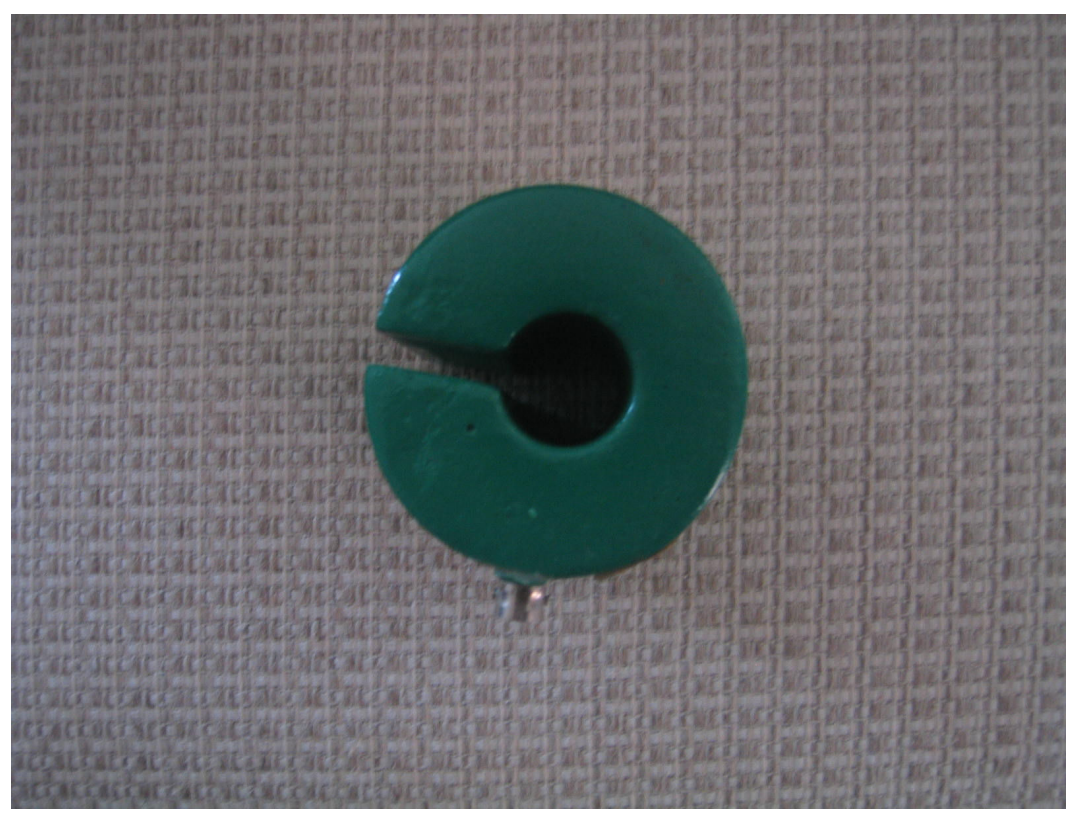

Figura 1.3 - Vista superior da bobina ensaiada inicialmente.

\section{4 - OBJETIVO}

Este trabalho tem como objetivo principal projetar, construir e ensaiar um protótipo da Bobina de Rogowski, bem como desenvolver métodos de ensaio para aperfeiçoar a medição para baixas correntes, identificando e corrigindo eventuais erros. 


\section{2 - METODOLOGIA}

\section{1 - ASPECTOS CONTRUTIVOS DA BOBINA DE ROGOWSKI}

Uma Bobina de Rogowski nada mais é que um transdutor de corrente em que o enrolamento primário é o próprio condutor ou barramento onde circula a corrente que se quer medir e possui um enrolamento secundário [1], [2] [3], [4] e [5]. Seu funcionamento é de forma semelhante ao de um transformador de corrente, mas com duas diferenças fundamentais quanto aos aspectos construtivos. Um aspecto de fundamental diferença entre o TC e a Bobina de Rogowski é que o enrolamento secundário desta é mantido em aberto, podendo também ser conectado a uma alta impedância e, outro, é o da bobina não possuir núcleo ferromagnético.

A Figura 2.1 mostra um modelo da Bobina de Rogowski. Nela, pode-se observar o enrolamento secundário mantido em aberto e a ausência do núcleo ferromagnético.

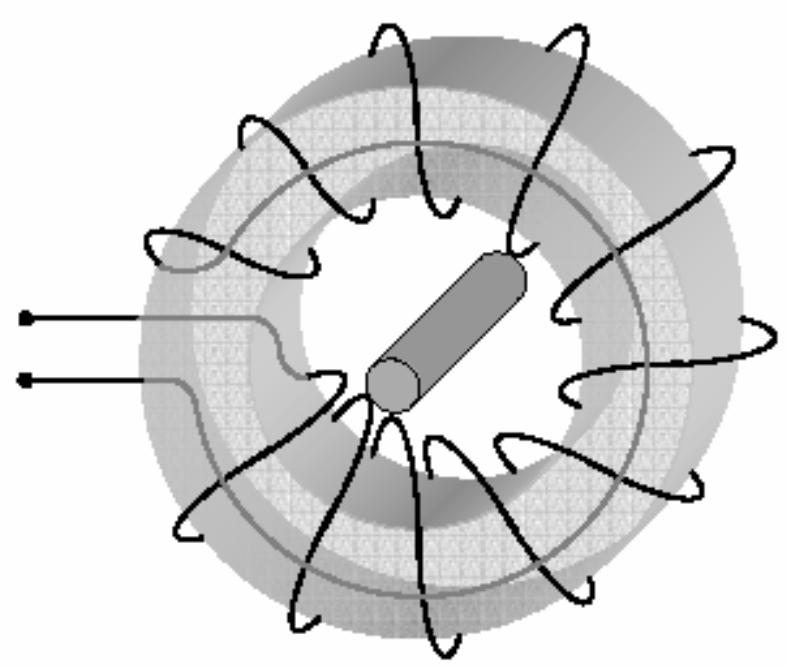

Figura 2.1 - Modelo da Bobina de Rogowski.

Não há fluxo de corrente no enrolamento secundário da Bobina de Rogowski quando este é mantido em aberto. Dessa maneira, a corrente e a força eletromotriz ( $\mathrm{fem}$ ) induzidas estão em fase, não havendo atraso entre estas, como acontece com circuitos $R L$, que tem esta característica intrínseca. 
A ausência de um núcleo ferromagnético na Bobina de Rogowski permite a conservação da linearidade da sua curva de magnetização e, dessa maneira, oferece a possibilidade da bobina ser calibrada quando este estiver operando em regime permanente senoidal.

O enrolamento secundário da Bobina de Rogowski pode ser construído de maneira rígida, utilizando um material dielétrico para o núcleo, ou flexível, sem nenhum núcleo, porém, em ambos os casos, de forma a ser aberto. Essa abertura do secundário é possibilitada devido à ausência do núcleo ferromagnético, permitindo que ela possa ser instalada em pontos de difícil acesso.

\section{2 - PRINCÍPIO DE FUNCIONAMENTO DA BOBINA DE ROGOWSKI}

O principio de funcionamento da Bobina de Rogowski está baseado na Lei de FaradayLenz [1] e [2], ou lei da indução eletromagnética, que relaciona a força eletromotriz induzida com a taxa de variação do fluxo magnético no tempo.

$$
f e m=-\frac{d}{d t} \Phi(t)
$$

A Lei de Faraday-Lenz, [6], [7], [8] e [9], afirma que a fem induzida tem valor igual ao módulo da derivada temporal do fluxo magnético e sinal contrário ao da taxa de variação do fluxo, como pode ser visto na equação (2.1).

\subsection{1 - Modelo matemático}

Quando o condutor ou barramento (enrolamento primário) está disposto no interior da Bobina de Rogowski (enrolamento secundário) e é percorrido por uma corrente elétrica variando no tempo, um campo magnético é gerado ao seu redor. Este campo induz, então, uma força eletromotriz no enrolamento secundário da bobina (indução magnética), havendo, assim, um acoplamento magnético entre os circuitos [1] e [2].

O condutor ou barramento no qual circula a corrente elétrica que se deseja medir atua de forma recíproca ao enrolamento da Bobina de Rogowski [1]. Eles interagem segundo o modelo ilustrado na Figura 2.2, formando um circuito magneticamente acoplado. 


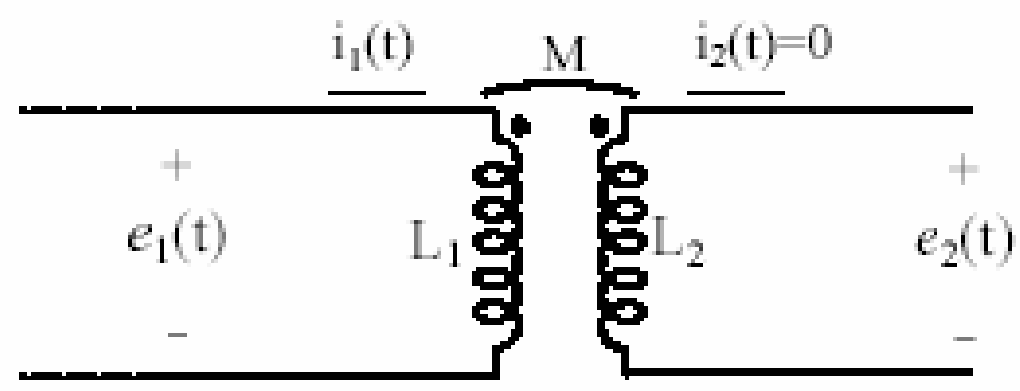

Figura 2.2 - Modelo de acoplamento magnético.

Analisando o modelo da Figura 2.2, pode-se formar o seguinte sistema de equações lineares para o circuito [10], dado pela equação (2.2):

$$
\left\{\begin{array}{l}
e_{1}(t)=L_{1} \frac{d}{d t} i_{1}(t)+M \frac{d}{d t} i_{2}(t) \\
e_{2}(t)=M \frac{d}{d t} i_{1}(t)+L_{2} \frac{d}{d t} i_{2}(t)
\end{array}\right.
$$

Onde:

$e(t)$ é a tensão no enrolamento (o sub-índice 1 se refere ao enrolamento primário, condutor ou barramento, e o 2, ao secundário);

$L$ é a indutância própria do enrolamento;

$\frac{d}{d t} i(t)$ é a taxa de variação no tempo da corrente elétrica no enrolamento; e

$M$ é a indutância mútua entre o enrolamento secundário e o condutor;

Lembrando-se que não há fluxo de corrente no enrolamento secundário do transdutor, pois este é mantido em aberto, conseqüentemente, $i_{2}(t)=0$ e, observando que $M$ é invariável no tempo, da equação (2.2), chega-se a equação (2.3):

$$
e_{2}(t)=M \frac{d}{d t} i_{1}(t)
$$


Pela equação (2.3), vê-se, claramente, que a fem induzida no enrolamento secundário da Bobina de Rogowski, $e_{2}(t)$, em volts $(\mathrm{V})$, é proporcional a indutância mútua entre o condutor e o enrolamento, $M$, em Henry $(\mathrm{H})$, e a taxa de variação no tempo da corrente elétrica no condutor, em A.s ${ }^{-1}$.

A partir daqui, tem-se duas alternativas de desenvolvimento para se encontrar a corrente elétrica que circula no condutor. Uma delas é o desenvolvimento a partir da Lei Circuital de Ampère, onde é feita uma aproximação, considerando o condutor com um comprimento infinito. A outra, é o desenvolvimento a partir da Lei de Biot-Savart, de onde se encontra uma expressão mais genérica para o fluxo magnético no interior do enrolamento secundário da Bobina de Rogowski para qualquer comprimento de condutor (enrolamento primário).

\subsection{2 - Desenvolvimento a partir da Lei Circuital de Ampère}

$\mathrm{Na}$ forma integral, a Lei Circuital de Ampère descreve que a corrente elétrica que circula em um condutor forma um campo magnético com intensidade $\vec{H}(t)$ [6], [7], [8] e [9], como explicitado pela equação (2.4):

$$
\oint \vec{H}(t) \cdot d \vec{l}=\int_{S} \vec{J} \cdot d \vec{S}
$$

Onde:

$\vec{H}(t)$ é o vetor intensidade de campo magnético, em A.m ${ }^{-1}$;

$d \vec{l}$ é o vetor elemento diferencial de comprimento, em m;

$\vec{J}$ é o vetor densidade de corrente elétrica no condutor, em A.m ${ }^{-2}$; e

$d \vec{S}$ é o elemento diferencial de superfície transversal do condutor, em $\mathrm{m}^{2}$.

O lado direito da igualdade da equação (2.4) constitui a corrente elétrica variando no tempo que circula no condutor, ou seja, $i_{1}(t)$. Do lado esquerdo da equação (2.4) vê-se que intensidade de campo magnético também varia no tempo. Assim, da equação (2.4), obtêm-se a equação (2.5): 


$$
\oint \vec{H}(t) \cdot d \vec{l}=i_{1}(t)
$$

A Figura 2.3, mostra o ângulo entre o vetor intensidade de campo magnético, $\vec{H}(t)$, e o vetor elemento diferencial de comprimento, $d \vec{l}$.

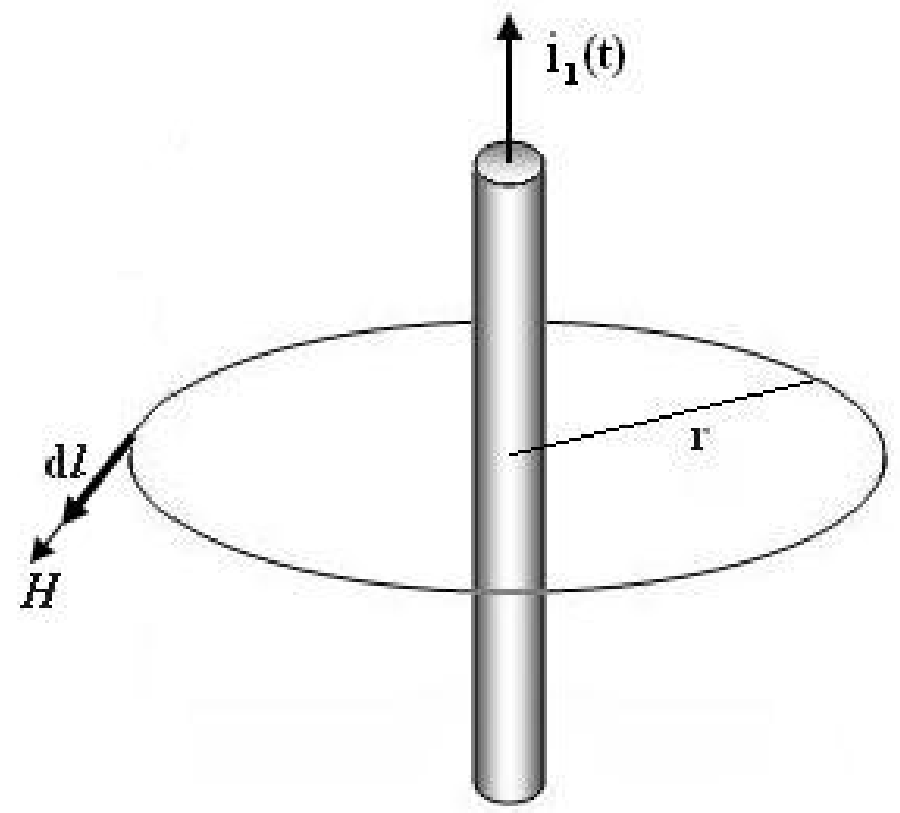

Figura 2.3 - Ângulo entre $\vec{H}(t)$ e $d \vec{l}$.

Na Figura 2.3, observa-se que o ângulo entre $\vec{H}(t)$ e $d \vec{l}$ é de $0^{\circ}$. Deste modo, resolvendo-se o produto escalar do integrando da equação (2.5) [11] e [12], chega-se a equação (2.6):

$$
\oint H(t) \cdot d l=i_{1}(t)
$$

A intensidade de campo magnético pode ser encontrada somando-se todas as contribuições dos elementos diferenciais $d \vec{l}$ da equação (2.6). Mas o vetor elemento diferencial de comprimento pode ser dado por $d \vec{l}=r d \theta$. Assim, tem-se que, fora do condutor, $\vec{H}(t)$ é calculada pela equação (2.7): 


$$
H(t)=\frac{1}{2 \pi \cdot r} i_{1}(t)
$$

Onde:

$r$ é a distância do ponto no qual se calcula a intensidade de campo magnético (interior do enrolamento secundário) ao condutor primário.

Novamente, a ausência de um núcleo ferromagnético na Bobina de Rogowski permite a manutenção de sua linearidade, visto que seu núcleo é formado por um meio linear, como o ar, que possui permeabilidade $\mu_{0}=4 \pi \cdot 10^{-7}\left[\frac{T}{A . m}\right]$, que é permeabilidade magnética do espaço livre. O módulo da densidade de fluxo magnético, $B(t)$, pode ser encontrado pela equação (2.8):

$$
B(t)=\mu_{0} H(t)
$$

Substituindo a equação (2.7) na equação (2.8), o módulo da densidade de fluxo magnético também pode ser obtido pela equação (2.9):

$$
B(t)=\frac{\mu_{0}}{2 \pi \cdot r} i_{1}(t)
$$

O fluxo magnético pode ser calculado pela equação (2.10):

$$
\Phi(t)=B(t) \cdot S
$$

Onde:

$S$ é a área, em $\mathrm{m}^{2}$, que envolve a densidade de fluxo magnético.

Considerando que o enrolamento secundário da Bobina de Rogowski tem formato circular, possui um raio $r_{s}$ e que seu centro está a uma distância $r$ do condutor primário, 
como mostrado na Figura 2.4, a área do enrolamento secundário que envolve a densidade de fluxo magnético é igual à área de um círculo e é dada pela equação (2.11):

$$
S=\pi \cdot r_{s}^{2}
$$

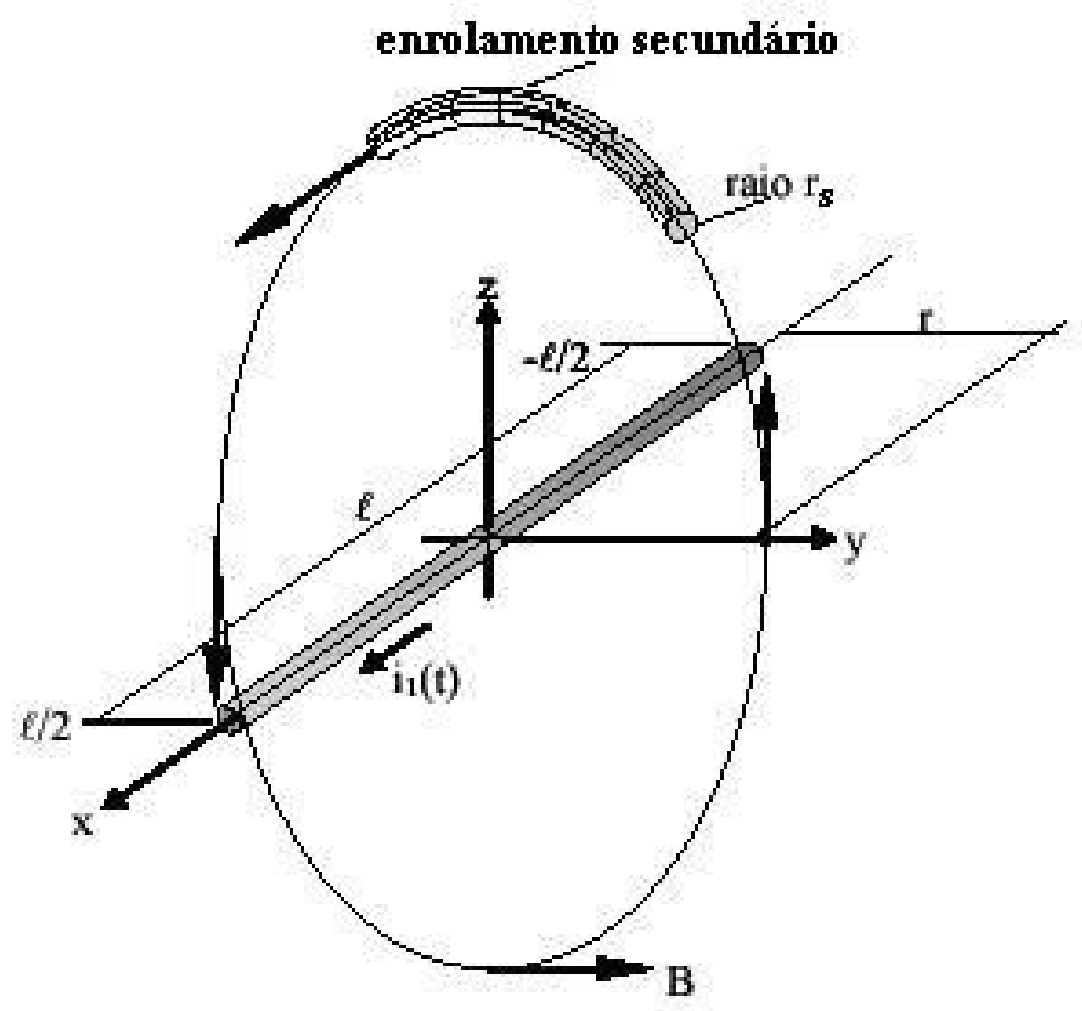

Figura 2.4 - Condutor e enrolamento secundário.

Substituindo a equação (2.9) e a equação (2.11) na equação (2.10), o fluxo magnético pode ser obtido pela equação (2.12):

$$
\Phi(t)=\frac{\mu_{0} r_{s}^{2}}{2 . r} i_{1}(t)
$$

O valor do fluxo magnético encontrado pela equação (2.12) não representa um valor prático, uma vez que se baseia no fato de que o condutor no qual circula a corrente que se quer medir (enrolamento primário da Bobina de Rogowski) tem comprimento infinito. 


\subsection{3 - Desenvolvimento a partir da Lei de Biot-Savart}

A Lei de Biot-Savart permite calcular, em qualquer ponto do espaço, a densidade do campo magnético originado por uma corrente elétrica que passa em um condutor. A Bobina de Rogowski não possui núcleo ferromagnético. Assim, no espaço livre, a corrente elétrica $i_{1}(t)$ que circula em um comprimento elementar $d \vec{l}$ do condutor (enrolamento primário) orientado no sentido da corrente, origina, no ponto $\mathrm{P}_{2}$ do enrolamento secundário, que está a uma distância $\vec{R}$ de $d \vec{l}$, uma densidade de campo magnético elementar $d B(t)$ que é dada pela equação (2.13):

$$
d B(t)=\frac{\mu_{0} i_{1}(t)}{4 \pi} \frac{d \vec{l} \times \vec{a}_{R}}{|\vec{R}|^{2}}
$$

Onde:

$\vec{a}_{R}$ é o vetor unitário na direção do vetor $\vec{R}$.

Observando-se a Figura 2.5, tem-se que as coordenadas dos pontos $\mathrm{P}_{1}$ e $\mathrm{P}_{2}$ são $(\mathrm{x}, 0,0)$ e $(0, \mathrm{y}, 0)$, respectivamente. Assim, o vetor $\vec{R}$ é dado pela equação (2.14):

$$
\vec{R}=-x \vec{i}+y \vec{j}
$$

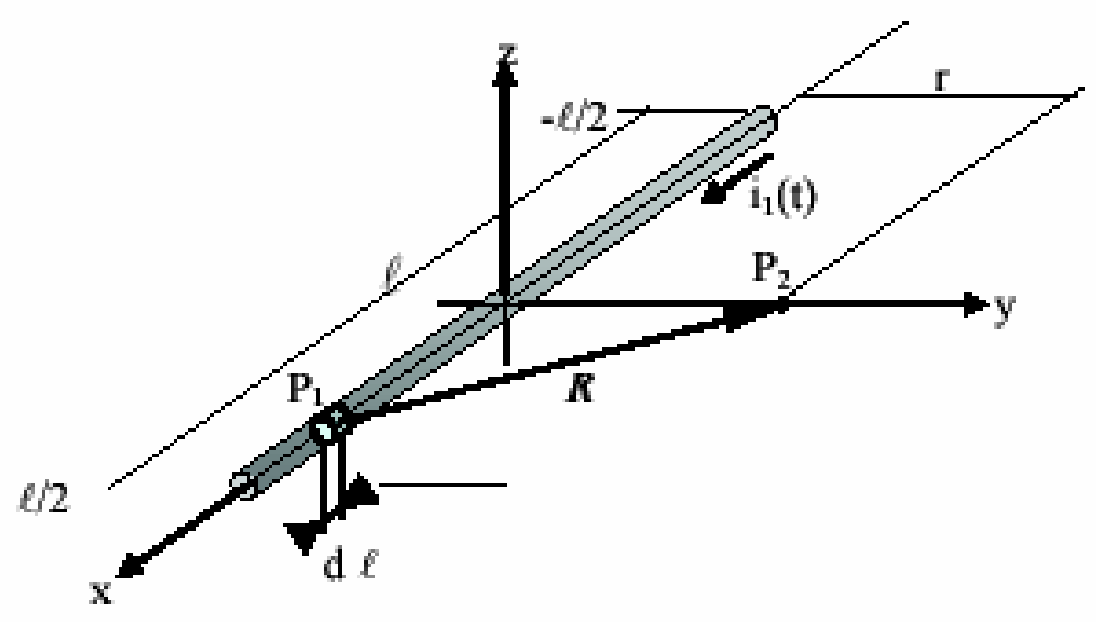


Figura 2.5 - Condutor no espaço (coordenadas retangulares).

E, do mesmo modo, o vetor unitário $\vec{a}_{R}$ pode ser dado pela equação (2.15):

$$
\vec{a}_{R}=\frac{-x \vec{i}+y \vec{j}}{\sqrt{x^{2}+y^{2}}}
$$

O comprimento elementar $d \vec{l}$ pode ser expresso pela equação (2.16) em função de x na forma vetorial:

$$
d \vec{l}=d x \vec{i}
$$

Por conseguinte, a densidade de campo magnético elementar $d B(t)$ modifica-se para equação (2.17):

$$
d B(t)=\frac{\mu_{0} i_{1}(t)}{4 \pi} \frac{d x \vec{i} \times-x \vec{i}+y \vec{j}}{\left(x^{2}+y^{2}\right)^{3 / 2}}
$$

Resolvendo-se o produto vetorial [11] e [12], a equação (2.17) toma a forma da equação (2.18):

$$
d B(t)=\frac{\mu_{0} i_{1}(t)}{4 \pi} \frac{y d x}{\left(x^{2}+y^{2}\right)^{3 / 2}} \vec{k}
$$

Define-se agora uma transformação de coordenadas [12], de coordenadas retangulares $(\mathrm{x}, \mathrm{y}, \mathrm{z})$ para coordenadas cilíndricas $(\mathrm{h}, \mathrm{r}, \theta)$ segundo a relação definida pelo conjunto de equações (2.19): 


$$
\left\{\begin{array}{l}
x=h \\
y=r \cos \theta \\
z=r \operatorname{sen} \theta \\
r^{2}=y^{2}+z^{2} \\
\operatorname{tg} \theta=\frac{z}{y}, \text { se } y \neq 0
\end{array}\right.
$$

Aplicando a transformação de coordenadas definida pelo conjunto de equações (2.19) na equação (2.18), tem-se a densidade de campo magnético elementar em termos de coordenadas cilíndricas expresso pela equação (2.20):

$$
d B(t)=\frac{\mu_{0} i_{1}(t)}{4 \pi} \frac{r d h}{\left(h^{2}+r^{2}\right)^{3 / 2}} \vec{a}_{\theta}
$$

Da equação (2.20), conclui-se que a densidade de campo magnético, ao longo de circunferências concêntricas ao condutor no qual circula a corrente elétrica, tem módulo constante.

Somando-se cada contribuição elementar $d B(t)$ ao longo do comprimento $l$, ou seja, integrando-se a equação (2.20), tem-se a equação (2.21):

$$
B_{\vec{a}_{\theta}}(t)=\frac{\mu_{0} i_{1}(t)}{4 \pi} \int_{-l / 2}^{l / 2} \frac{r d h}{\left(h^{2}+r^{2}\right)^{3 / 2}}
$$

Resolvendo-se a integral definida dada pela equação (2.21), encontra-se como resultado a equação (2.22), que é a densidade de campo magnético, a uma distância $r$, no enrolamento secundário da Bobina de Rogowski devido à corrente elétrica $i_{1}(t)$ que circula pelo condutor de comprimento $l$.

$$
B_{\vec{a}_{\theta}}(t)=\frac{\mu_{0} i_{1}(t)}{4 \pi \cdot r}\left(\frac{l}{\sqrt{\left(\frac{l}{2}\right)^{2}+r^{2}}}\right)
$$


Substituindo a equação (2.22) e a equação (2.11) na equação (2.10), o fluxo magnético pode ser calculado pela utilização da equação (2.23):

$$
\Phi_{\vec{a}_{\theta}}(t)=\frac{\mu_{0} r_{s}^{2} i_{1}(t)}{4 r}\left(\frac{l}{\sqrt{\left(\frac{l}{2}\right)^{2}+r^{2}}}\right)
$$

A equação (2.23) representa uma expressão genérica para o fluxo magnético no interior do enrolamento secundário da Bobina de Rogowski para qualquer comprimento $l$ de condutor (enrolamento primário).

Para $l>>r$, o condutor pode ser considerado de comprimento infinito. Deste modo, tomando-se o limite da equação (2.23) com $l$ tendendo ao infinito, observa-se que a equação (2.23) toma a forma da equação (2.12), como pode ser visto na equação (2.24):

$$
\lim _{l \rightarrow \infty} \Phi_{\vec{a}_{\theta}}(t)=\lim _{l \rightarrow \infty} \frac{\mu_{0} r_{s}^{2} i_{1}(t)}{4 r}\left(\frac{l}{\sqrt{\left(\frac{l}{2}\right)^{2}+r^{2}}}\right)=\frac{\mu_{0} r_{s}^{2}}{2 r} i_{1}(t)
$$

\subsection{4 - A relação entre a tensão no enrolamento secundário da Bobina de Rogowski e a corrente elétrica no enrolamento primário}

Como foi visto, utilizando o desenvolvimento a partir da Lei de Biot-Savart, encontrouse uma expressão genérica para o fluxo magnético no interior do enrolamento secundário do transdutor e, aplicando-se a aproximação do condutor ter comprimento infinito, chegou-se ao mesmo resultado do desenvolvimento a partir da Lei Circuital de Ampère. 
A partir da determinação do fluxo magnético no interior do enrolamento secundário da Bobina de Rogowski utilizando-se a Lei de Biot-Savart, pode-se encontrar a relação entre a tensão no secundário do transdutor, $e_{2}(t)$, e a corrente elétrica no condutor $i_{1}(t)$.

O fluxo concatenado [10] no enrolamento secundário da Bobina de Rogowski, considerando-se que este tenha $N$ espiras pode ser determinado pela equação (2.25):

$$
\lambda_{a_{\theta}}(t)=N \cdot \Phi_{\vec{a}_{\theta}}(t)
$$

Substituindo-se a equação (2.23) na equação (2.25), o fluxo concatenado no secundário do transdutor toma a forma da equação (2.26):

$$
\lambda_{a_{\theta}}(t)=N \frac{\mu_{0} r_{s}^{2} i_{1}(t)}{4 r}\left(\frac{l}{\sqrt{\left(\frac{l}{2}\right)^{2}+r^{2}}}\right)
$$

A indutância mútua $M$ entre o enrolamento secundário do transdutor e o condutor é definida como a relação entre o fluxo concatenado e a corrente $i_{1}(t)$ que circula pelo condutor, como dado pela equação (2.27):

$$
M=\frac{\lambda_{\vec{a}_{\theta}}(t)}{i_{1}(t)}
$$

Isolando-se $i_{1}(t)$ na equação (2.27) e substituindo na equação (2.3), obtém-se a tensão induzida no enrolamento secundário do transdutor, dado pela equação (2.28):

$$
e_{2}(t)=\frac{d}{d t} \lambda_{\vec{a}_{\theta}}(t)
$$

Substituindo-se a equação (2.26) na equação (2.28), a tensão induzida no secundário da Bobina de Rogowski toma a forma da equação (2.29): 


$$
e_{2}(t)=N \frac{\mu_{0} r_{s}^{2}}{4 r}\left(\frac{l}{\sqrt{\left(\frac{l}{2}\right)^{2}+r^{2}}}\right) \frac{d}{d t} i_{1}(t)
$$

Resolvendo-se a equação (2.29) para $i_{1}(t)$, a corrente elétrica no condutor será dada pela equação (2.30):

$$
i_{1}(t)=\left[N \frac{\mu_{0} r_{s}^{2}}{4 r}\left(\frac{l}{\sqrt{\left(\frac{l}{2}\right)^{2}+r^{2}}}\right)\right]^{-1} \cdot \int e_{2}(t) d t
$$

De forma alternativa, para $l>r$ na equação (2.30), chega-se ao mesmo resultado se for utilizado o fluxo magnético encontrado pelo desenvolvimento a partir da Lei Circuital de Ampère, considerando o condutor com comprimento infinito. 


\section{3 - PROJETO DA BOBINA DE ROGOWSKI}

\section{1 - CONSTRUÇÃO DA BOBINA}

O nosso protótipo da Bobina de Rogowski foi construído seguindo o modelo físico das bobinas obtidas no ENE, utilizando-se um tubo de PVC, isopor, um tubo de plástico e fios de cobre. Ela possui uma estrutura simples, o que é uma das vantagens propostas para esse tipo de bobina.

As medidas exatas da bobina seguem na Tabela 3.1. Esses valores são os valores constantes visto que parâmetros como o raio do secundário e o número de espiras variaram entre as diversas bobinas criadas e serão discutidos à medida que se avance no trabalho.

Tabela 3.1 - Aspectos construtivos do núcleo da bobina.

\begin{tabular}{|c|c|}
\hline Altura & $7,8 \mathrm{~cm}$ \\
\hline Diâmetro interno & $7,5 \mathrm{~cm}$ \\
\hline Raio interno do isopor & $1,4 \mathrm{~cm}$ \\
\hline Raio externo do isopor & $3,5 \mathrm{~cm}$ \\
\hline
\end{tabular}

Entenda-se por bobina o conjunto composto pelo núcleo isolante e o secundário. Por exemplo, a primeira bobina é o conjunto composto pelo núcleo e o primeiro secundário. Segue nesse capítulo a descrição de todos os secundários bem como dos métodos de ensaio.

O protótipo da bobina foi construído preenchendo-se o interior do tubo de PVC com isopor, disposto simetricamente, assim, formando o núcleo isolante, de acordo com as medidas da Tabela 3.1.

Em seguida, enrolou-se o fio de cobre, do tipo esmaltado $A W G 26$ e com $0,4 \mathrm{~mm}^{2}$ de seção transversal, em volta de um tubo de plástico de maneira a compor o secundário da bobina, de com o esquemático da bobina, que é mostrado Figura 3.1 a seguir. 


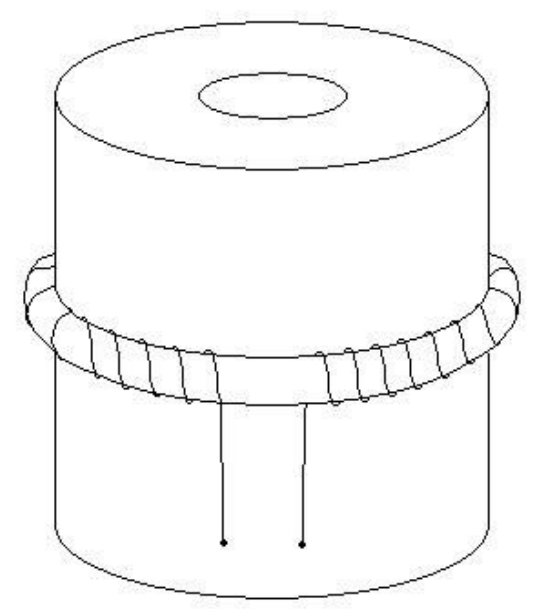

Figura 3.1 - Esquemático da Bobina.

Como a Bobina de Rogowski é constituída principalmente de material isolante, de maneira a apresentar as vantagens discutidas nos capítulos anteriores, foi necessário escolher materiais que fossem de fácil manipulação, fáceis de obter e que possuíssem as características isolantes desejadas para a construção da bobina.

Para compor o núcleo central da bobina optou-se por utilizar um tubo de PVC, preenchido com isopor. A escolha pelo tubo de PVC e pelo isopor foi devido ao fato de serem materiais fáceis de manejar, de adquirir e que já apresentam comercialmente o formato adequado para a construção da bobina.

O enchimento de isopor foi proposto objetivando uma maior centralização do condutor porque, como já foi discutido em capítulos anteriores, o campo magnético gerado e a tensão resultante dependem muito da simetria da bobina bem como do perfeito posicionamento simétrico do condutor dentro da bobina.

Inicialmente, para compor o núcleo do secundário, foi considerado usar papel. Porém, como o fluxo magnético depende da simetria e do raio do secundário, optou-se em usar um tubo de plástico de maneira a conservar uma simetria aceitável. O fio de cobre foi então enrolado no tubo de plástico e o conjunto encaixado no conjunto tubo de PVCisopor compondo a bobina. O número de espiras e o raio do tubo de plástico variaram de acordo com a etapa de desenvolvimento da bobina e serão discutidos na próxima 
seção. As Figuras 3.2 e 3.3 mostram as vista lateral e superior, respectivamente, do núcleo da bobina.

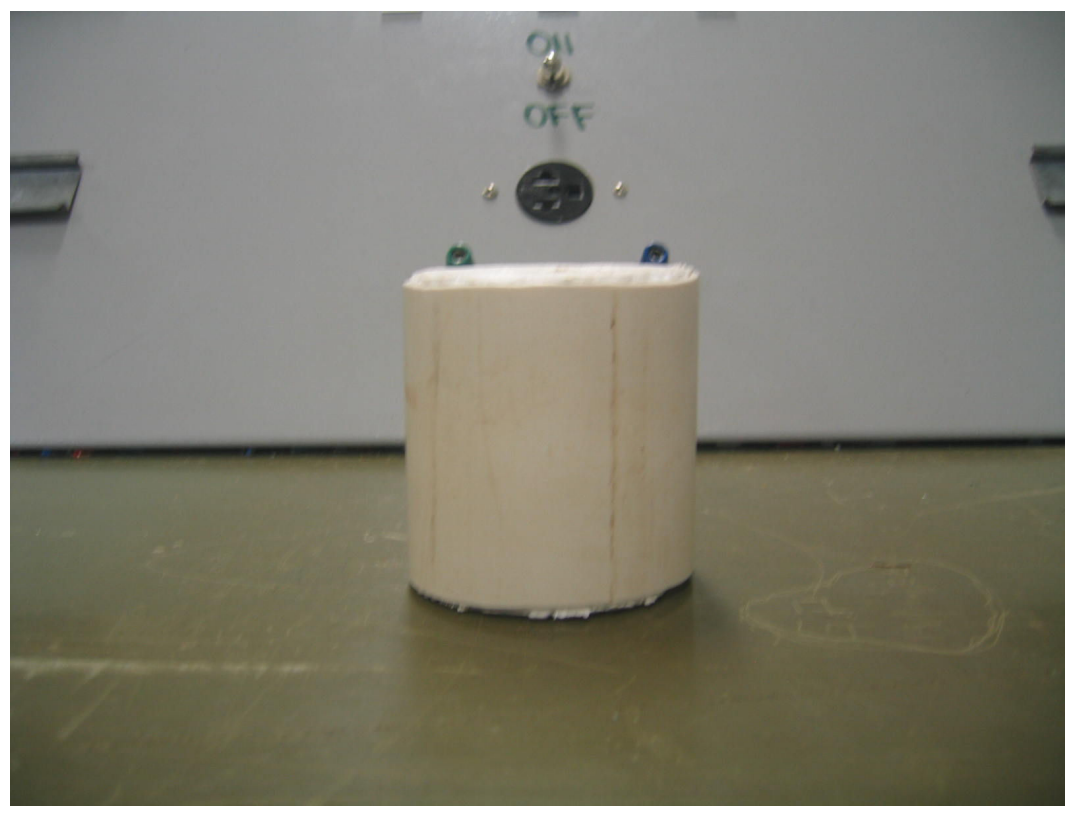

Figura 3.2 - Vista lateral do núcleo da bobina.

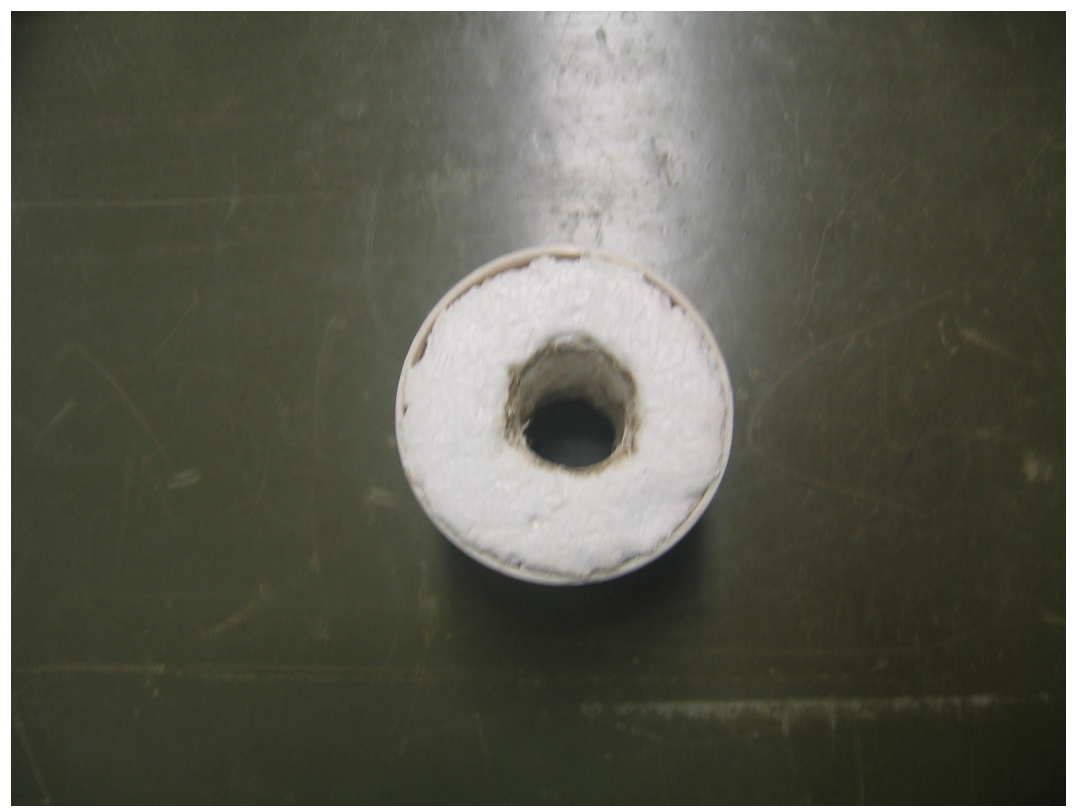

Figura 3.3 - Vista superior do núcleo da bobina. 


\section{2 - ETAPAS DE DESENVOLVIMENTO DA BOBINA}

O projeto contou basicamente com três fases principais de mudanças e adaptações da bobina de forma a se melhorar cada vez mais os resultados obtidos, aproximando-os cada vez mais dos resultados esperados teoricamente.

Em seguida, faz-se uma descrição das bobinas bem como das motivações para modificá-las, deixando as discussões dos resultados para o próximo capítulo.

\subsection{1 - Primeira etapa}

O primeiro modelo de secundário utilizado foi um tubo de plástico amarelo e a saída livre para ser conectada ao protoboard. Os parâmetros do secundário seguem na Tabela 3.2 abaixo:

Tabela 3.2 - Aspectos construtivos do primeiro secundário.

\begin{tabular}{|c|c|}
\hline Comprimento & $26 \mathrm{~cm}$ \\
\hline Diâmetro & $0,6 \mathrm{~cm}$ \\
\hline Distância do centro do tubo ao centro da bobina & $4 \mathrm{~cm}$ \\
\hline Número de espiras & 35 \\
\hline
\end{tabular}

Foram realizados inúmeros testes e ensaios razoavelmente satisfatórios, mas que ainda poderiam ser muito melhorados. Alguns testes e resultados da bobina com esse secundário serão apresentados e discutidos no capítulo seguinte.

A tensão esperada era muito baixa, da ordem de poucos $\mu \mathrm{V}$. Com isso o ruído se tornou um problema muito maior que o previsto. Diante destas dificuldades, foi decidido que, para se obter um fluxo magnético e um fluxo concatenado maiores e, conseqüentemente, uma tensão de saída maior, era necessário aumentar um pouco as medidas do secundário e o número de espiras.

As Figuras 3.4 e 3.5 mostram, respectivamente, uma imagem do primeiro secundário e uma da bobina composta com esse secundário. 


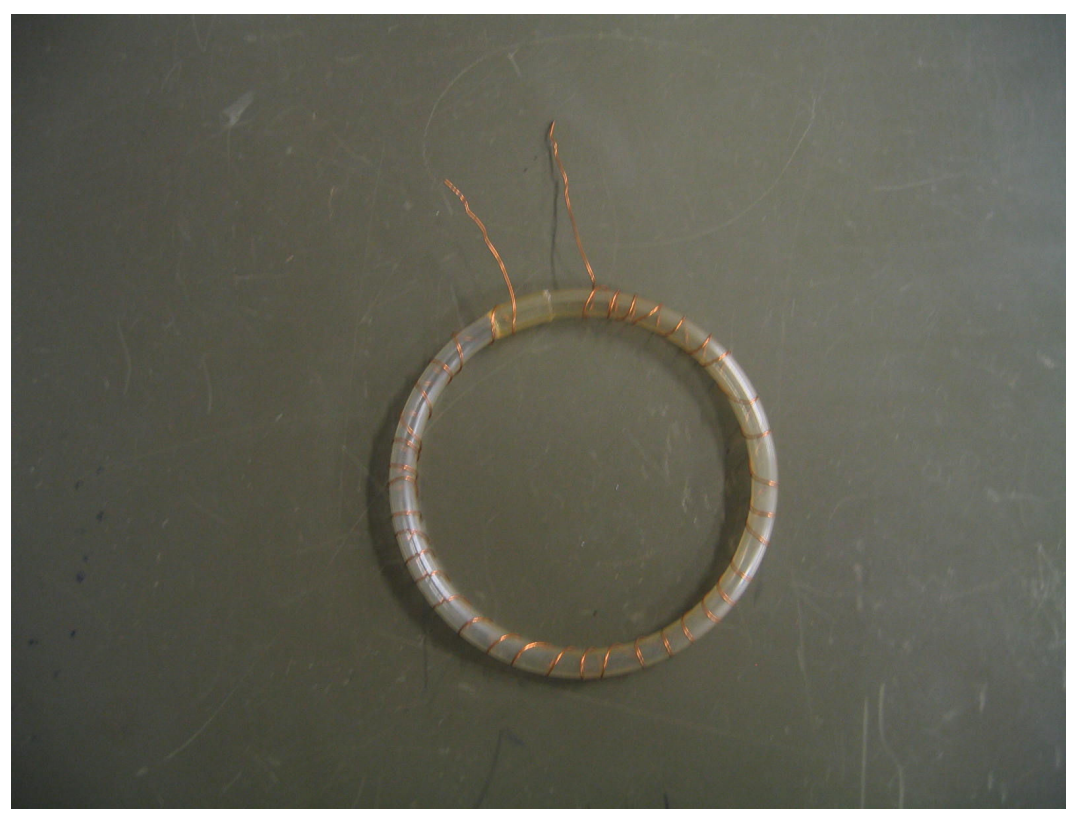

Figura 3.4 - Primeiro secundário.

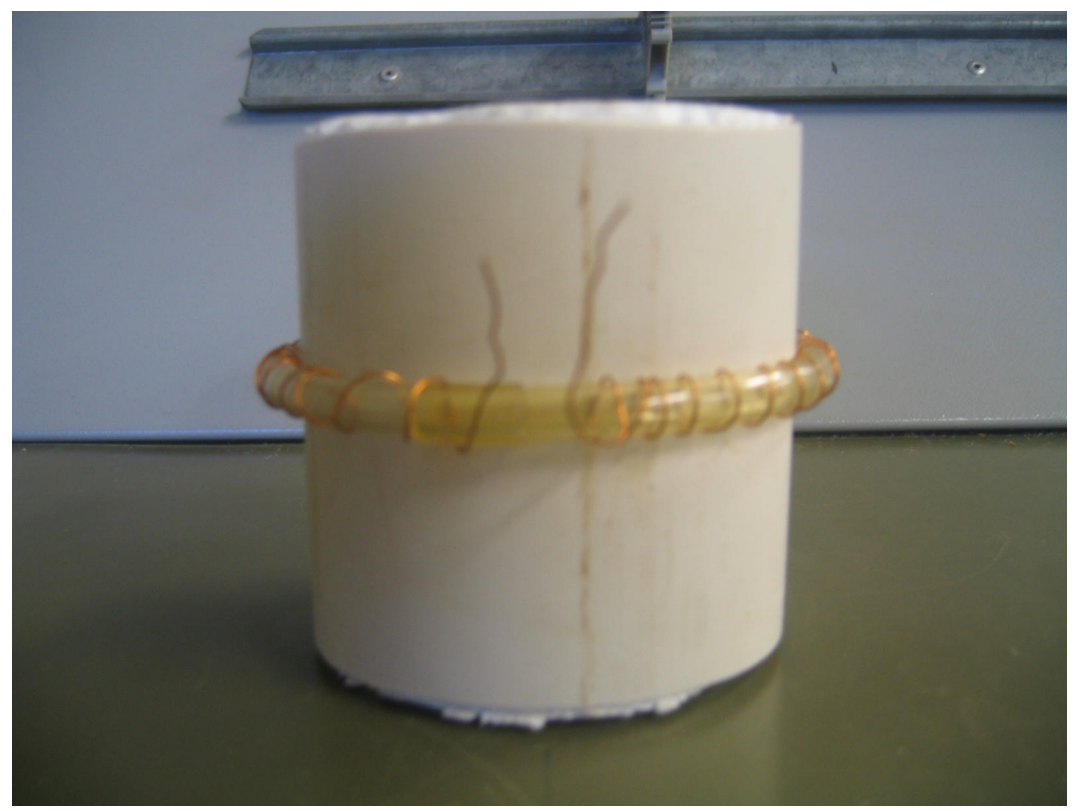

Figura 3.5 - Primeira bobina.

\subsection{2 - Secunda Etapa}

Diante de algumas dificuldades encontradas e que serão posteriormente detalhadas, decidiu-se por criar um novo secundário objetivando um maior fluxo magnético concatenado e, conseqüentemente, uma tensão maior no secundário. 
Utilizou-se um tubo de plástico transparente cujos aspectos construtivos seguem abaixo na Tabela 3.3:

Tabela 3.3 - Aspectos construtivos do segundo secundário.

\begin{tabular}{|c|c|}
\hline Comprimento & $29.8 \mathrm{~cm}$ \\
\hline Diâmetro & $1 \mathrm{~cm}$ \\
\hline Distância do centro do tubo ao centro da bobina & $5 \mathrm{~cm}$ \\
\hline Número de espiras & 50 \\
\hline
\end{tabular}

Colocou-se também a saída ligada a um cabo coaxial de $36 \mathrm{~cm}$ de comprimento. A saída em cabo coaxial foi utilizada de maneira a se observar se isso poderia ou não influenciar no resultado bem como diminuir um pouco o ruído.

Os testes e resultados utilizando esse novo secundário serão discutidos no próximo capítulo. Pode-se adiantar que, mesmo os resultados já sendo melhores, decidiu-se projetar um novo secundário de maneira a aumentar mais o fluxo magnético concatenado.

Optou-se por utilizar um novo secundário porque nas etapas seguintes de ensaios pensou-se também em utilizar um amplificador e um filtro e, assim, precisar-se-ia da saída livre para ser conectada ao protoboard.

As Figuras 3.6 e 3.7 mostram, respectivamente, uma imagem do segundo secundário e uma da bobina composta com esse secundário. 


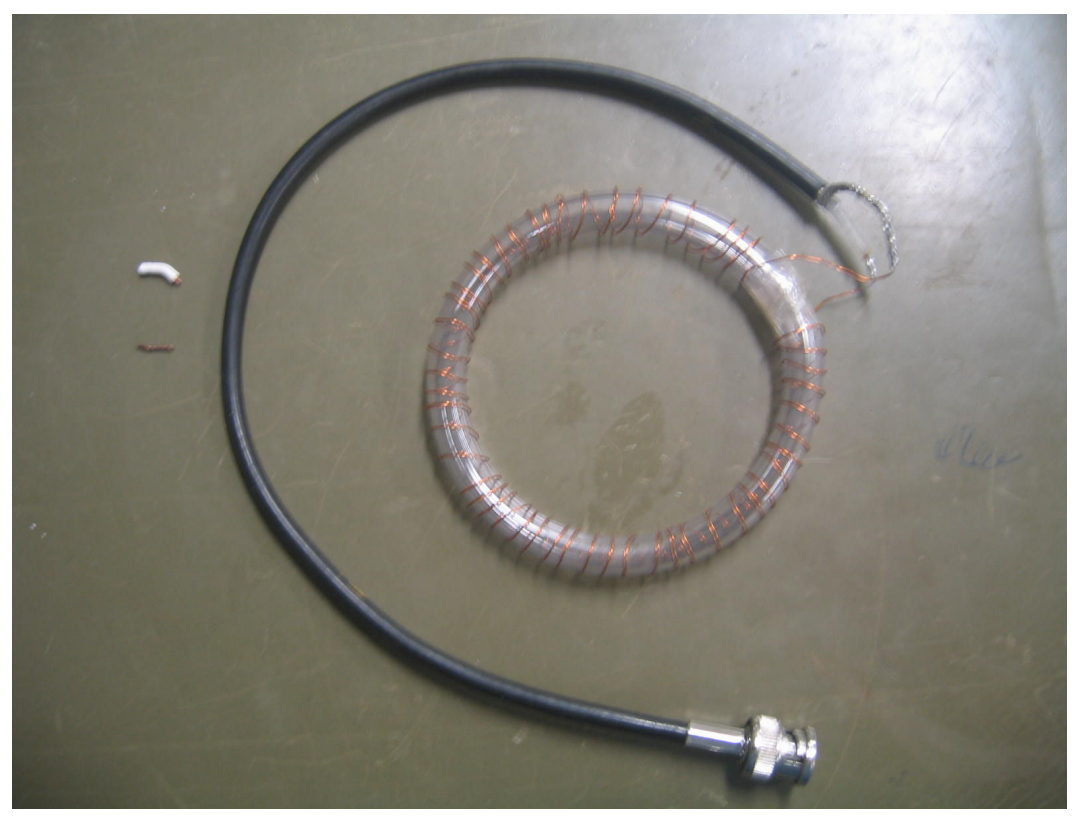

Figura 3.6 - Segundo secundário.

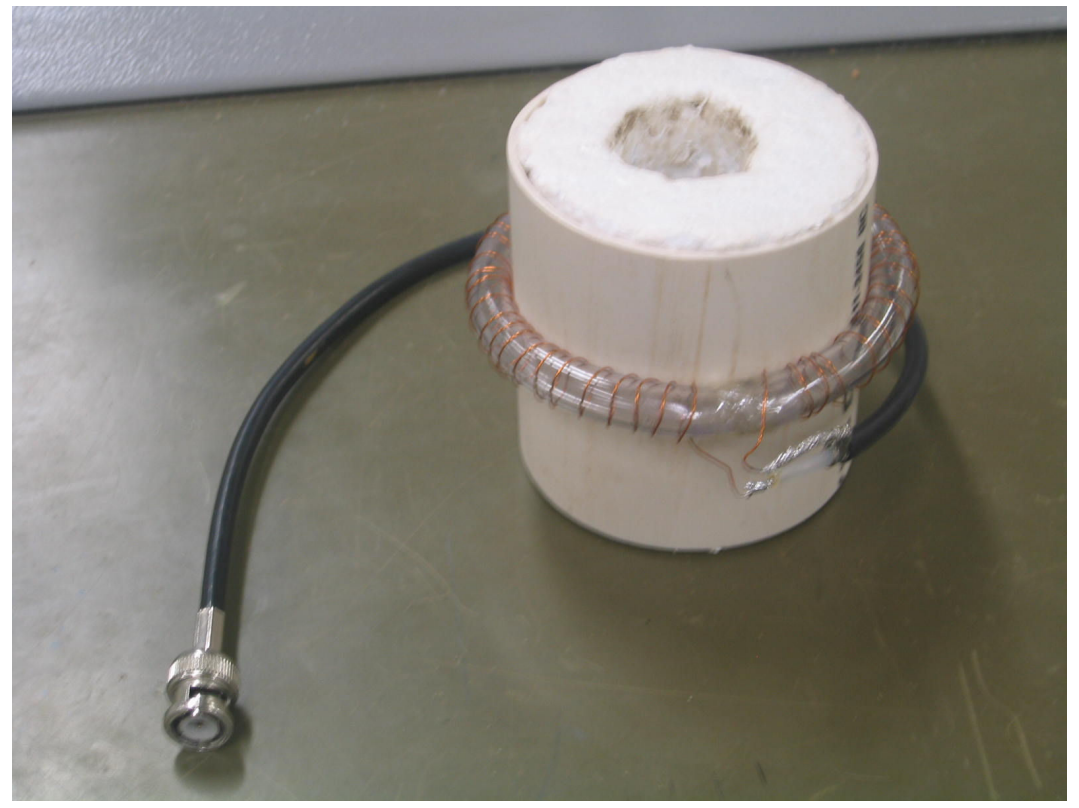

Figura 3.7 - Segunda bobina.

\subsection{3 - Terceira Etapa}

Como se pretendia utilizar um amplificador e/ou um filtro em ensaios subseqüentes, bem como se gostaria de obter um fluxo magnético concatenado maior, decidiu-se criar um novo secundário que não tivesse a saída em cabo coaxial, para possibilitar a utilização do protoboard. 
Utilizou-se o mesmo tubo de plástico, com a diferença de a saída poder ser conectada ao protoboard e com 150 espiras, ao invés de 50. A Figura 3.8 mostra uma imagem do terceiro secundário.

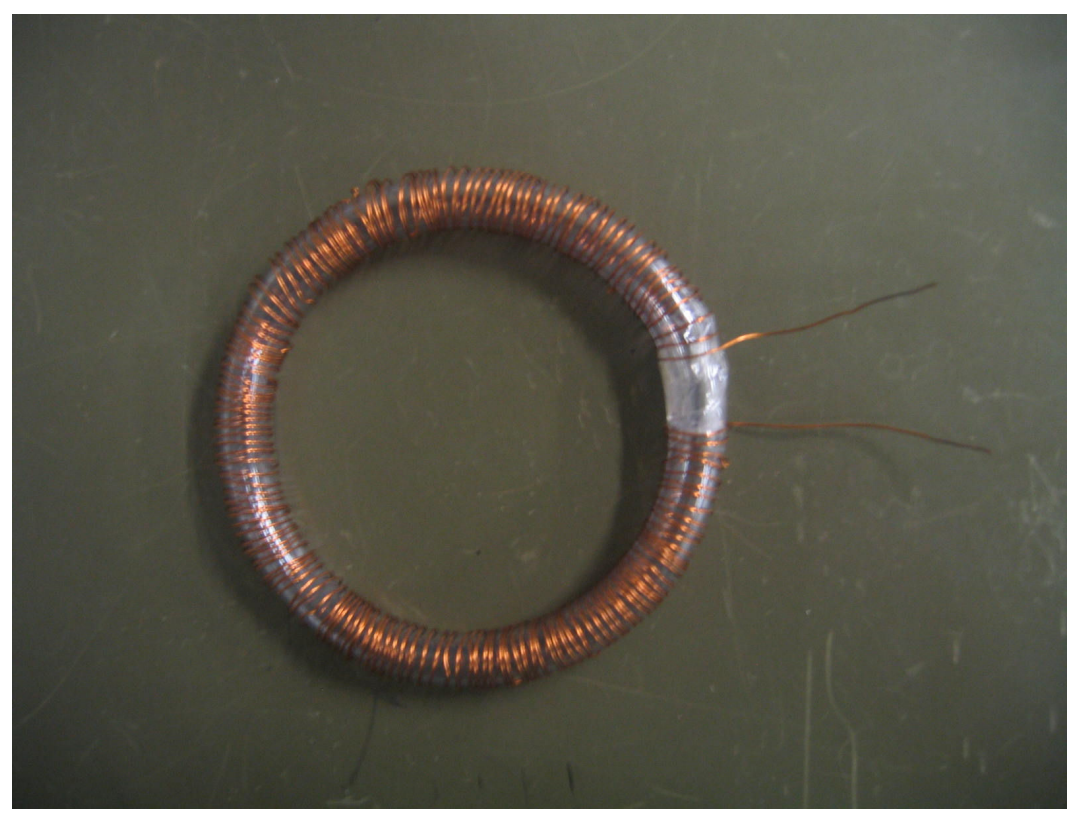

Figura 3.8 - Terceiro secundário.

Durante os testes com esse novo secundário optou-se por melhorar um pouco mais o núcleo central de PVC-isopor da bobina. Visto que a centralização do condutor é fundamental para se obter valores bem próximos da teoria, decidiu-se colocar mais um preenchimento interno na bobina. Criou-se um suporte de papel de maneira a centralizar ainda mais os fios condutores que passavam por dentro da bobina. A Figura 3.9 mostra a terceira bobina, a versão final do nosso protótipo da bobina de Rogowski. 


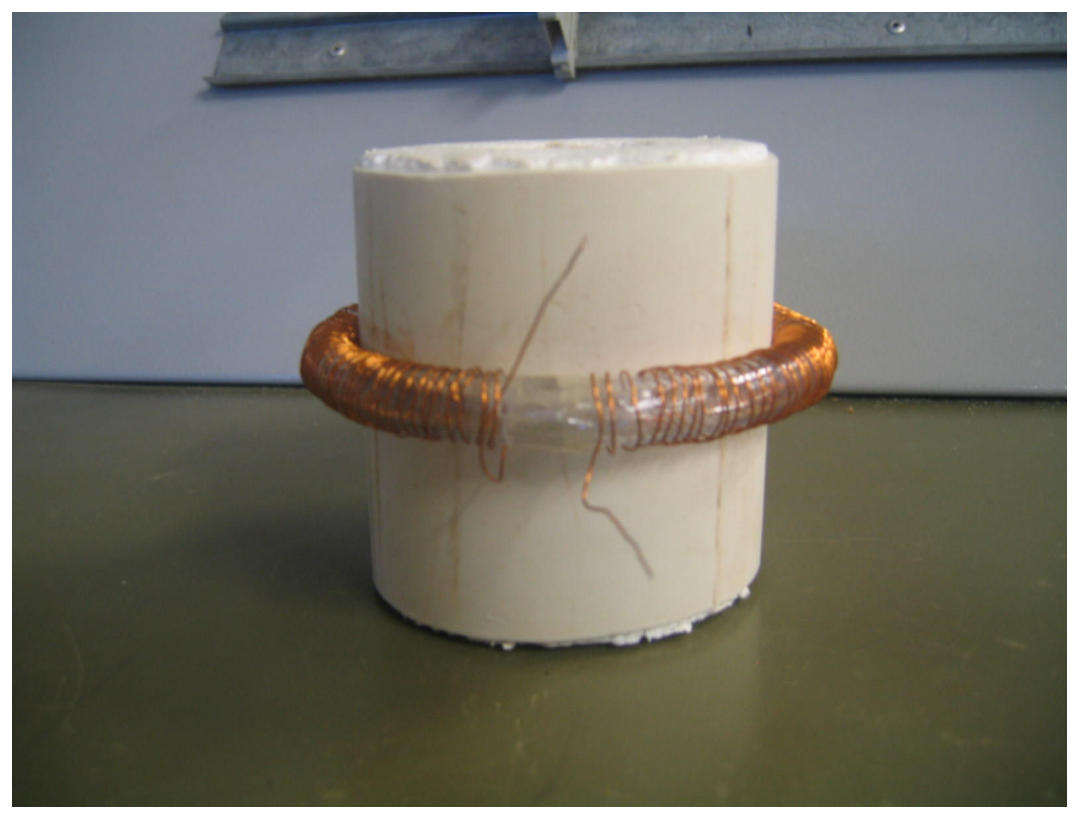

Figura 3.9 - Terceira bobina.

\section{3 - O AMBIENTE DE ENSAIO}

Os ensaios com nosso protótipo da bobina de Rogowski foram realizados no laboratório de instalações elétricas no prédio do SG-11. A bancada utilizada foi desenvolvida na própria DTE - Divisão Técnica Laboratorial - da UnB - Universidade de Brasília com fornecimento de $380 / 220 \mathrm{~V}$, trifásica e com o aterramento ligado ao aterramento do prédio. Além da bancada foram utilizados os seguintes equipamentos:

- Cabos do tipo banana-banana de $1,5 \mathrm{~mm}^{2}$ de seção transversal, específicos para instrumentação;

- Multímetros digitais Minipa ET-2507 True rms;

- Osciloscópio digital de dois canais, Agilent 54622D de $100 \mathrm{MHz}$ e 200 Msamples/s, com drive de disquete;

- Carga resistiva trifásica, Dane Eletrical Controls com unidade trifásica dimensionada para $6 \mathrm{~kW}$ em $380 \mathrm{~V}$, chaveada por alavancas;

- Protoboard Pront-O-Labor 550. 


\section{4 - MÉTODOS DE ENSAIO}

Para se testar as bobinas era preciso montar um circuito de maneira a obter a maior corrente possível.

Considerou-se, inicialmente, fazer uma associação em paralelo de transformadores $110 / 12 \mathrm{~V}$ de $24 \mathrm{~W}$, o que nos levou a outra preocupação, quanto à carga. Necessitar-seia de uma carga de $2,4 \Omega$ que suportasse $60 \mathrm{~W}$.

Porém, após se conversar com os técnicos do laboratório, certificou-se que os equipamentos disponíveis à realização do ensaio atenderiam às especificações.

Visto que se teria disponível uma carga trifásica de $6 \mathrm{~kW}$, considerou-se mais pertinente utilizá-la, montando-a diretamente na rede de alimentação. Utilizou-se uma das fases da carga (a fase A) variando sua carga sempre de $100 \mathrm{~W}$ em $100 \mathrm{~W}$, começando em 2000 W e diminuindo, até $1500 \mathrm{~W}$. Com isso, conseguimos uma corrente máxima de 9,09 A. A Figura 3.10 mostra o esquema do circuito utilizado em todos os ensaios e a Tabela 3.4 mostra os possíveis valores de corrente em relação à carga utilizada.

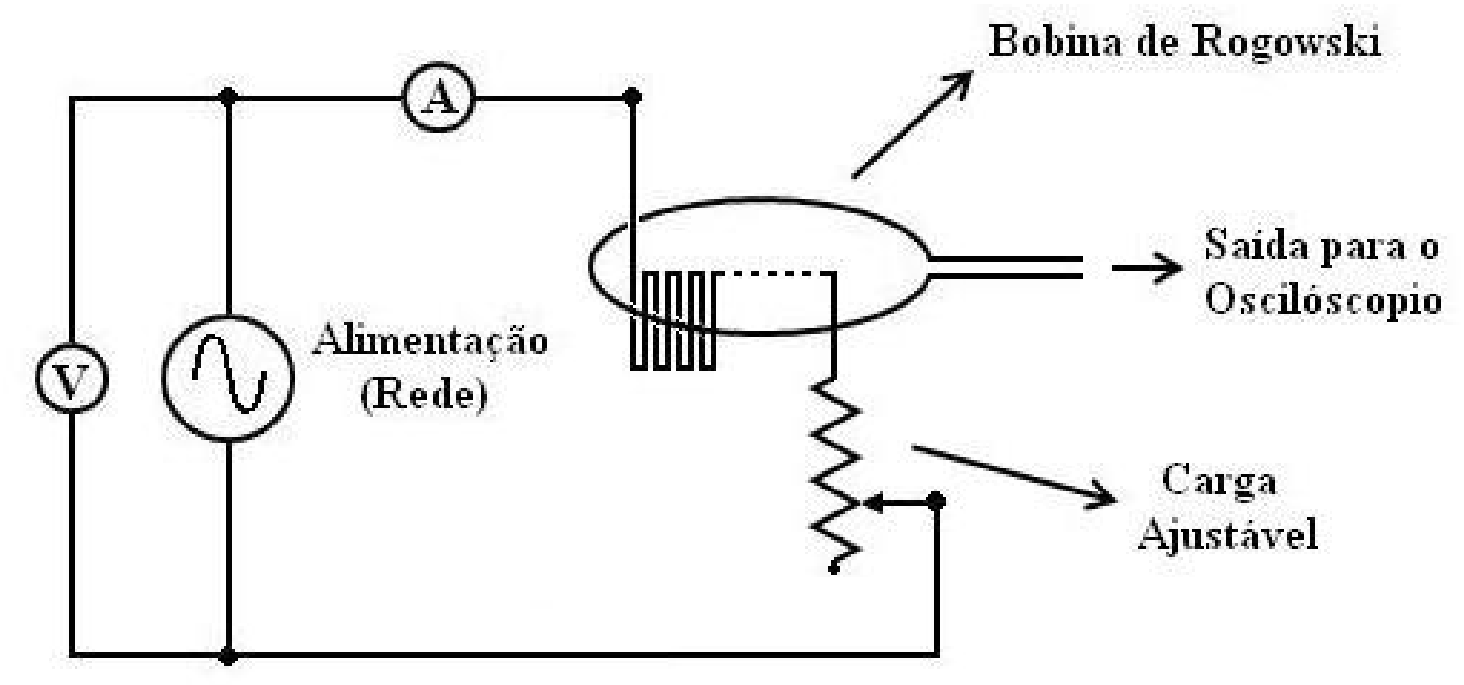

Figura 3.10 - Circuito utilizado para os ensaios. 
Tabela 3.4 - Possíveis valores para corrente, considerando uma tensão de $220 \mathrm{~V}$.

\begin{tabular}{|c|c|c|c|}
\hline $\begin{array}{c}\text { Carga } \\
(\mathrm{kVA})\end{array}$ & $\begin{array}{c}\text { Corrente } \\
(\mathrm{A})\end{array}$ & $\begin{array}{c}\text { Carga } \\
(\mathrm{kVA})\end{array}$ & $\begin{array}{c}\text { Corrente } \\
(\mathrm{A})\end{array}$ \\
\hline 100 & 0,45 & 1100 & 5,00 \\
\hline 200 & 0,91 & 1200 & 5,45 \\
\hline 300 & 1,36 & 1300 & 5,91 \\
\hline 400 & 1,82 & 1400 & 6,36 \\
\hline 500 & 2,27 & 1500 & 6,82 \\
\hline 600 & 2,73 & 1600 & 7,27 \\
\hline 700 & 3,18 & 1700 & 7,73 \\
\hline 800 & 3,64 & 1800 & 8,18 \\
\hline 900 & 4,09 & 1900 & 8,64 \\
\hline 1000 & 4,55 & 2000 & 9,09 \\
\hline
\end{tabular}

A Figura 3.11 a seguir mostra a curva da corrente em função da carga.

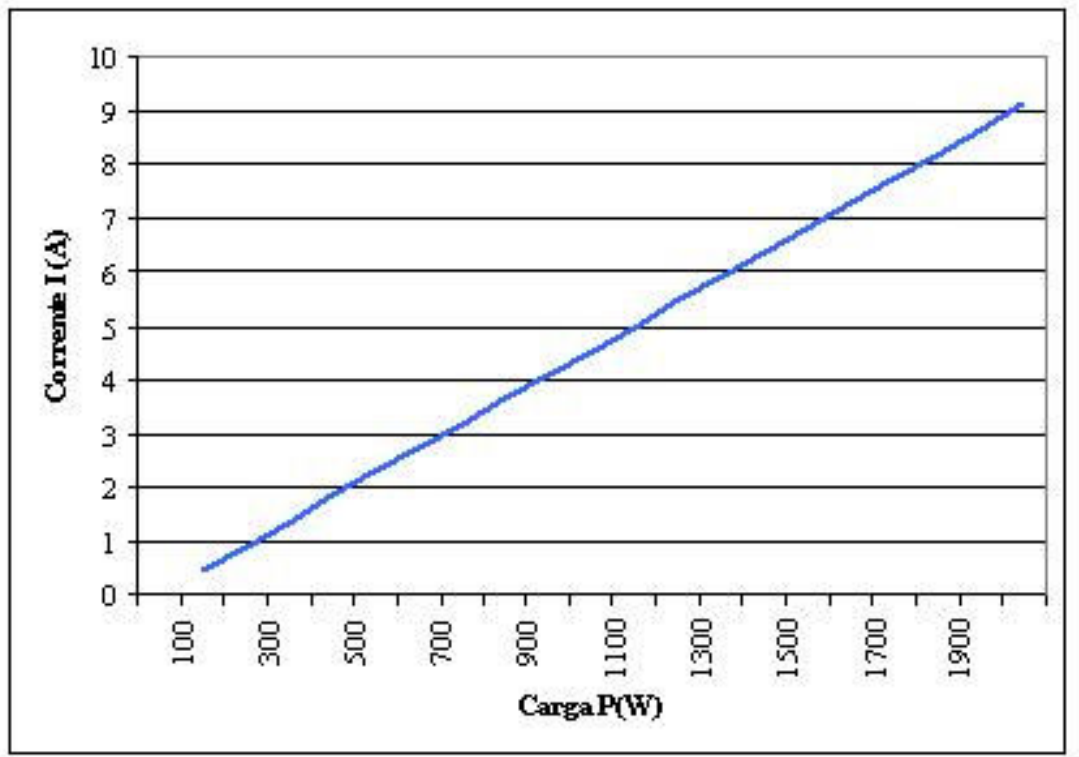

Figura 3.11 - Corrente em função da carga.

De maneira a obter a maior corrente possível e, conseqüentemente, um fluxo concatenado maior, o condutor foi passado várias vezes por dentro da bobina. (Os valores exatos dependem do teste e serão explicitados no próximo capítulo). 
Durante o desenvolvimento do projeto, foram utilizados vários métodos de ensaio e outros procedimentos, como filtro, de maneira a se obter resultados mais próximos possíveis das expectativas teóricas.

Os métodos foram sendo aperfeiçoados na medida em que se aprofundava mais na teoria de campos magnéticos bem como quando um determinado método se mostrava insatisfatório.

\subsection{1 - Primeiro método}

Antes de se iniciarem os testes, já se tinha uma grande dificuldade a ser superada. Como era conseguido apenas uma corrente de, aproximadamente, $9 \mathrm{~A}$, foi necessário passar o fio condutor várias vezes dentro da bobina objetivando obter uma corrente maior e, conseqüentemente, um fluxo concatenado maior. Com o maior cabo disponível, conseguia-se uma corrente de 50 A. Nessa etapa, o condutor era passado encostando-se ao secundário de acordo com o esquema da Figura 3.12, que segue abaixo.

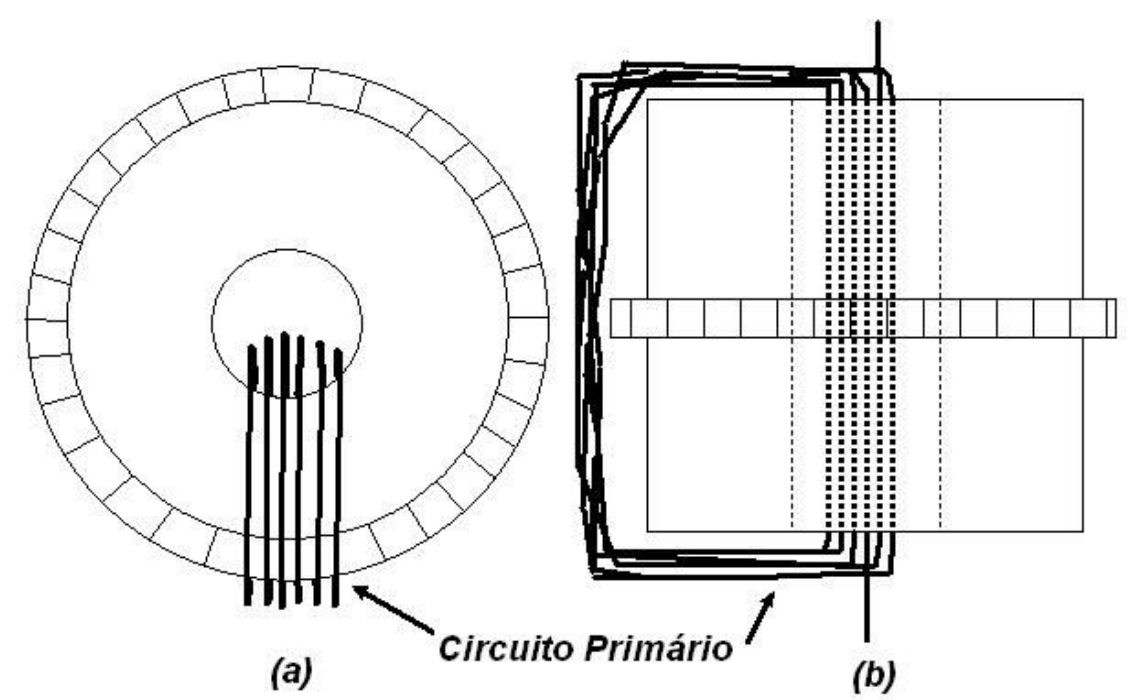

Figura 3.12 - Primeiro método de medição; (a) Vista superior; (b) Vista lateral.

Porém, visto que os resultados obtidos com essa forma de medição ainda estavam muito longe dos valores esperados teoricamente, conclui-se que o problema deveria estar na forma de medição. Vale ressaltar que todos os resultados com cada método e com cada bobina, bem como os resultados esperados em cada situação serão discutidos detalhadamente no próximo capítulo. 


\subsection{2 - Segundo método}

Depois de se analisar a forma de medição e os resultados, percebeu-se que um campo magnético é gerado no interior da bobina, mas um campo semelhante é gerado pelos condutores que passam pelo lado de fora da bobina. Devido a esse fato, o campo externo à bobina estaria influenciando o campo total percebido pelo secundário o que poderia explicar o valor extremamente alto encontrado com o método anterior. Com isso, decidiu-se passar o condutor externo à bobina com uma distância de aproximadamente $20 \mathrm{~cm}$ da bobina prendendo-o com fita adesiva tanto no interior da bobina quanto do lado de fora. A Figura 3.13 exemplifica o método.

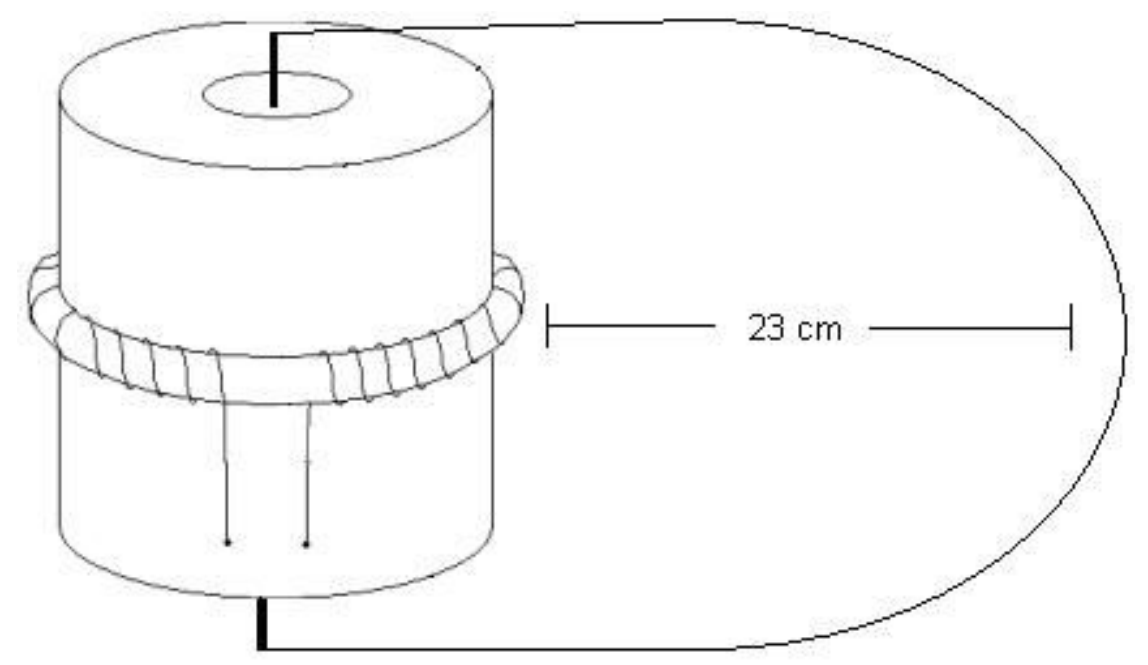

Figura 3.13 - Segundo método de medição.

Realizando-se os ensaios dessa maneira, os resultados foram um pouco mais coerentes, mas ainda estavam longe de serem considerados satisfatórios. Diante dessa dificuldade realizaram-se mais testes e continuou-se estudando a teoria de campos magnéticos e buscando-se uma nova solução. Devido ao tamanho cabo, utilizando esse método nós conseguimos atingir apenas $45 \mathrm{~A}$ de corrente concatenada.

\subsection{3 - Terceiro método}

Após algumas análises, percebeu-se que seria interessante se, ao invés de se colocar os fios do condutor, externos à bobina, todos apenas de um lado da bobina, colocasse-se 
uma volta de cada lado, seria possível que os campos gerados por cada lado se anulassem ou, devido às condições de simetria que não eram perfeitas, pelo menos diminuíssem a contribuição total do campo externo sobre a bobina. Os ensaios foram então realizados de acordo com o esquema da Figura 3.14. De forma a conduzir os ensaios da maneira sugerida, tomou-se o cuidado de passar o condutor um número impar de vezes dentro da bobina. Como descrito anteriormente, devido ao tamanho do cabo, conseguimos passa-lo apenas cinco vezes dentro da bobina obtendo uma corrente concatenada máxima de $45 \mathrm{~A}$.

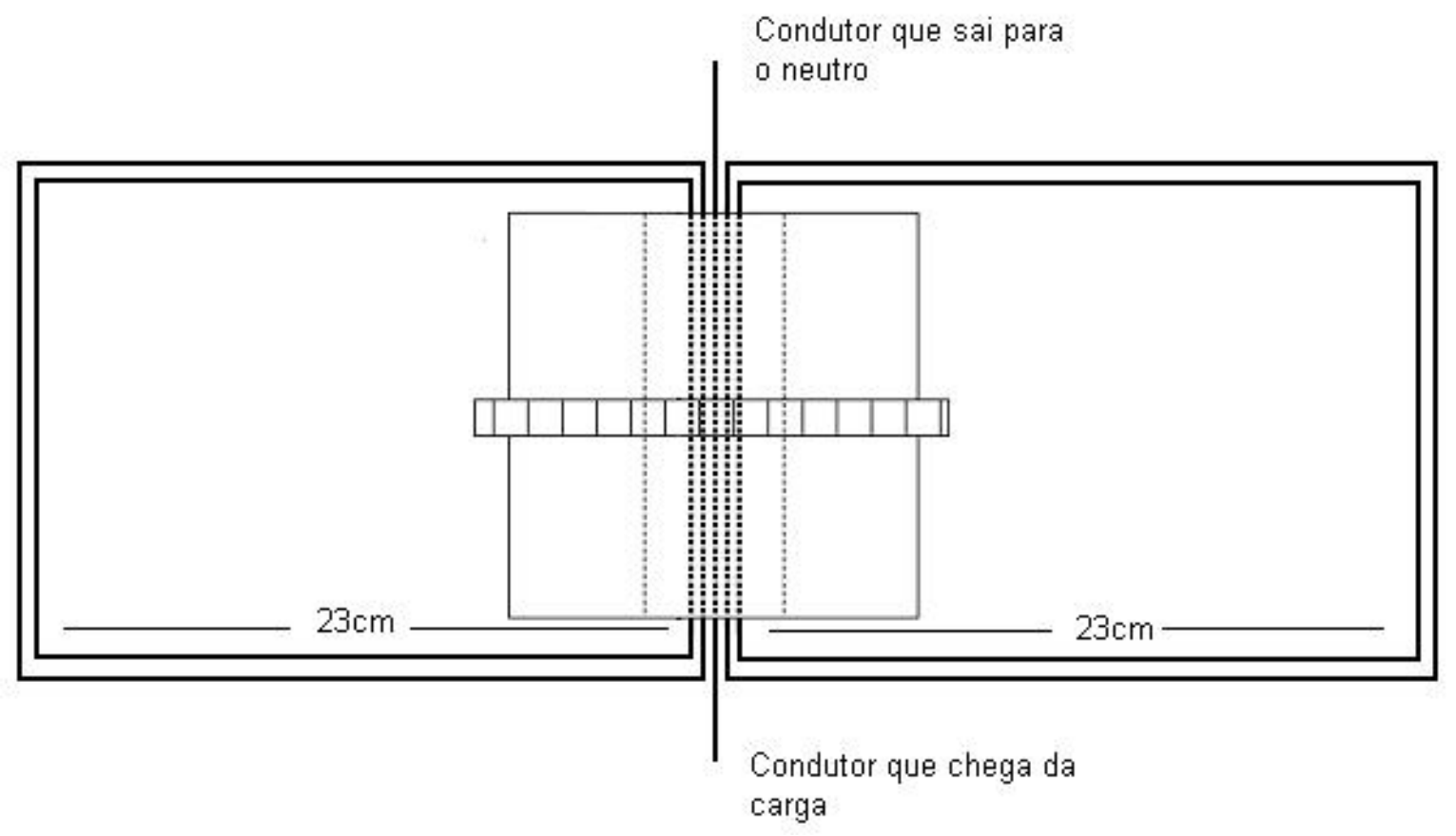

Figura 3.14 - Terceiro método de medição.

Como esperado, conseguiu-se diminuir bastante o valor da tensão obtida aproximando mais o resultado obtido do resultado esperado teoricamente. Contudo, baseado em novas observações experimentais e teóricas, decidiu-se tentar aperfeiçoar um pouco mais a forma de se ensaiar, de maneira a obter resultados mais precisos.

\subsection{4 - Quarto método}

Novamente, buscando-se alcançar a melhor maneira possível de realizar os ensaios em laboratórios de baixa tensão, decidiu-se modificar um pouco mais nosso método de ensaio. A forma de ensaiar adotada foi praticamente a mesma, entretanto, nesse método, 
desenvolveu-se uma maneira simples de centralizar o conjunto de fios condutores no interior da bobina, mas que se mostrou bastante eficiente.

Amarrou-se com fita adesiva o conjunto de fios condutores que passavam dentro da bobina, assim esse conjunto pode ser considerado como se fosse um único condutor de raio aumentado.

Outra pequena mudança foi uma adaptação nova da bobina. Preencheu-se, depois de posicionar os fios condutores dentro da bobina, o espaço restante com dois suportes de papel em forma de semi-cilindro, de $5,5 \mathrm{~cm}$ de comprimento e $2 \mathrm{~cm}$ de raio, de maneira a arranjar os fios condutores dentro do mesmo. A Figura 3.15 mostra um esquemático aproximado do modelo real.

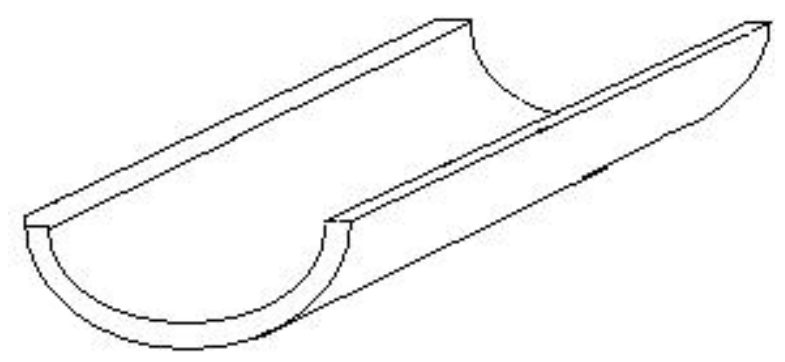

Figura 3.15 - Esquemático do suporte de papel.

Com o suporte de papel e os fios condutores presos como de fossem um único condutor obtivemos resultados muito próximos dos resultados esperados teoricamente e que foram considerados satisfatórios.

\section{5 - O PROJETO DO FILTRO}

De modo a melhorar os resultados obtidos, percebeu-se que seria interessante projetar e construir um filtro com a intenção de eliminar ou, pelo menos, reduzir os sinais de alta freqüência. Basicamente, quer-se eliminar o ruído com a utilização do filtro.

Optou-se por um filtro passivo do tipo passa-baixas que apresentasse uma freqüência de corte de aproximadamente $100 \mathrm{~Hz}$. 
O filtro passa-baixas foi projetado da seguinte maneira:

A partir do modelo do circuito do filtro, que é mostrado a seguir na Figura 3.16, desenvolveu-se o seguinte raciocínio:

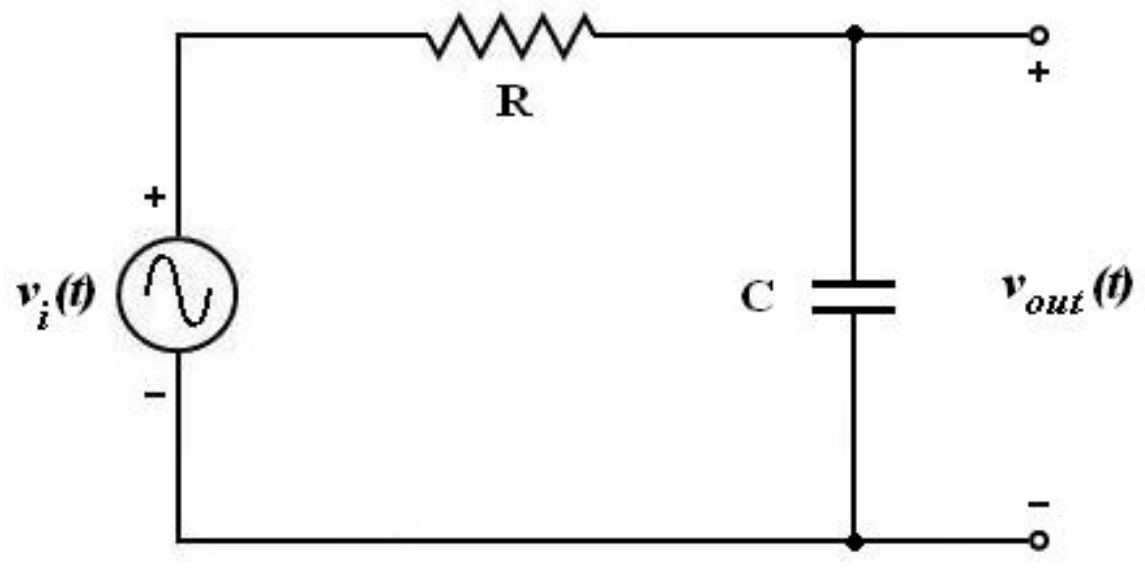

Figura 3.16 - Modelo do filtro passa-baixas.

$$
\begin{gathered}
R i(t)+\frac{1}{C} \int i(t) d t=v_{i}(t) \\
\frac{1}{C} \int i(t) d t=v_{\text {out }}(t)
\end{gathered}
$$

Onde:

$R$ é a resistência, em $\Omega$;

$i(t)$ é a corrente que circula, em A;

$C$ é a capacitância, e $\mu \mathrm{F}$;

$v_{i}$ é a tensão de entrada, em V; e

$v_{\text {out }}$ é a tensão de saída, em V.

Aplicando a transformada de Laplace em ambas as equações obtemos:

$$
R I(s)+\frac{1}{C} \frac{1}{s} I(s)=V_{i}(s)
$$




$$
\frac{1}{C} \frac{1}{s} I(s)=V_{\text {out }}(s)
$$

Dividindo a saída pela entrada e realizando as manipulações necessárias obtemos:

$$
\frac{V_{\text {out }}(s)}{V_{i}(s)}=\frac{1}{R C s+1}
$$

O que equivale a

$$
G(s)=\frac{1}{R C s+1}
$$

Sabemos que a freqüência de corte, $f_{c}$, é dada pela relação 3.7:

$$
f_{c}=\frac{1}{2 \pi R C}
$$

Analisando os valores de capacitâncias disponíveis no laboratório, decidiu-se utilizar a capacitância de $0,01 \mu \mathrm{F}$, de maneira a reduzir o valor máximo do resistor.

Como a freqüência de corte desejada é de $100 \mathrm{~Hz}$, o produto $\mathrm{RC}$ deve ser igual a 0,0015932. Logo, $\mathrm{R}=159,32 \mathrm{k} \Omega$. Como o laboratório não dispõe de tal resistor, utilizou-se um resistor de $150 \mathrm{k} \Omega$ em série com um de $10 \mathrm{k} \Omega$.

Foram realizados então os testes com o filtro de maneira a verificar seu funcionamento. Calculando-se o módulo do $G(s)$ para várias freqüências, determinaram-se os valores esperados teoricamente.

A Tabela 3.5 compara os valores esperados teoricamente, considerando um sinal de entrada de $1,1 \mathrm{~V}$, com os obtidos na prática e a Figura 3.17 mostra as curvas das tensões de saída esperada e obtida. Em seguida, a Tabela 3.6 apresenta os mesmos resultados, porém em decibéis $(\mathrm{dB})$ e a Figura 3.18 mostra as curvas das tensões, também em dB. 
Tabela 3.5 - Resultados dos ensaios do filtro.

\begin{tabular}{|c|c|c|}
\hline $\begin{array}{c}\text { Freqüência } \\
(\mathrm{Hz})\end{array}$ & $\begin{array}{c}\text { Tensão de saída esperada } \\
(\mathrm{mV})\end{array}$ & $\begin{array}{c}\text { Tensão de saída obtida } \\
(\mathrm{mV})\end{array}$ \\
\hline 10 & 1090 & 990 \\
\hline 30 & 1050 & 960 \\
\hline 50 & 980 & 940 \\
\hline 80 & 858 & 840 \\
\hline 100 & 777 & 780 \\
\hline 150 & 605 & 660 \\
\hline 300 & 345 & 369 \\
\hline 500 & 210 & 235 \\
\hline 800 & 135 & 150 \\
\hline 1000 & 99 & 131 \\
\hline 1500 & 73 & 84 \\
\hline
\end{tabular}

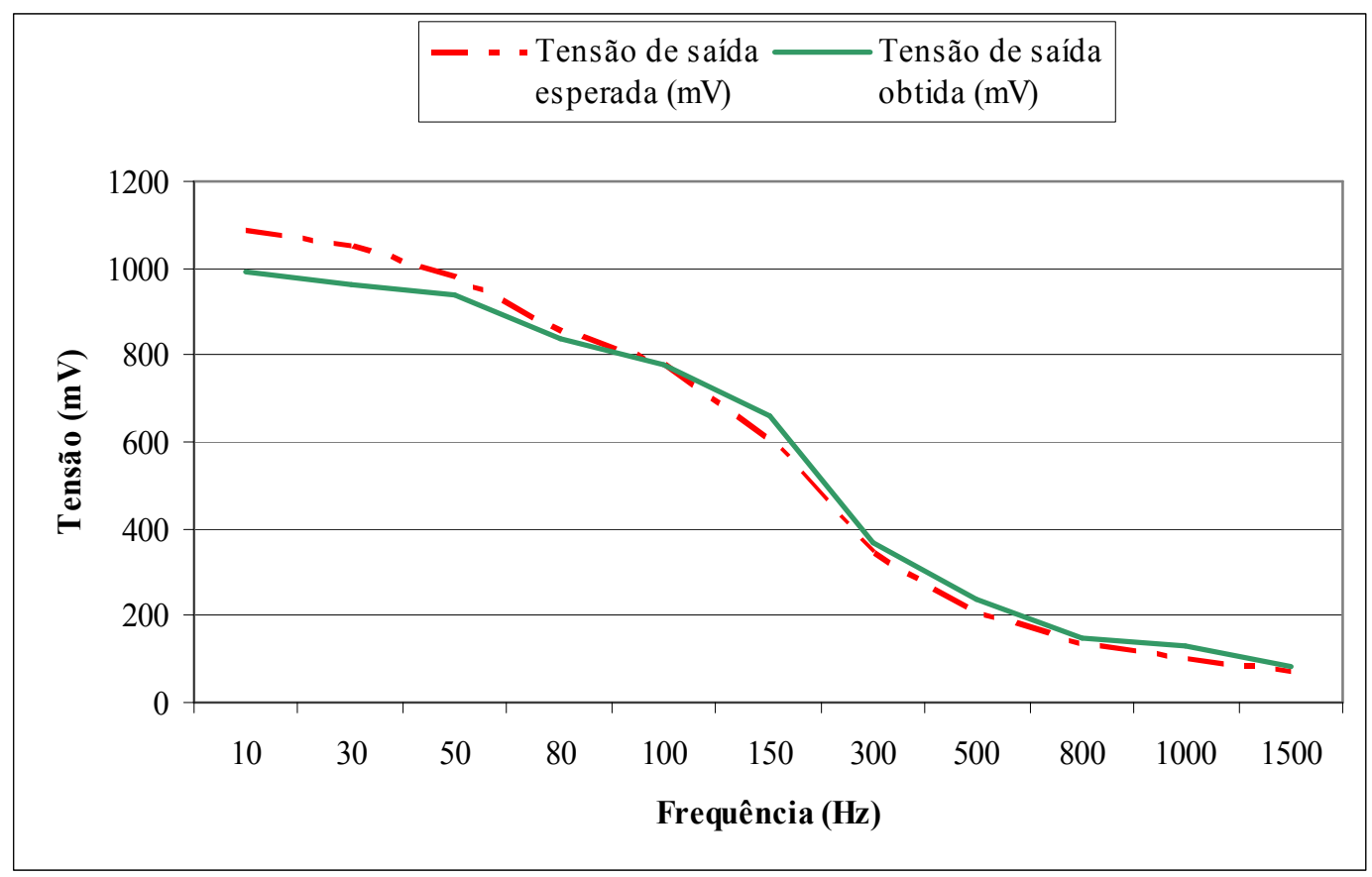

Figura 3.17 - Tensões de saída esperada e obtida, em mV, em função da freqüência. 
Tabela 3.6 - Resultados dos ensaios do filtro em dB.

\begin{tabular}{|c|c|c|}
\hline $\begin{array}{c}\text { Freqüência } \\
(\mathrm{Hz})\end{array}$ & $\begin{array}{c}\text { Tensão de } \\
\text { saída } \\
\text { esperada (dB) }\end{array}$ & $\begin{array}{c}\text { Tensão de } \\
\text { saída } \\
\text { obtida (dB) }\end{array}$ \\
\hline 10 & 0,7 & $-0,1$ \\
\hline 30 & 0,4 & $-0,4$ \\
\hline 50 & $-0,2$ & $-0,5$ \\
\hline 80 & $-1,3$ & $-1,5$ \\
\hline 100 & $-2,2$ & $-2,2$ \\
\hline 150 & $-4,4$ & $-3,6$ \\
\hline 300 & $-9,2$ & $-8,7$ \\
\hline 500 & $-13,6$ & $-12,6$ \\
\hline 800 & $-17,4$ & $-16,5$ \\
\hline 1000 & $-20,1$ & $-17,7$ \\
\hline 1500 & $-22,7$ & $-21,5$ \\
\hline
\end{tabular}

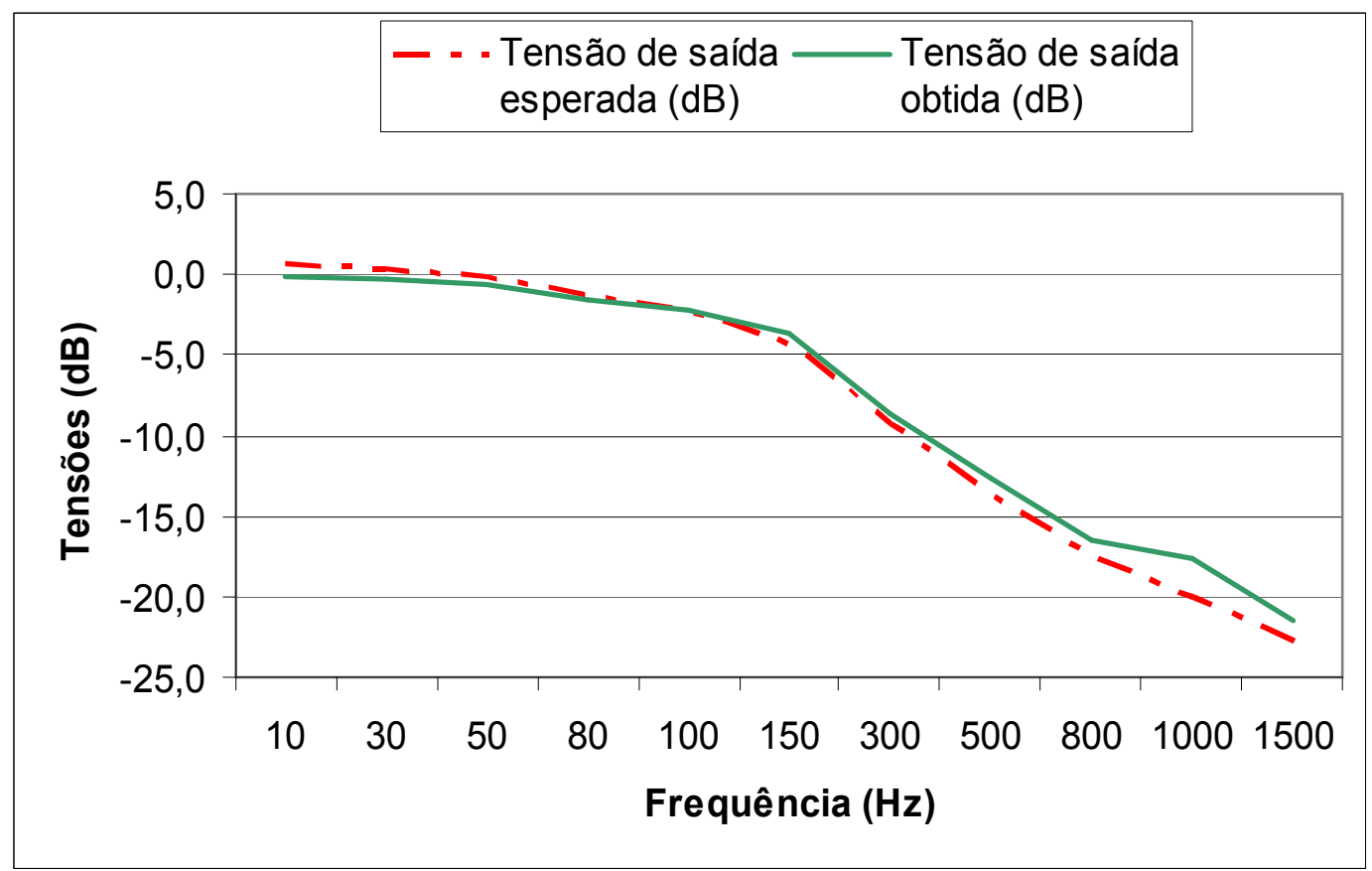

Figura 3.18 - Tensões de saída esperada e obtida, em dB, em função da freqüência.

A partir da observação das Figuras 3.17 e 3.18, pode-se concluir que a resposta em freqüência do filtro é bastante satisfatória. 
Agora, as Figuras 3.19, 3.20, 3.21, 3.22 e 3.23 mostram, respectivamente, as formas de onda de saída do filtro obtidas para as freqüências de $10 \mathrm{~Hz}, 50 \mathrm{~Hz}, 100 \mathrm{~Hz}, 500 \mathrm{~Hz}$ e $1000 \mathrm{~Hz}$ :

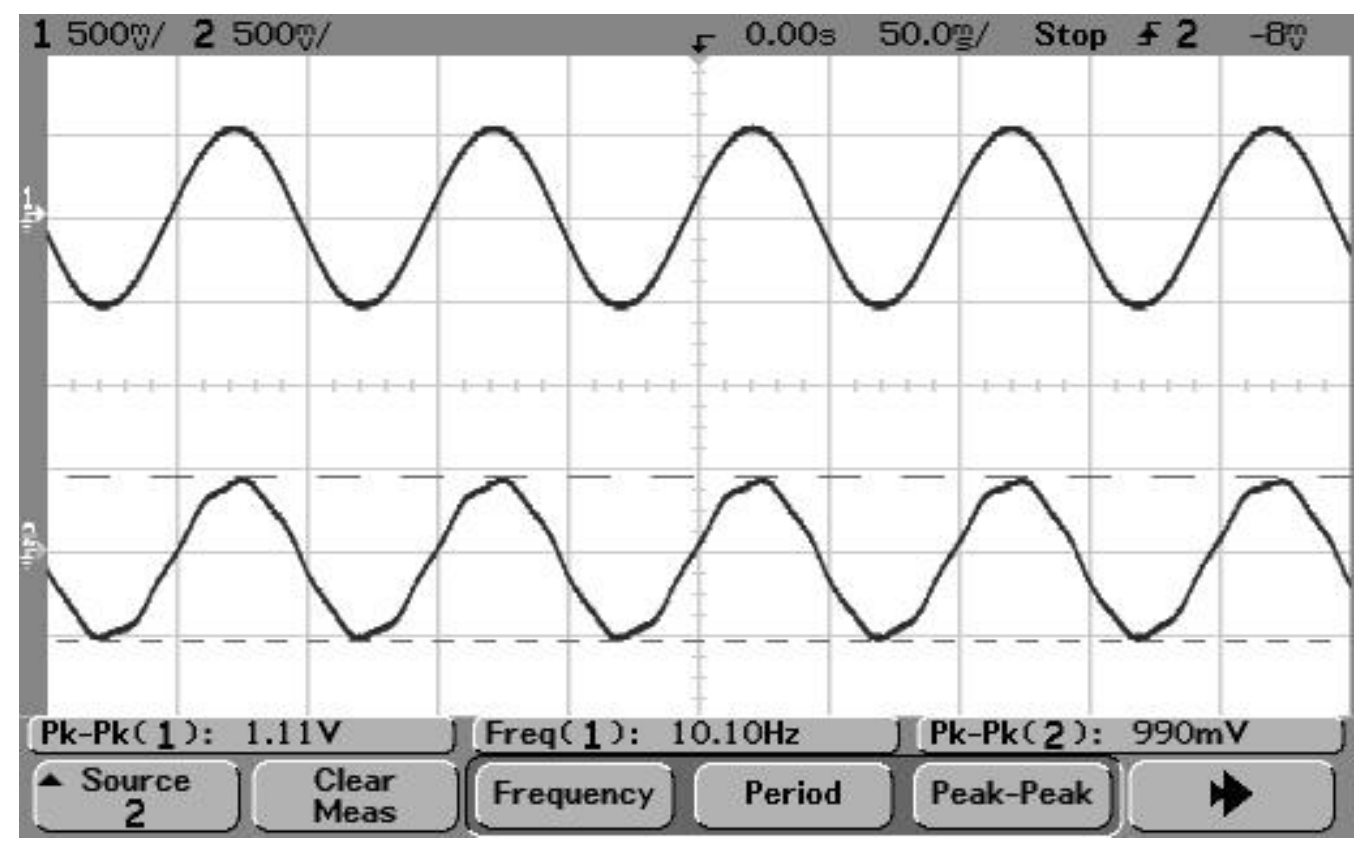

Figura 3.19 - Onda obtida com sinal de $10 \mathrm{~Hz}$.

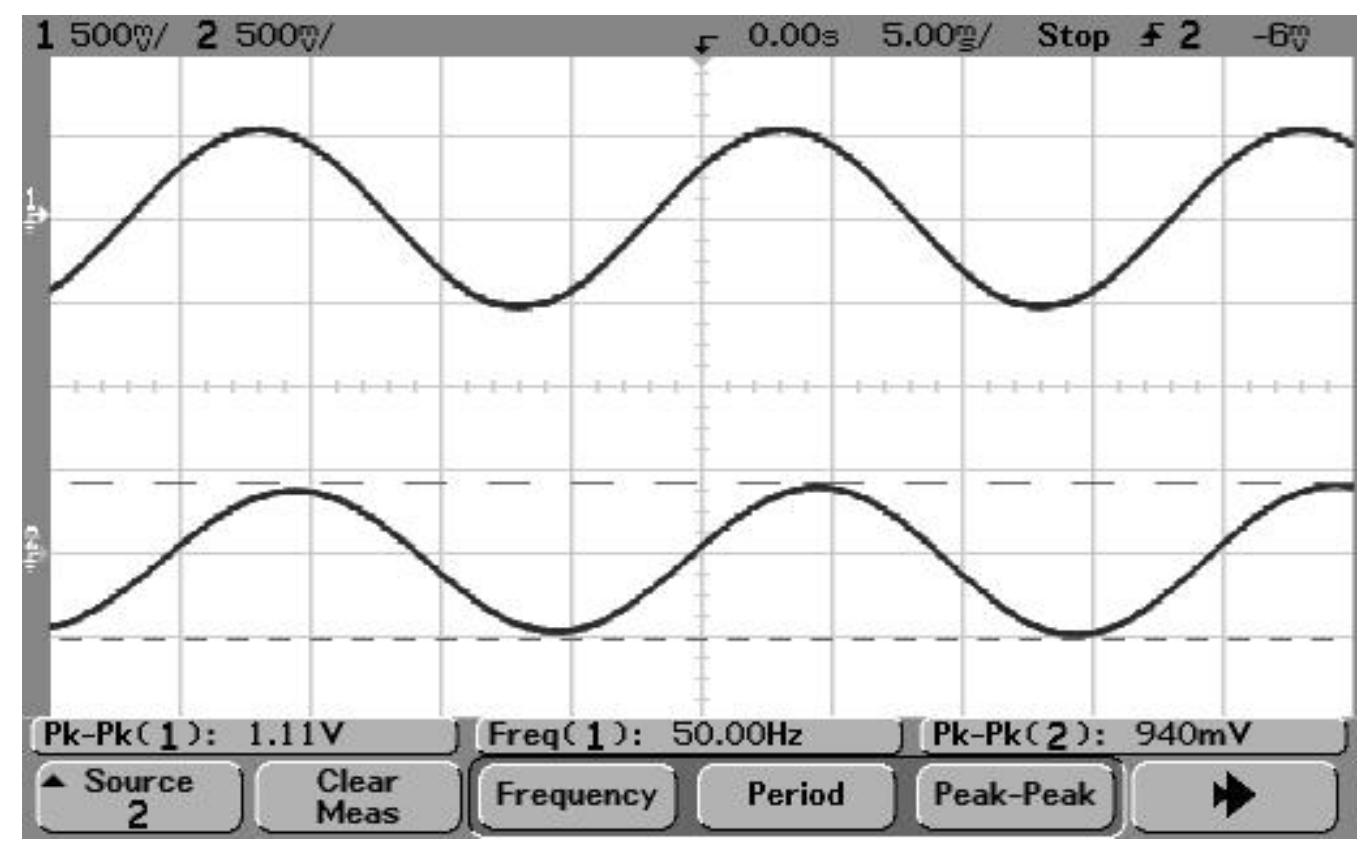

Figura 3.20 - Onda obtida com sinal de $50 \mathrm{~Hz}$. 


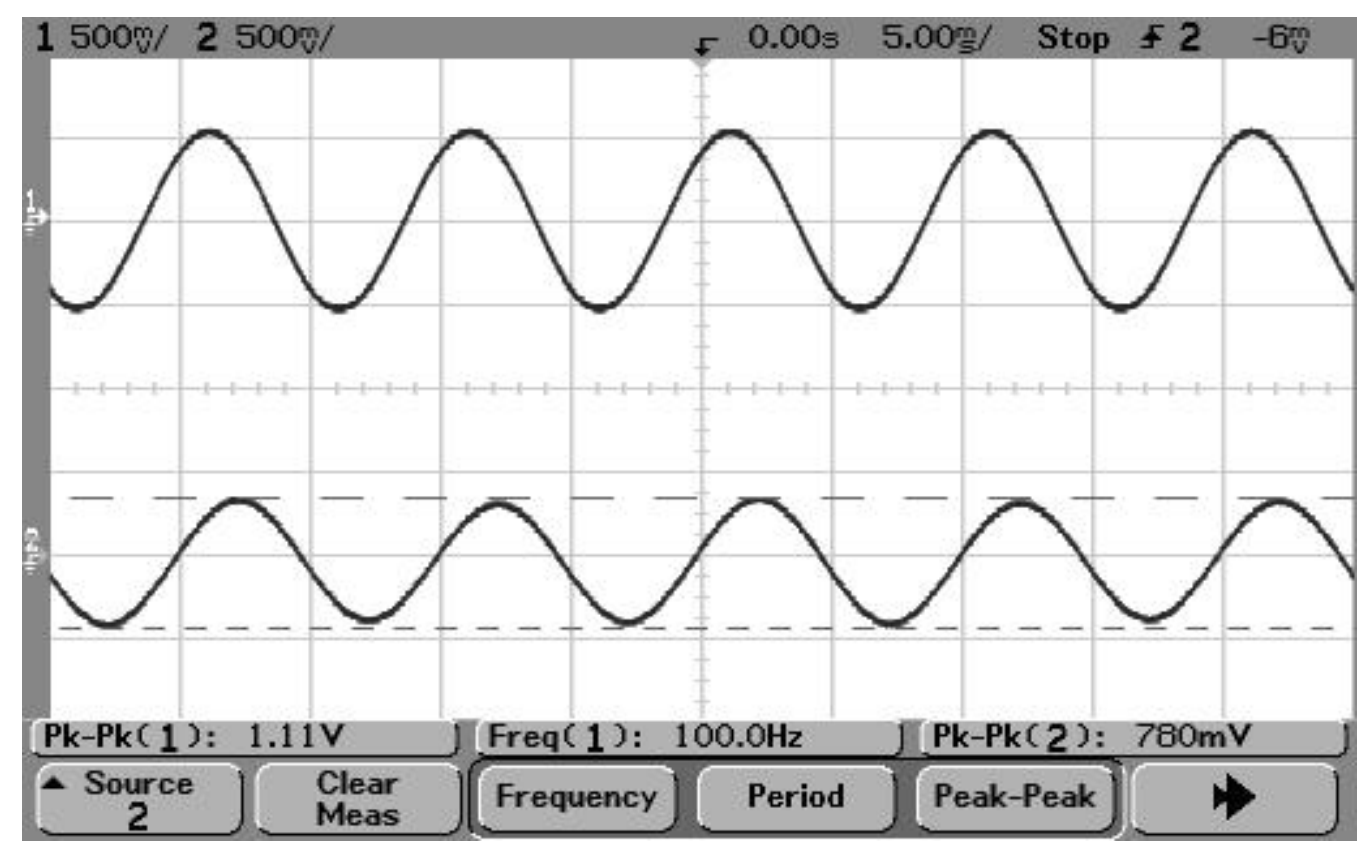

Figura 3.21 - Onda obtida com sinal de $100 \mathrm{~Hz}$.

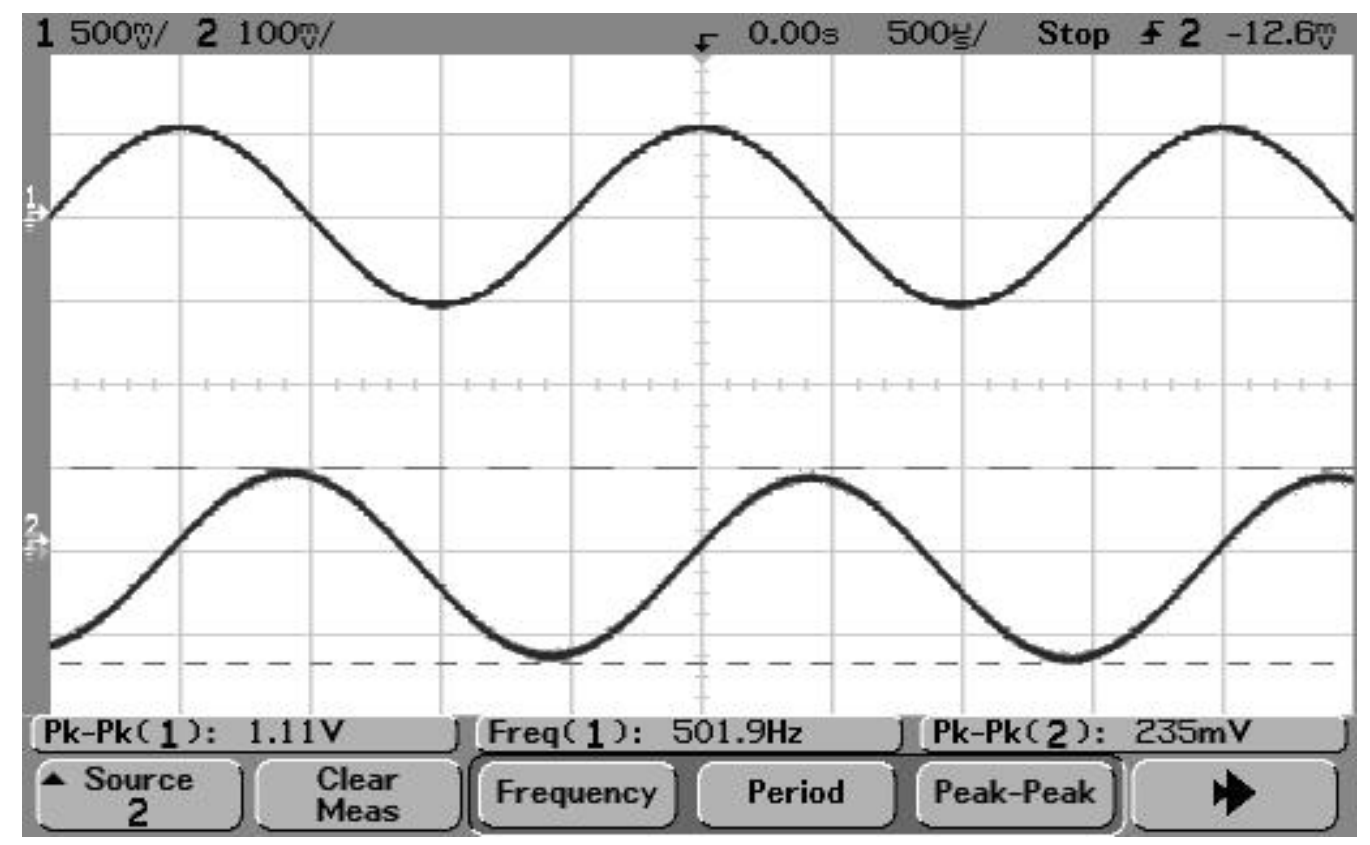

Figura 3.22 - Onda obtida com sinal de, aproximadamente, $500 \mathrm{~Hz}$. 


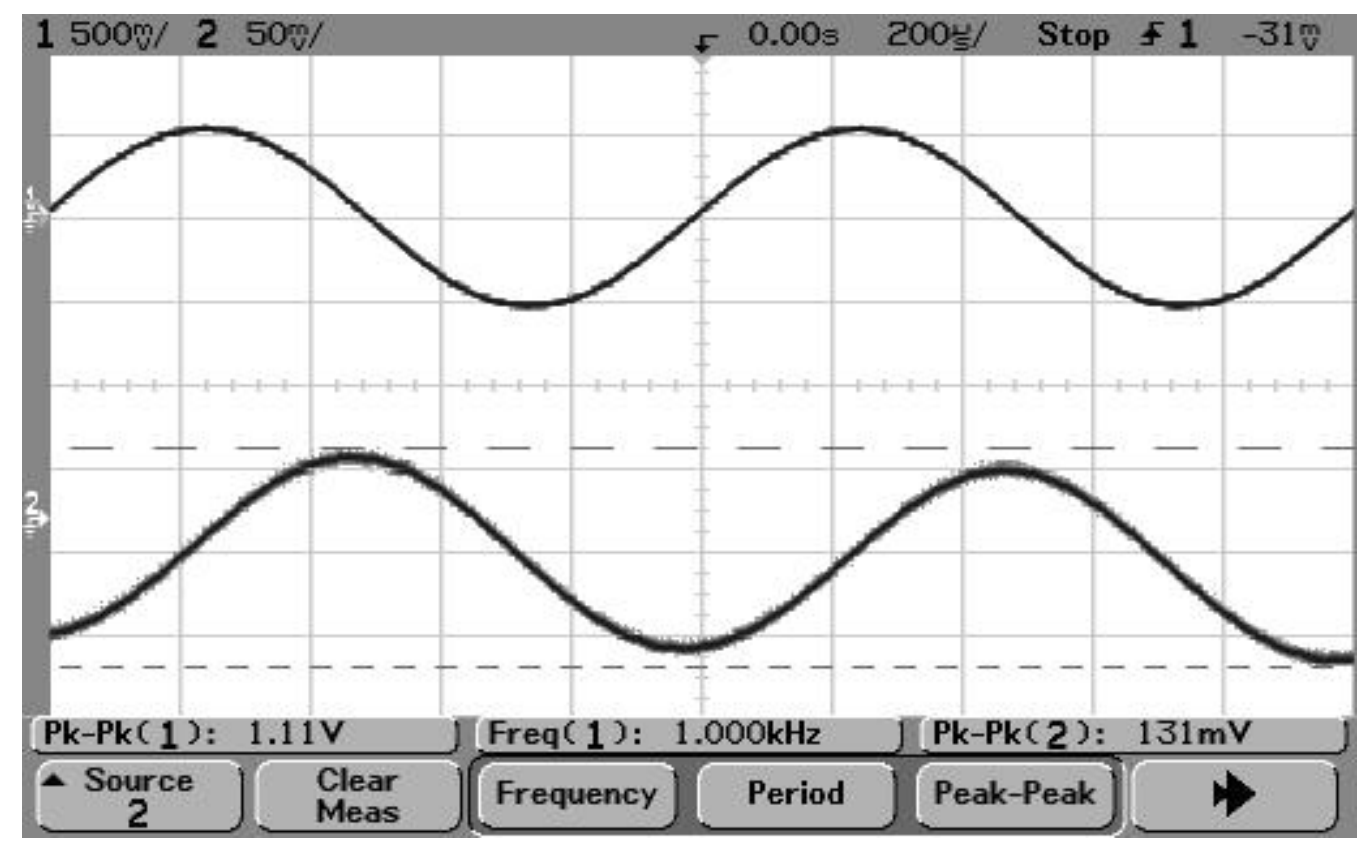

Figura 3.23 - Onda obtida com sinal de $1000 \mathrm{~Hz}$.

Como se pode observar pelos valores medidos nos ensaios e pelas formas de onda, o filtro funciona satisfatoriamente e atenderá os propósitos de nossos experimentos. Houve uma pequena diferença entre os valores esperados teoricamente e os encontrados na prática. Isto se deve, principalmente, um possível mau contato nos cabos utilizados para os ensaios. Para cada cabo diferente utilizado, obtemos um resultado um pouco diferente, mas nada muito significativo. $O$ simples fato de segurar firmemente a conexão entre o cabo e o canal do osciloscópio já apresentava melhoras significativas nos sinais obtidos.

\section{6 - PRINCIPAIS DIFICULDADES}

\subsection{1 - Baixas correntes}

Como já foi mencionada, uma grande dificuldade encontrada foi o fato de se trabalhar com correntes muito baixas, se comparadas com a ordem de grandeza das correntes para o qual a bobina é desenvolvida teoricamente.

A corrente gerada pela bancada não passava de 9,1 A. Com esse valor de corrente a tensão esperada no secundário da bobina seria de poucos $\mu \mathrm{V}$, fato que, associado ao ruído, tornaria impossível a leitura de algum sinal confiável. 
Diante desta dificuldade, decidiu-se passar o condutor várias vezes dentro da bobina de maneira a se conseguir uma corrente concatenada maior. Com isso, conseguiram-se correntes de até 102 A. Entretanto, essa solução para o problema das baixas correntes acabou resultando em outra dificuldade: os condutores que passavam externos à bobina também são fontes geradoras de campos magnéticos que acabaram por interferir no sinal obtido no secundário da bobina.

As formas encontradas para minimizar esses campos foram apresentadas nos métodos de ensaio descritos nesse capítulo.

Logo, a próxima dificuldade a ser vencida seria descobrir uma maneira eficiente de anular ou minimizar a influência dos campos externos sem, contudo, influenciar o campo gerado pelo conjunto de condutores internos à bobina.

\subsection{2 - Ruído}

Uma segunda grande dificuldade que merece destaque foi a presença de ruído. Um importante agravante que colaborou para o ruído se tornar mais do que uma dificuldade, mas um fator que impedia qualquer leitura de tensão no secundário confiável foi o fato de estarmos trabalhando com valores muito baixos de corrente. Assim, o valor máximo para o sinal de saída esperado com a maior corrente gerada era $2 \mathrm{mV}$. O ruído médio obtido era da ordem de $20 \mathrm{mV}$.

O problema com o ruído foi uma considerável dificuldade, principalmente nos estágios iniciais.

Algumas soluções foram apresentadas como, mudança do comprimento do cabo que realizava a conexão entre o protoboard e o osciloscópio e mudança da saída do secundário da bobina, passando-a para cabo coaxial.

Entretanto, o problema só pode ser corrigido eficientemente a partir do momento que, estudando-se melhor os equipamentos, descobriu-se uma função do osciloscópio que trabalhava calculando a média do sinal (tecla average). Foi decidido que seria 
interessante também projetar um filtro passa-baixas de maneira a atenuar as altas freqüências.

Modificando-se as escalas de amplitude pico-a-pico e de tempo, utilizando-se a função average do osciloscópio e o filtro, conseguiu-se praticamente eliminar o ruído, obtendo um sinal coerente em regime permanente. 


\section{4 - TESTES E RESULTADOS}

Nesse capítulo, serão apresentados os resultados obtidos com cada bobina e com os respectivos métodos de ensaio aplicados a cada uma delas, bem como serão discutidos esses resultados comparando-os com os resultados esperados em teoria.

De maneira a facilitar a compreensão dos resultados, as subseções serão divididas por bobina e por método adotado em cada caso.

Como foi demonstrada no capítulo 2, segundo a teoria, a relação que nos permite calcular a corrente com base na tensão obtida no secundário é a equação (2.30), que será repetida abaixo por uma questão de praticidade:

$$
i_{1}(t)=\left[N \frac{\mu_{0} r_{s}^{2}}{4 r}\left(\frac{l}{\sqrt{\left(\frac{l}{2}\right)^{2}+r^{2}}}\right)\right]^{-1} \cdot \int e_{2}(t) d t
$$

Contudo, devido aos aspectos construtivos de nossas bobinas, que não são completamente simétricos, e ao fato desse projeto objetivar testar a aplicabilidade da Bobina de Rogowski, decidiu-se por aplicar os testes com um foco diferenciado.

Aplicando um valor conhecido de corrente ser-se-ia capaz de, por meio das relações já descritas no capítulo 2, determinarem-se os valores de tensão esperados no secundário da bobina. O nosso objetivo, portanto, é obter os valores de tensão no secundário, mais próximos possíveis dos esperados teoricamente.

É importante ressaltar que todos os valores obtidos são de pico-a-pico e também que os resultados apresentaram freqüência igual a $60 \mathrm{~Hz}$ com algumas variações de, no máximo, $2 \mathrm{~Hz}$. 


\section{1 - TESTES E RESULTADOS DA PRIMEIRA BOBINA}

A primeira bobina, ressalvando apenas que se entenda por primeira bobina o conjunto composto pelo primário e pelo secundário com 35 espiras e cujos aspectos construtivos e características foram apresentados no capítulo anterior, foi o nosso primeiro contato com os ensaios, permitindo que, através dos seus resultados, fosse-se capaz de aperfeiçoar nossos métodos até que fosse possível alcançar os resultados esperados em teoria.

A primeira bobina foi a menos testada, sendo ensaiada apenas com primeiro e o segundo método, ambos descrito no capítulo 3, porque, à medida que se aprofundava na teoria, percebia-se a necessidade de modificar um pouco os aspectos construtivos da bobina bem como melhorar os métodos de ensaio empregados. Vale lembrar que o primeiro método consiste em passar os fios condutores externos encostados na lateral da bobina e o segundo método consiste em passar os fios condutores externos a certa distância do centro da bobina de maneira a diminuir a influência dos campos externos.

Os resultados de tensão no secundário esperados teoricamente para a primeira bobina foram calculados da seguinte maneira:

Partindo da equação (2.23), que segue novamente abaixo:

$$
\Phi_{\vec{a}_{\theta}}(t)=\frac{\mu_{0} r_{s}^{2} i_{1}(t)}{4 r}\left(\frac{l}{\sqrt{\left(\frac{l}{2}\right)^{2}+r^{2}}}\right)
$$

Onde:

$\mu_{0}$ é a permeabilidade magnética do meio e vale $4 \pi \cdot 10^{-7}$ T/A.m;

$r_{s}$ é o raio do secundário;

$i_{1}(t)$ é a corrente no primário e vale I.sen $(\omega \mathrm{t})$ onde $\omega=2 \pi f=377$;

$r$ é a distancia entre o centro da bobina e o centro do secundário; e 
$l$ é o comprimento do condutor.

Para nossa bobina esses parâmetros equivalem a:

$\mu_{0}=4 \pi \cdot 10^{-7} \mathrm{H} / \mathrm{m} ;$

$r_{s}=0,003 \mathrm{~m} ;$

$r=0,04 \mathrm{~m} ; \mathrm{e}$

$l=0,35 \mathrm{~m}$.

Sendo o valor de $l$ arbitrado de maneira a diminuir a influência dos campos dos condutores antes de entrar e após sair da bobina.

Agora, substituindo os valores obtemos:

$$
\Phi(t)=1,387.10^{-10} . i_{1}(t) \mathrm{Wb}
$$

Como $i_{1}(t)=45,5(\omega \mathrm{t})$, onde $\omega=2 \pi f$, e $\mathrm{N}=35$ espiras e freqüência $f$ de $60 \mathrm{~Hz}$ obtemos:

$$
\begin{gathered}
\lambda(t)=N . \Phi(t) \text { Wb.espira } \\
\lambda(t)=4,823 \cdot 10^{-9} . i_{1}(t) \text { Wb.espira }
\end{gathered}
$$

Agora, sabendo que a derivada do fluxo concatenado em função do tempo equivale à tensão no secundário obtemos:

$$
\frac{d \lambda(t)}{d t}=0,1 \cos (377 t) \mathrm{Wb}
$$

Logo:

$$
e_{2}(t)=0,1 \cos (377 t) \mathrm{mV}
$$




\subsection{1 - Resultados obtidos}

Os valores obtidos com a primeira bobina utilizando o primeiro e segundo métodos ficaram bem distantes dos resultados esperados teoricamente, fato que motivou a modificar mais os métodos de ensaio e a própria bobina. Os resultados obtidos se devem muito ao fato do método de ensaio ainda ser ineficiente, mas, nesse ponto do experimento, ainda se estava tendo muitos problemas com ruído, visto que se estava obtendo um ruído inicial médio de aproximadamente $20 \mathrm{mV}$, valor 2.410 vezes maior que o sinal de tensão esperado em teoria.

Entretanto, vale observar que modificando o método, passando do primeiro para o segundo, já houve uma boa melhora dos resultados, mas, mesmo assim, os resultados ainda estavam longe de serem considerados satisfatórios. A Tabela 4.1 mostra os resultados esperados bem como os resultados o primeiro método.

Tabela 4.1 - Valores de tensão obtidos com a primeira bobina e o primeiro método.

\begin{tabular}{|c|c|c|}
\hline Corrente em A & Tensão $e_{2}$ esperada em mV & $\begin{array}{c}\text { Tensão } e_{2} \text { obtida em mV } \\
\text { (primeiro método) }\end{array}$ \\
\hline 45,5 & 0,083 & 48,4 \\
\hline 43 & 0,08 & 45,8 \\
\hline 40,8 & 0,074 & 42,3 \\
\hline 38,4 & 0,07 & 39,6 \\
\hline 36,3 & 0,066 & 36,5 \\
\hline 34,1 & 0,062 & 33,2 \\
\hline
\end{tabular}

A Tabela 4.2 a seguir mostra os resultados obtidos utilizando o segundo método de ensaio. 
Tabela 4.2 - Valores de tensão obtidos com a primeira bobina e o segundo método.

\begin{tabular}{|c|c|c|}
\hline Corrente em A & Tensão $e_{2}$ esperada em mV & $\begin{array}{c}\text { Tensão } e_{2} \text { obtida em mV } \\
\text { (segundo método) }\end{array}$ \\
\hline 45,5 & 0,083 & 33,1 \\
\hline 43 & 0,08 & 31 \\
\hline 40,8 & 0,074 & 28,5 \\
\hline 38,4 & 0,07 & 25,8 \\
\hline 36,3 & 0,066 & 22,2 \\
\hline 34,1 & 0,062 & 18,9 \\
\hline
\end{tabular}

Com base nos resultados obtidos, percebeu-se que seria interessante modificar um pouco a estrutura do secundário, de maneira a obter valores teóricos maiores de tensão. Porém a estrutura física da bobina não poderia ser muito modificada devido às condições do laboratório. Caso se criasse uma bobina muito grande, aumentar-se-ia bem a tensão obtida, mas ficaria mais complicado a maneira de medir e, provavelmente, terse-ia que trabalhar com correntes ainda menores. Portanto, decidiu-se concentrar os esforços em se aperfeiçoar a forma de ensaiar.

As Figuras 4.1 e 4.2 mostram as formas de onda obtidas para 45,5 A utilizando o primeiro e o segundo método, respectivamente: 


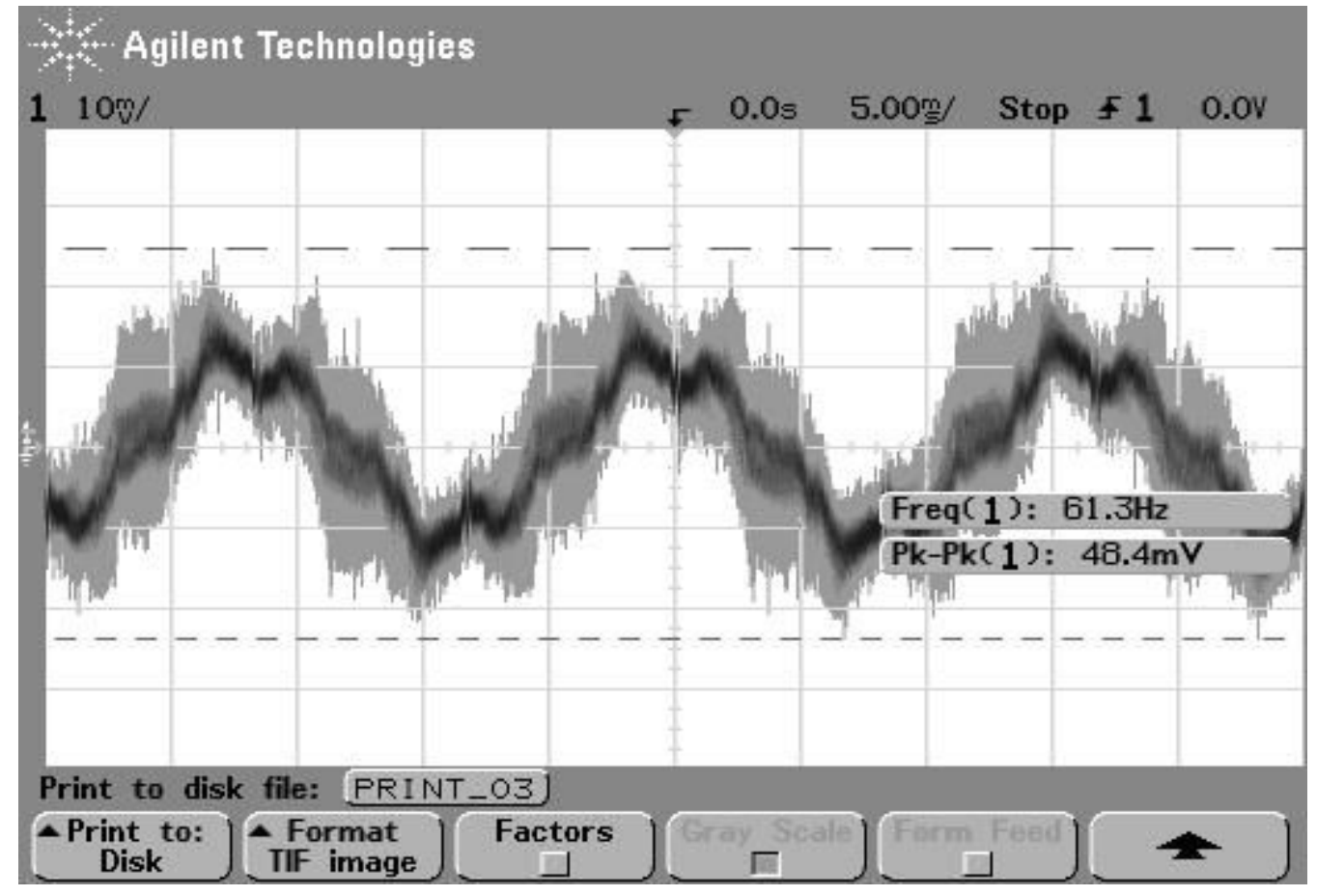

Figura 4.1 - Forma de onda capturada utilizando o primeiro método.

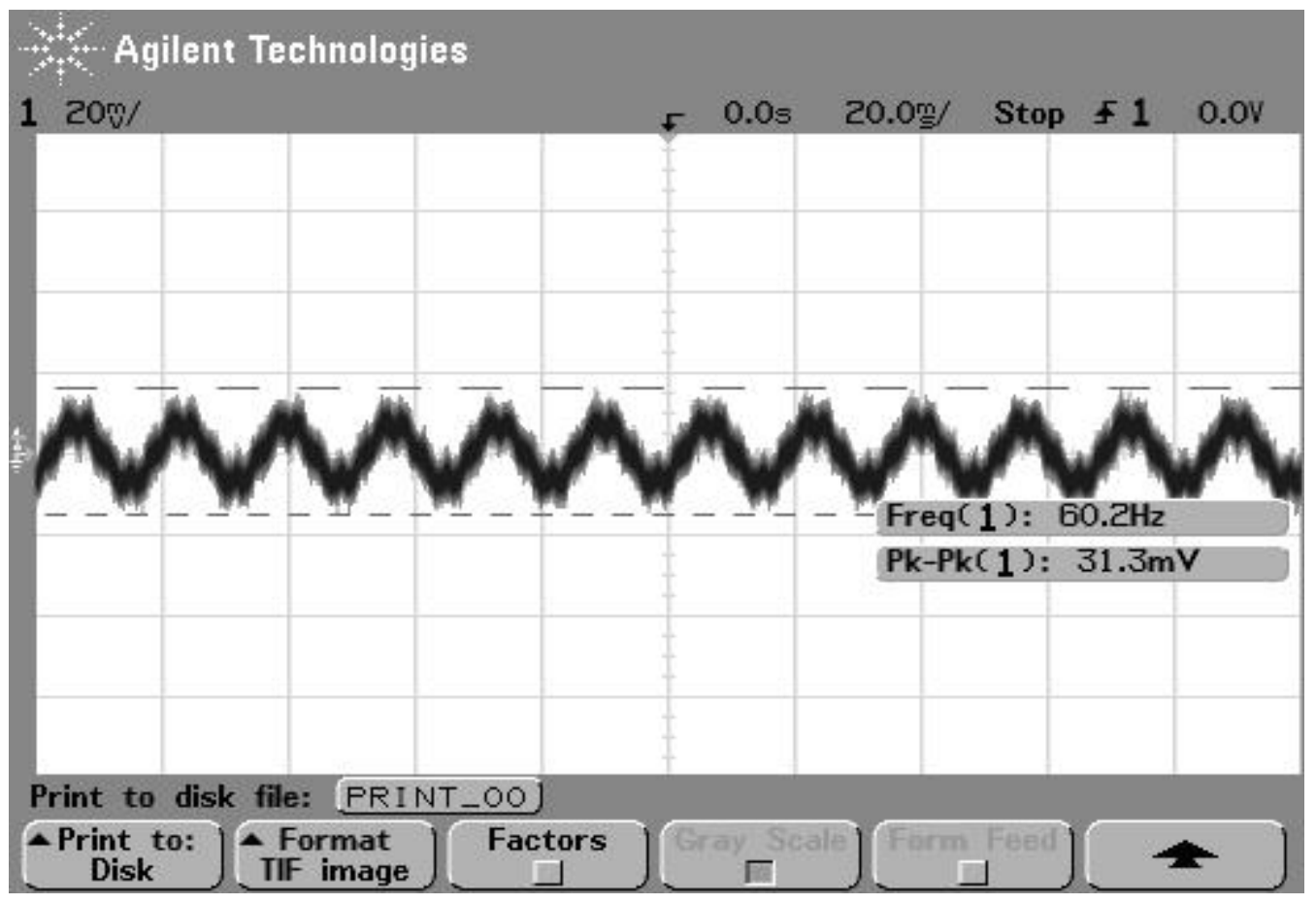

Figura 4.2 - Forma de onda capturada utilizando o segundo método. 


\section{2 - TESTES E RESULTADOS DA SEGUNDA BOBINA}

Utilizando agora a segunda bobina (50 espiras e $1 \mathrm{~cm}$ de diâmetro do tubo do secundário), descrita no capítulo anterior, a tensão esperada aumentou um pouco, mas os resultados só foram melhorados com o emprego de novos métodos de ensaio.

Começaram-se os testes utilizando o segundo método de ensaio. Ele se mostrou um pouco melhor, mas igualmente ineficiente. Os valores obtidos inicialmente ainda estavam longe de serem considerados satisfatórios. Os valores esperados teoricamente foram calculados da seguinte maneira:

Inicialmente, como com o secundário anterior, utilizou-se o mesmo raciocínio da bobina anterior partindo da equação (2.23) com os seguintes valores dos parâmetros:

$\mu_{0}=4 \pi \cdot 10^{-7} \mathrm{H} / \mathrm{m}$

$r_{s}=0,005 \mathrm{~m} ; \mathrm{e}$

$r=0,04 \mathrm{~m}$

A partir desse ponto do experimento começou-se a arbitrar vários valores de $l$ para melhor determinar qual seria o melhor valor de $l$ para que o campo magnético gerado pelos condutores que passam fora da bobina, mas ainda alinhados verticalmente com a mesma não exercessem grande influência no resultado obtido. Foram calculados resultados esperados para vários valores de $l$.

A seguir, substituindo os valores mostrados acima na equação (2.23) com o $l$ inicial igual a $0,09 m$ obteve-se o seguinte:

$$
\Phi(t)=2,443 \cdot 10^{-10} . i_{1}(t) \mathrm{Wb}
$$

E, lembrando que:

$$
\lambda(t)=N . \Phi(t) \text { Wb.espira }
$$

Com $N=50$ espiras, temos: 


$$
\lambda(t)=1,2215 \cdot 10^{-8} \cdot i_{1}(t) \text { Wb.espira }
$$

Observe que $I_{1}(t)=44,3 \operatorname{sen}(\omega \mathrm{t})$, onde $\omega=2 \pi f$ e freqüência $f=60 \mathrm{~Hz}$.

Agora, utilizando a equação (2.28) abaixo:

$$
e_{2}(t)=\frac{d}{d t} \lambda(t) \mathrm{V}
$$

$\mathrm{e}$

$$
\frac{d \lambda(t)}{d t}=0,2 \cos (377 t) \mathrm{Wb}
$$

Logo:

$$
e_{2}(t)=0,2 \cos (377 t) \mathrm{mV}
$$

A Tabela 4.3 mostra os valores de tensão esperados no secundário da bobina para diversos valores de $l$ :

Tabela 4.3 - Valores esperados de tensão variando o valor de $l$.

\begin{tabular}{|c|c|}
\hline Comprimento $l$ em metros & Tensão $e_{2} \mathrm{em} \mathrm{mV}$ \\
\hline 0,12 & 0,23 \\
\hline 0,16 & 0,25 \\
\hline 0,25 & 0,274 \\
\hline 0,35 & 0,282 \\
\hline 0,5 & 0,287 \\
\hline 1,0 & 0,30 \\
\hline
\end{tabular}

Para $l=1 \mathrm{~m}$ o resultado esperado seria igual ao caso do condutor ter comprimento infinito. Logo, adotou-se o valor de $l=35 \mathrm{~cm}$. 


\subsection{1 - Resultados obtidos}

Os resultados obtidos com a segunda bobina utilizando o segundo método seguem na Tabela 4.4.

Tabela 4.4 - Valores obtidos com a segunda bobina e o segundo método.

\begin{tabular}{|c|c|c|}
\hline Valor de corrente em A & Tensão $e_{2}$ esperada em $\mathrm{mV}$ & Tensão $e_{2}$ obtida em mV \\
\hline 44,3 & 0,28 & 23,46 \\
\hline 43 & 0,27 & 22,1 \\
\hline 40,8 & 0,262 & 19,7 \\
\hline 38,4 & 0,246 & 17,9 \\
\hline 36,3 & 0,233 & 16,0 \\
\hline 34,1 & 0,216 & 14,2 \\
\hline
\end{tabular}

Como se pode observar pelos resultados os valores obtidos, apesar de mais próximos estão muito longe dos valores esperados. A Figura 4.3 mostra a forma de onda capturada para uma corrente de 44,3 A.

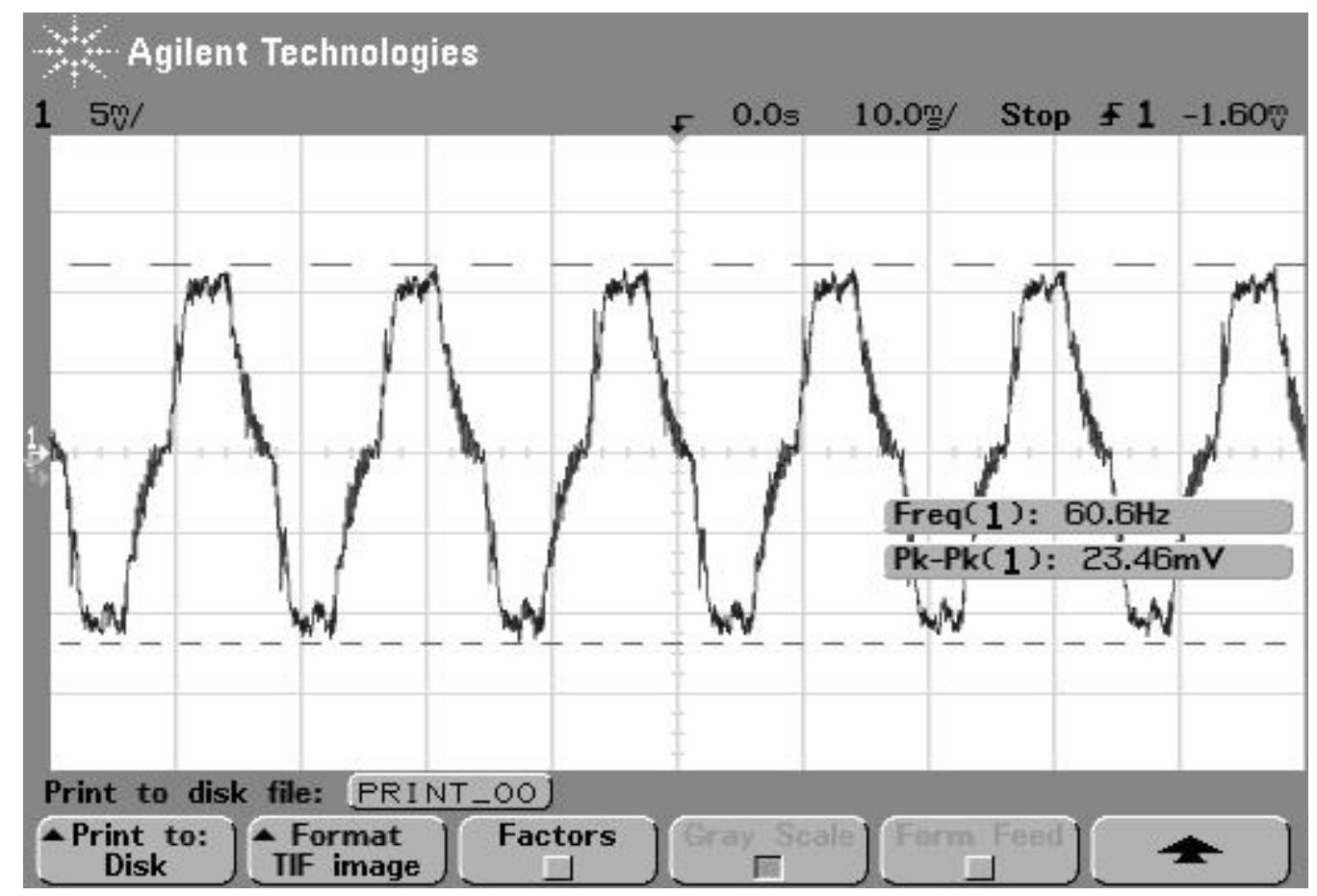

Figura 4.3 - Forma de onda capturada com 44,3 A e com o segundo método. 
Após se estudar um pouco mais a teoria de campos magnéticos, decidiu-se modificar mais uma vez o método de ensaio, aplicando agora o terceiro método de ensaio, explicado no capítulo anterior. Relembrado que o terceiro método consiste em passar os condutores externos à bobina a certa distância do centro da bobina, mas, diferente do segundo método, os condutores devem ser igualmente divididos passando o mesmo numero de voltas de cada lado de maneira anular os campos externos gerados pelos próprios condutores.

De maneira a tentar diminuir o ruído obtido, substituiu-se a saída do secundário, que antes era conectada ao osciloscópio através do protoboard, por um cabo curto de saída coaxial. Simultaneamente, estudou-se o manual do osciloscópio procurando uma possível forma de diminuir o máximo possível o ruído. Conseguimos através de mudanças de escalas e da tecla average do osciloscópio eliminar praticamente todo o ruído decaindo o valor de alguns $\mathrm{mV}$ para poucos $\mu \mathrm{V}$.

Diante dessas mudanças, conseguiu-se obter valores muito mais próximos dos esperados teoricamente. Os valores obtidos com essas mudanças no ensaio e no equipamento seguem na Tabela 4.5.

Vale ressaltar que os valores de tensão que seguem nas Tabelas abaixo são valores médios visto que o sinal apresentou uma oscilação de $+/-0,08 \mathrm{mV}$.

Tabela 4.5 - Valores de tensão obtidos com o terceiro método.

\begin{tabular}{|c|c|c|}
\hline Corrente concatenada em A & Tensão $e_{2}$ esperada em mV & Tensão $e_{2}$ obtida em mV \\
\hline 45,4 & 0,28 & 1,29 \\
\hline 43,0 & 0,27 & 1,2 \\
\hline 40,8 & 0,262 & 1,16 \\
\hline 38,4 & 0,246 & 1,10 \\
\hline 36,3 & 0,233 & 1,03 \\
\hline 34,1 & 0,216 & 0,99 \\
\hline
\end{tabular}

Como é possível notar, os valores obtidos estão muito mais próximos dos valores de tensão esperados teoricamente. Contudo, esses valores ainda não podem ser 
considerados satisfatórios. As formas de onda obtidas para 45,4 A e para 38,4 A seguem respectivamente nas Figuras 4.4 e 4.5.

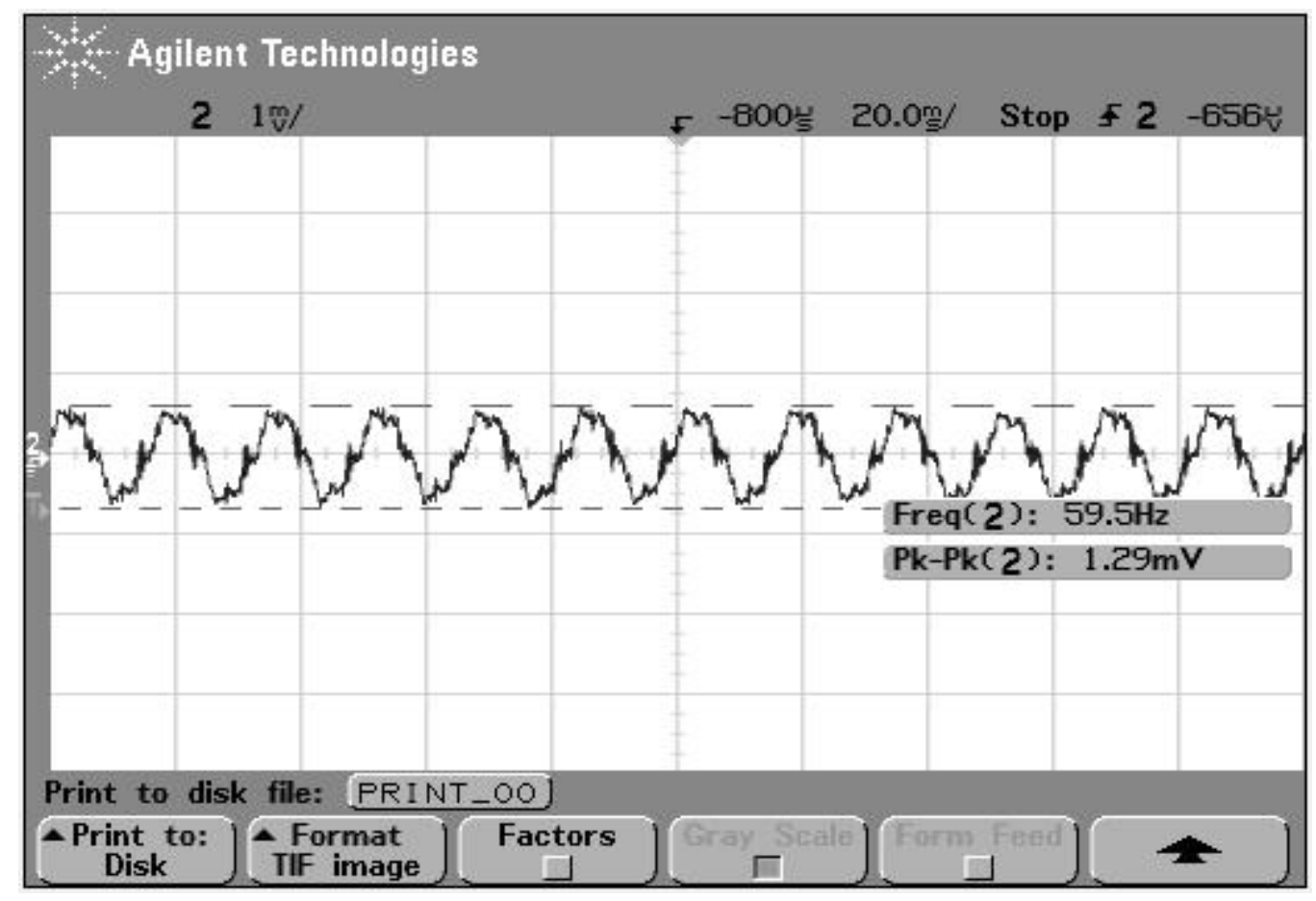

Figura 4.4 - Forma de onda obtida com a 45,4 A e o terceiro método.

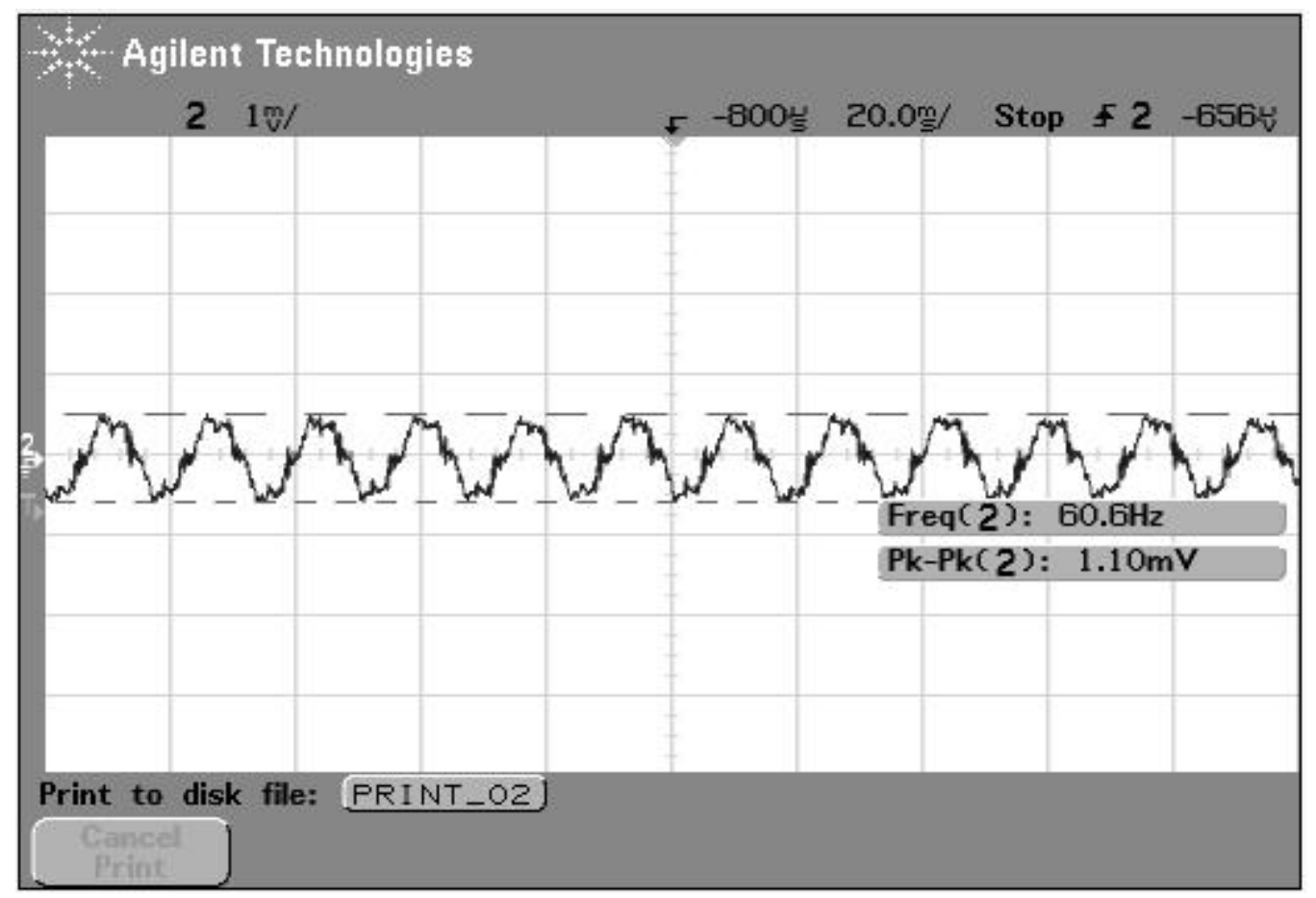

Figura 4.5 - Forma de onda obtida com a 38,4 A e o terceiro método. 
Baseando-se nos resultados obtidos, bem como nas formas de onda obtidas, decidiu-se, novamente, modificar um pouco mais a bobina e se possível, melhorar um pouco mais o método de ensaio.

\section{3 - TESTES E RESULTADOS DA TERCEIRA BOBINA}

Agora, utilizando a terceira bobina (com 150 espiras), descrita no capítulo anterior, conseguiu-se aumentar mais o valor de tensão esperado. Essa bobina foi ensaiada utilizando o terceiro e o quarto método. Os valores esperados teoricamente para a nova bobina (a bobina com o terceiro secundário) foram calculados respeitando a equação (2.23).

Para o novo secundário os valores dos parâmetros são os mesmos da bobina anterior com a diferença que o $l$ adotado será de $0,4 \mathrm{~m}$. Logo, o fluxo magnético será:

$$
\begin{gathered}
\Phi(t)=1,745 \cdot 10^{-10} \cdot i(t) \cdot\left(\frac{0,4}{\sqrt{\left(\left(\frac{0,4}{2}\right)^{2}+(0,045)^{2}\right)}}\right) \mathrm{Wb} \\
\Phi(t)=1,745 \cdot 10^{-10} \cdot i(t) \cdot 1,9512 \mathrm{~Wb} \\
\Phi(t)=3,41 \cdot 10^{-10} \cdot i(t) . \mathrm{Wb}
\end{gathered}
$$

O fluxo concatenado é dado por:

$$
\lambda(t)=N . \Phi(t) \text { Wb.espira }
$$

Com $N=150$ espiras, temos:

$$
\lambda(t)=5,115 \cdot 10^{-8} \cdot i_{1}(t) \text { Wb.espira }
$$


Lembrando que $I_{l}(t)=45,4 \operatorname{sen}(\omega \mathrm{t})$, onde $\omega=2 \pi f$ e freqüência $f=60 \mathrm{~Hz}$.

Agora, utilizando a equação (2.28) sabendo que:

$$
e_{2}(t)=\frac{d}{d t} \lambda(t) \mathrm{V}
$$

e

$$
\frac{d \lambda(t)}{d t}=0,87 \cos (377 t) \mathrm{Wb}
$$

Logo:

$$
e_{2}(t)=0,87 \cos (377 t) \mathrm{mV}
$$

\subsection{1 - Resultados obtidos}

Como já foi mencionado, a terceira bobina foi ensaiada por vários métodos diferentes. Os resultados que seguem abaixo na Tabela 4.6 foram obtidos utilizando o terceiro método de ensaio. Vale lembrar que esse secundário foi conectado ao osciloscópio por intermédio do protoboard.

Tabela 4.6 - Valores de tensão obtidos com a terceira bobina e o terceiro método.

\begin{tabular}{|c|c|c|}
\hline Corrente concatenada em A & Tensão $e_{2}$ esperada em mV & Tensão $e_{2}$ obtida em mV \\
\hline 45,4 & 0,87 & 3,74 \\
\hline 43,0 & 0,83 & 3,45 \\
\hline 40,8 & 0,786 & 3,3 \\
\hline 38,4 & 0,74 & 3,18 \\
\hline 36,3 & 0,67 & 3,02 \\
\hline 34,1 & 0,65 & 2,92 \\
\hline
\end{tabular}

As Figuras 4.6, 4.7 e 4.8 que seguem abaixo mostram as formas de onda capturadas para as correntes de 45,4 A, 38,4 A e 34,1 A respectivamente: 


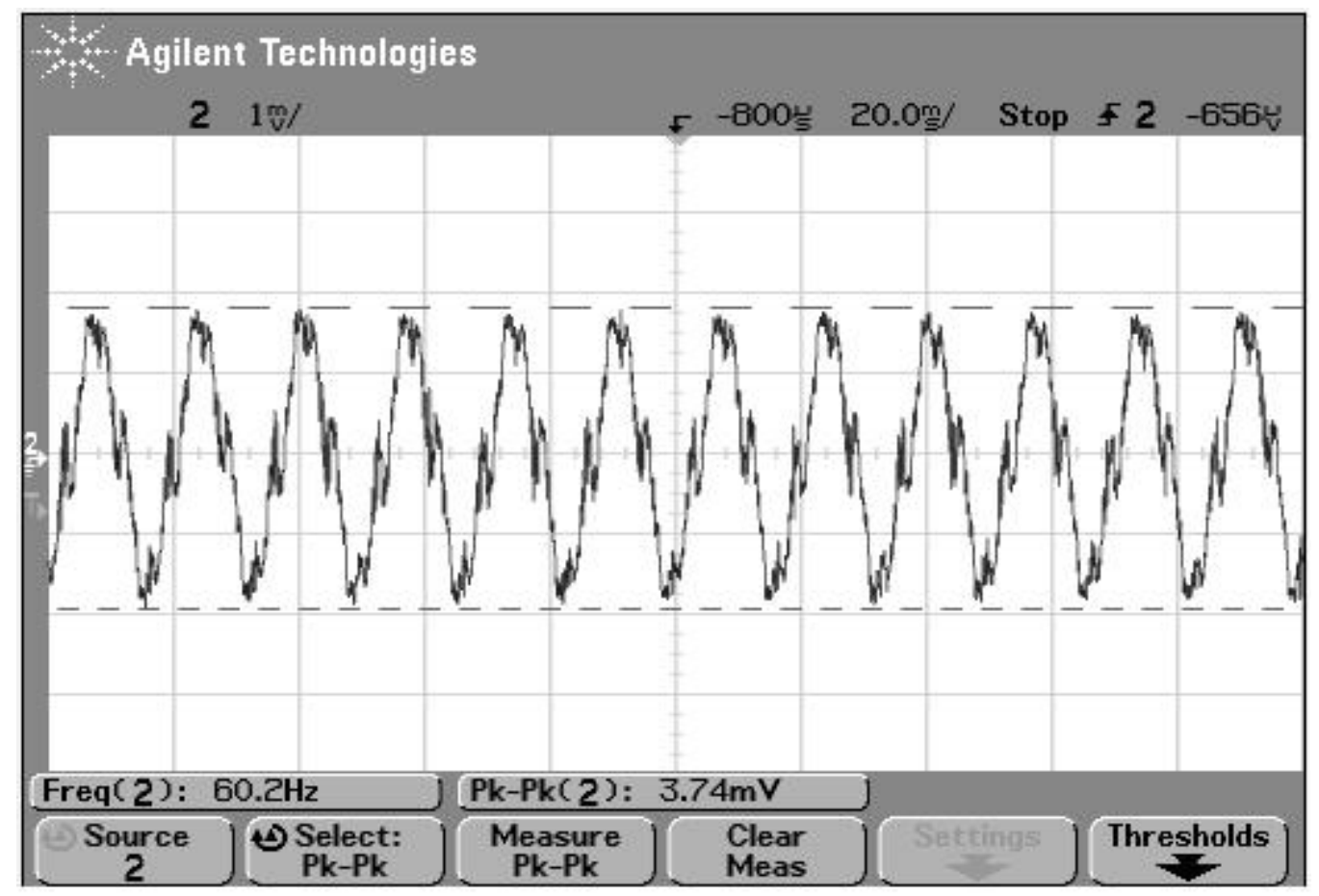

Figura 4.6 - Forma de onda obtida com 45,4 A e o terceiro método.

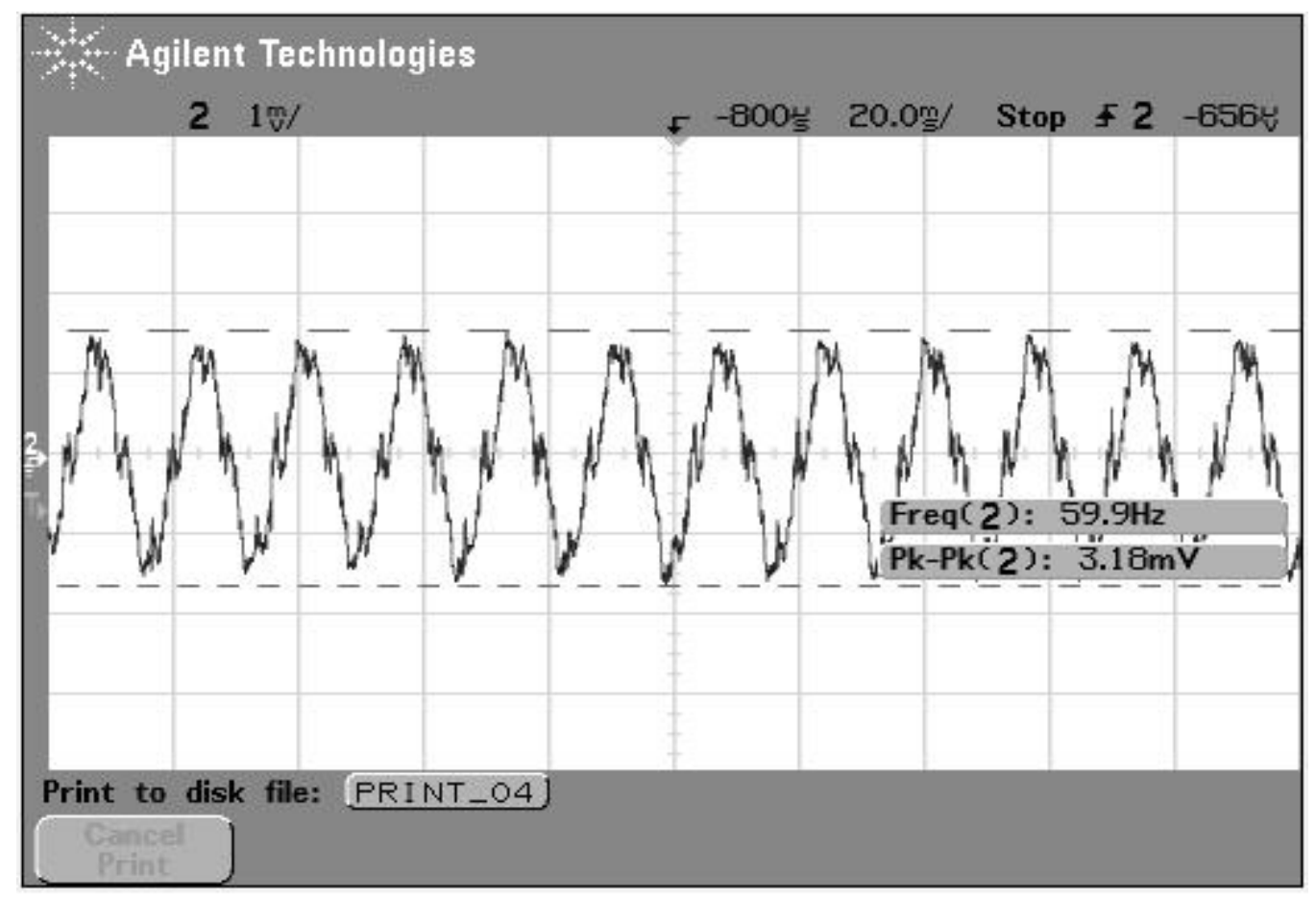

Figura 4.7 - Forma de onda obtida 38,4 A e o terceiro método. 


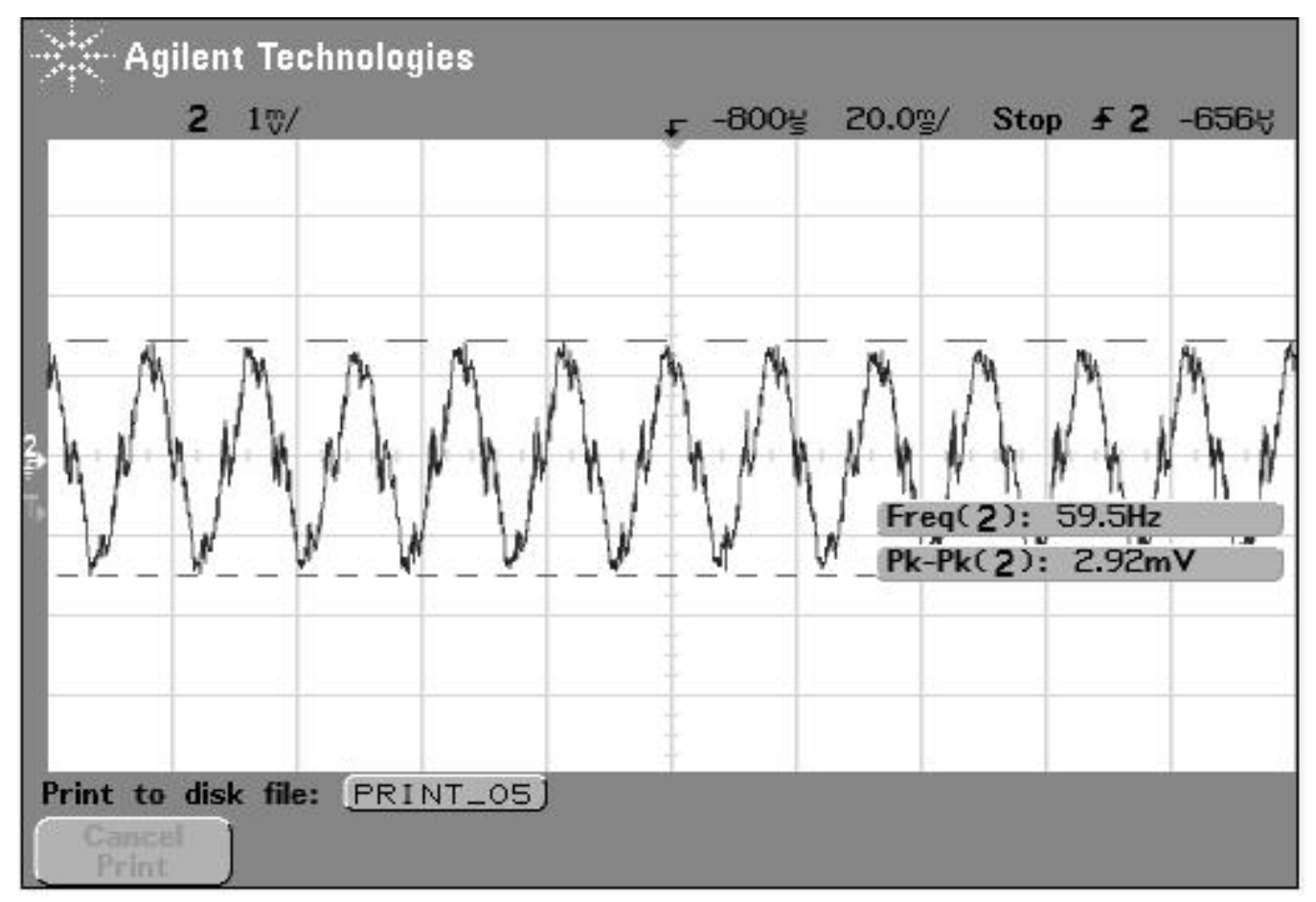

Figura 4.8 - Forma de onda obtida 34,1 A e o terceiro método.

Os valores obtidos estão próximos dos valores esperados em teoria, mas também não podem ser considerados satisfatórios.

Portanto, o próximo passo foi repetir os ensaios com a terceira bobina e o terceiro método, porém utilizando um filtro passa-baixas, no qual o projeto e as características foram descritos no capítulo anterior.

A Tabela 4.7 mostra os resultados obtidos com a terceira bobina, o terceiro método e o filtro passa-baixas:

Tabela 4.7 - Valores de tensão obtidos com a terceira bobina, o terceiro método e o filtro.

\begin{tabular}{|c|c|c|}
\hline Corrente concatenada em A & Tensão $e_{2}$ esperada em mV & Tensão $e_{2}$ obtida em mV \\
\hline 45,4 & 0,87 & 2,07 \\
\hline 43,0 & 0,83 & 2,02 \\
\hline 40,8 & 0,786 & 1,86 \\
\hline 38,5 & 0,74 & 1,75 \\
\hline 36,3 & 0,67 & 1,68 \\
\hline 34,2 & 0,65 & 1,39 \\
\hline
\end{tabular}


As Figuras 4.9, 4.10 e 4.11 que seguem abaixo mostram as formas de onda capturadas para as correntes de 45,4 A, 38,5 A e 34,2 A respectivamente:

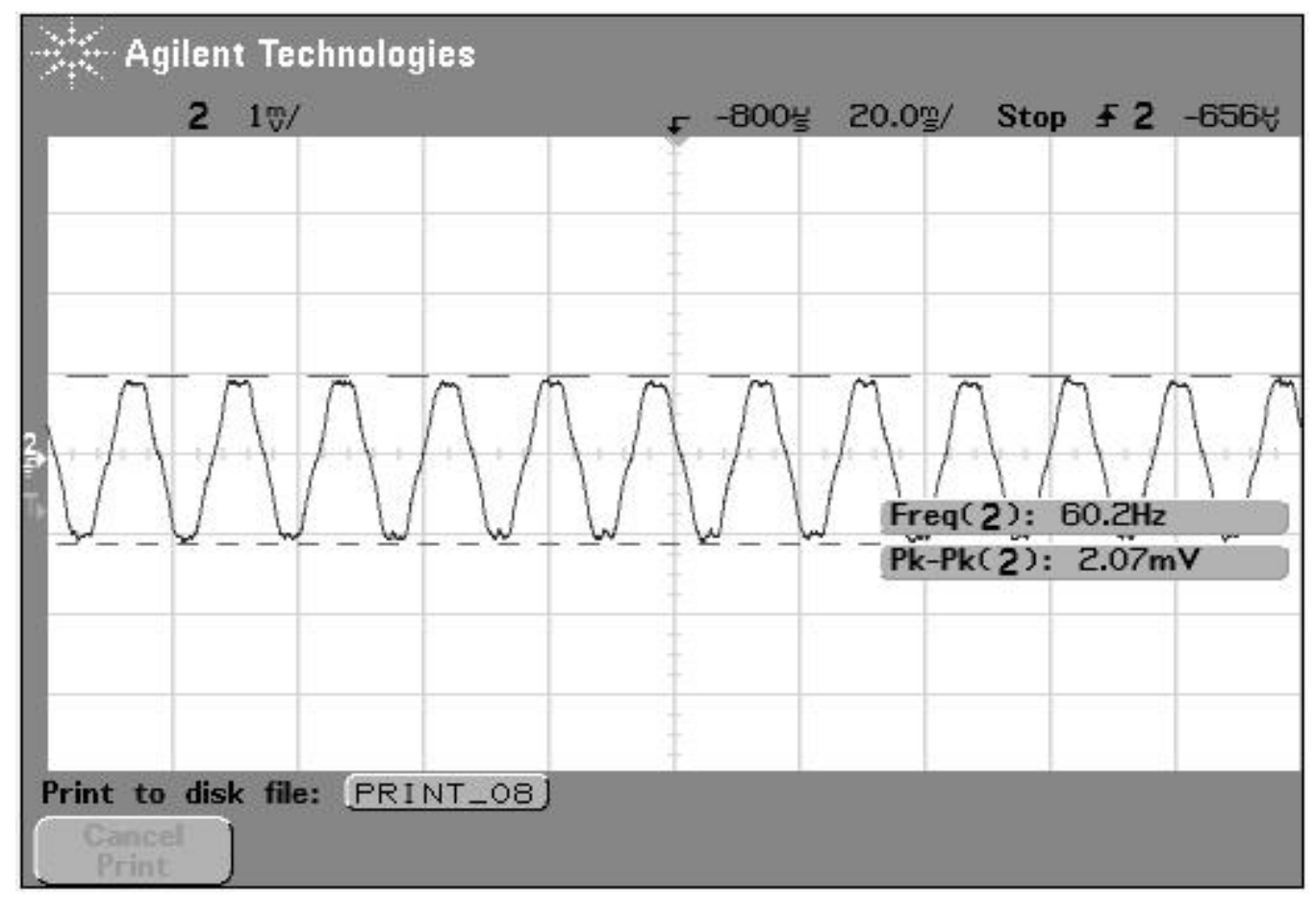

Figura 4.9 - Forma de onda obtida com 45,4 A, terceiro método e o filtro.

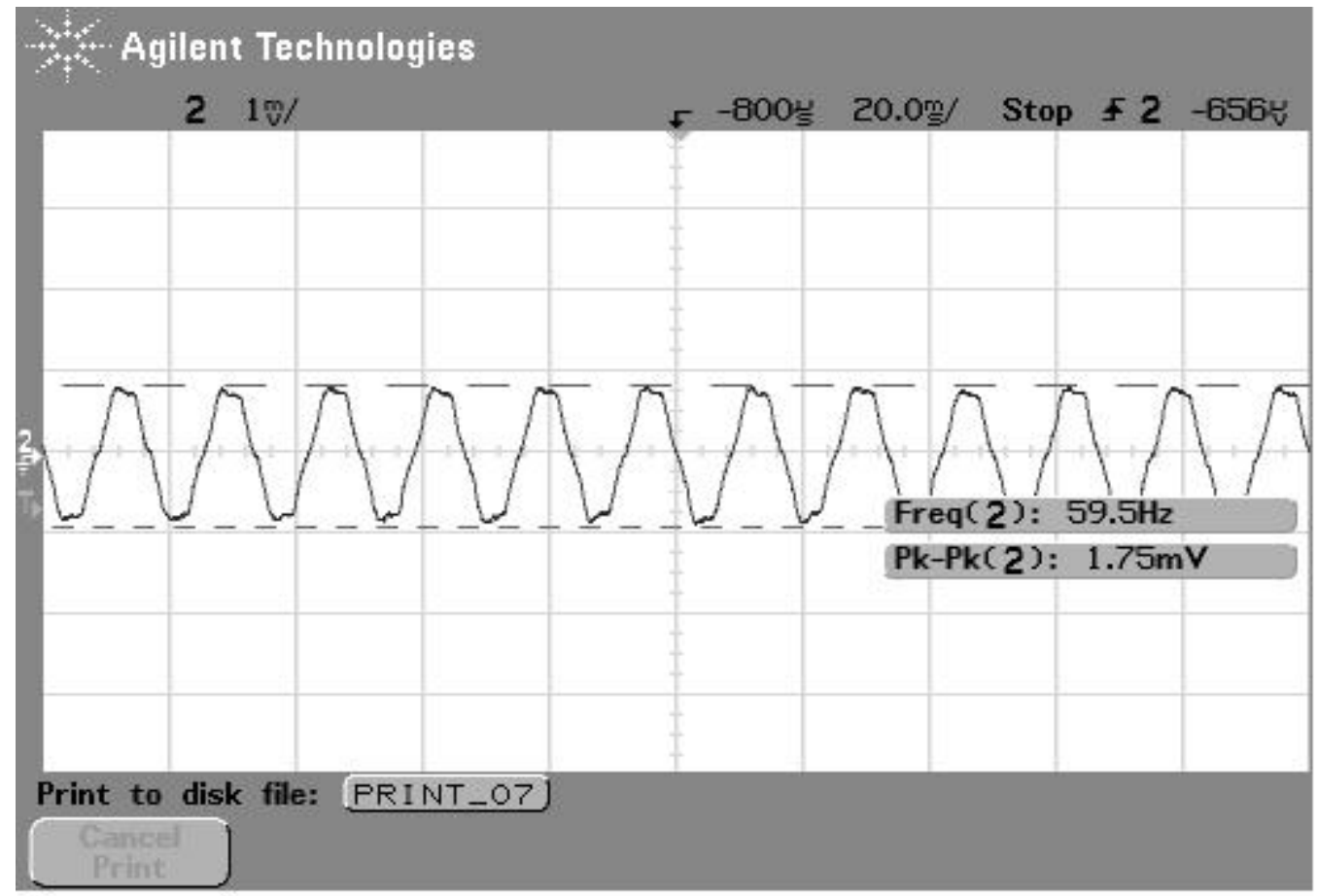

Figura 4.10 - Forma de onda obtida com 38,5 A, terceiro método e o filtro. 


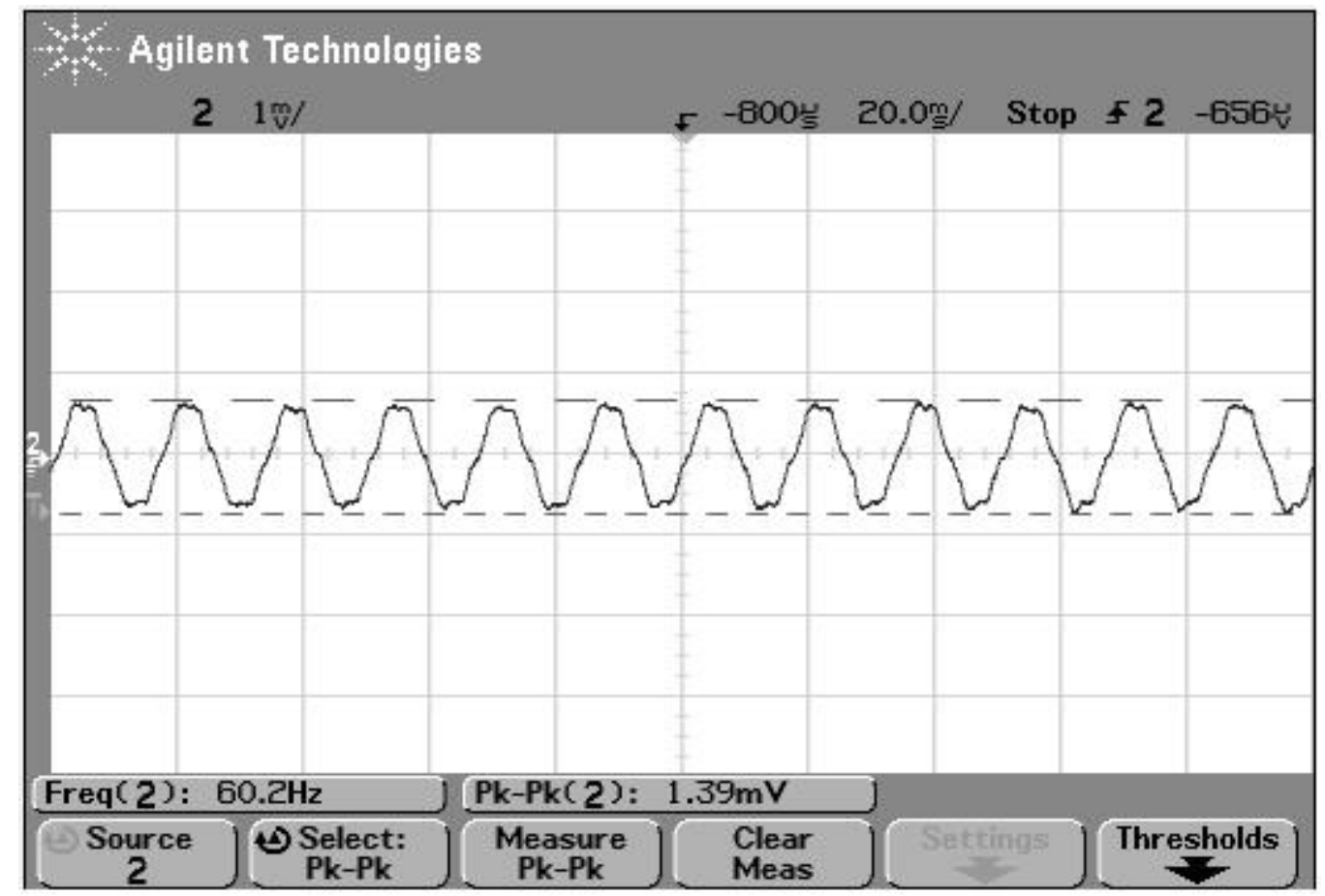

Figura 4.11 - Forma de onda obtida com 34,2 A, terceiro método e o filtro.

Como podemos observar pela Tabela 4.7, os valores estão próximos dos esperados, mas ainda podem ser melhorados.

A etapa seguinte foi repetir os ensaios anteriores (terceira bobina, terceiro método e filtro passa-baixas), porém centralizando os condutores para um melhor concatenamento do fluxo magnético interno.

A Tabela 4.8 mostra os resultados obtidos com esse tipo de ensaio:

Tabela 4.8 - Valores de tensão obtidos com a terceira bobina, o terceiro método filtro e condutor centralizado.

\begin{tabular}{|c|c|c|}
\hline Corrente concatenada em A & Tensão $e_{2}$ esperada em mV & Tensão $e_{2}$ obtida em mV \\
\hline 45,4 & 0,87 & 1,11 \\
\hline 43,0 & 0,83 & 1,02 \\
\hline 40,8 & 0,78 & 0,94 \\
\hline 38,5 & 0,74 & 0,86 \\
\hline 36,3 & 0,67 & 0,74 \\
\hline 34,2 & 0,65 & 0,60 \\
\hline
\end{tabular}




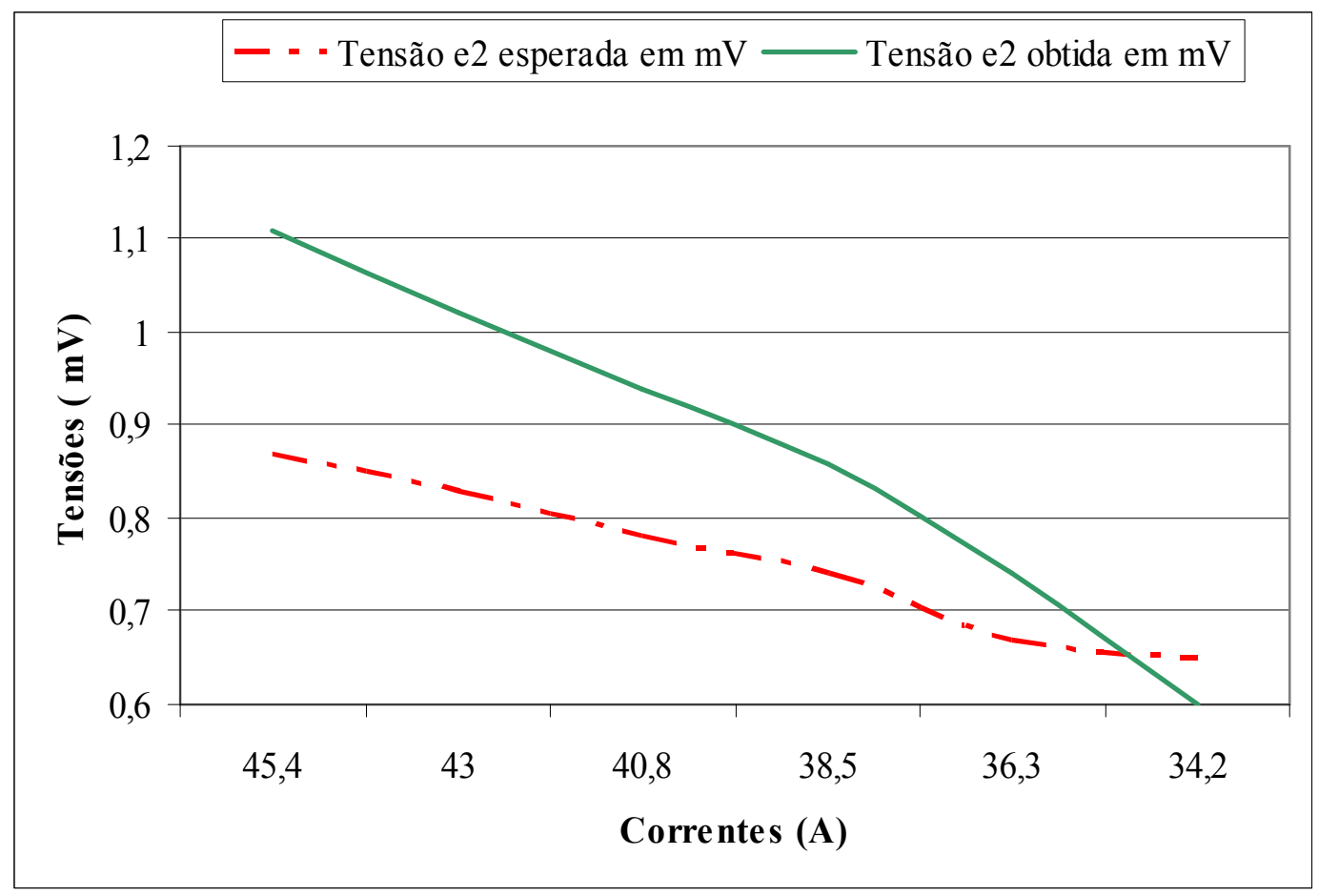

Figura 4.12 - Tensões esperada e medida com a terceira bobina, o terceiro método, filtro e condutor centralizado.

As Figuras 4.13, 4.14 e 4.15 que seguem abaixo mostram as formas de onda capturadas para as correntes de 45,4 A, 38,5 A e 34,2 A respectivamente: 


\section{Agilent Technologies}

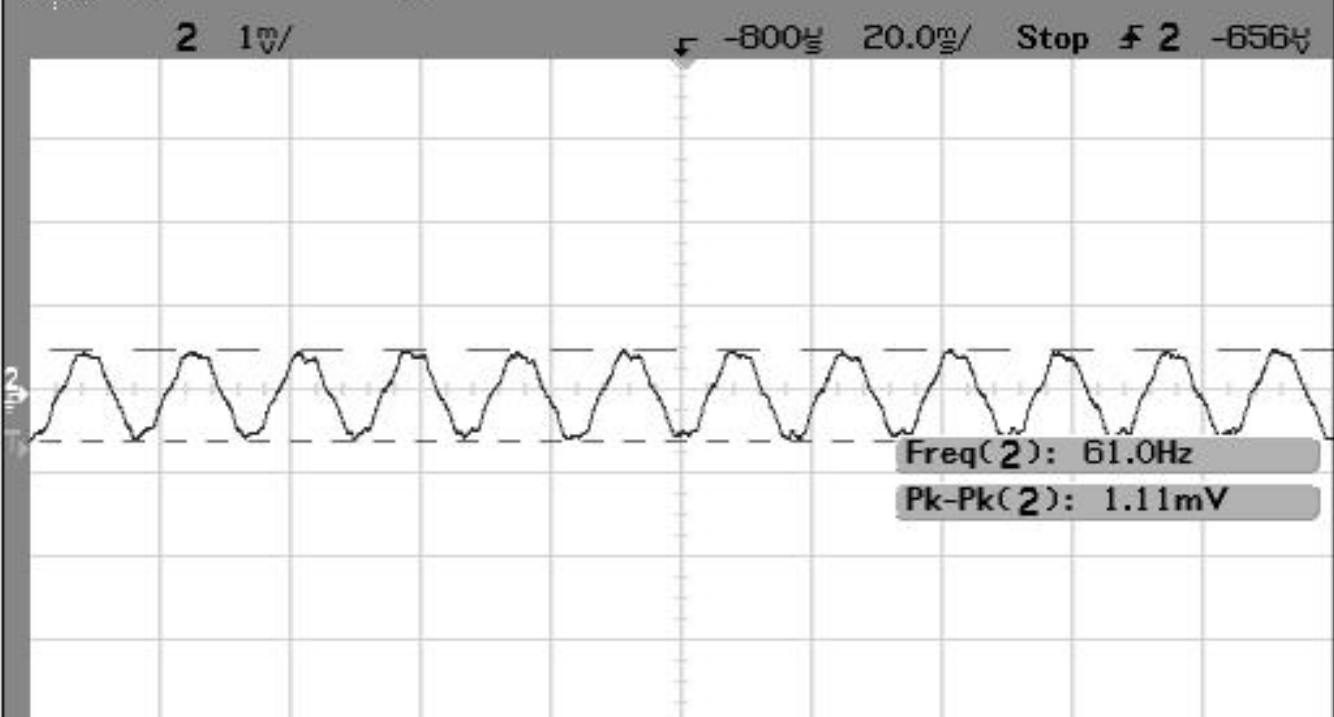

Print to disk file: PRINT_09

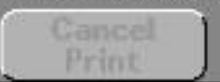

Figura 4.13 - Forma de onda obtida com 45,4 A, terceiro método, filtro e o condutor centralizado.

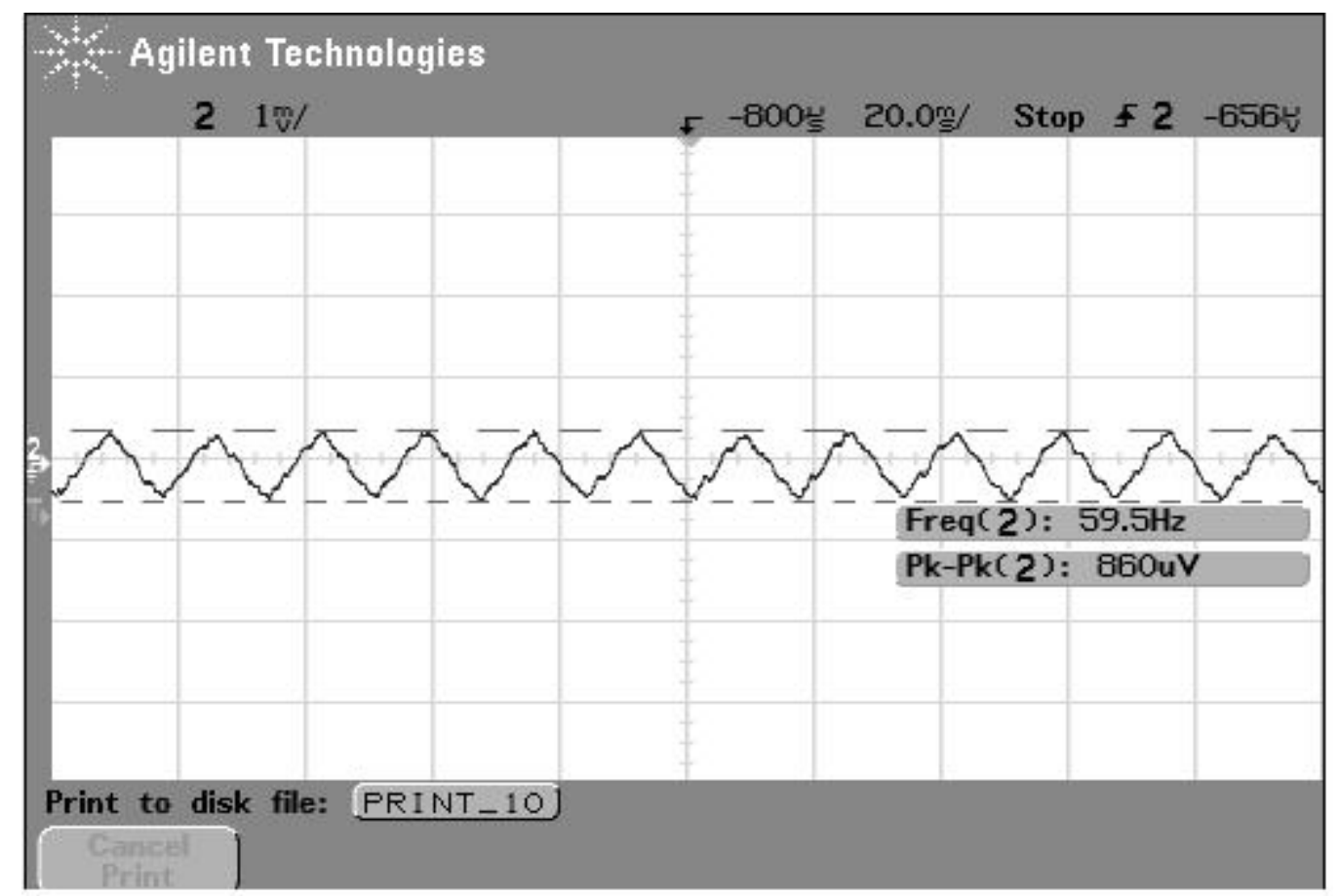

Figura 4.14 - Forma de onda obtida com 38,5 A, terceiro método, filtro e condutor centralizado. 


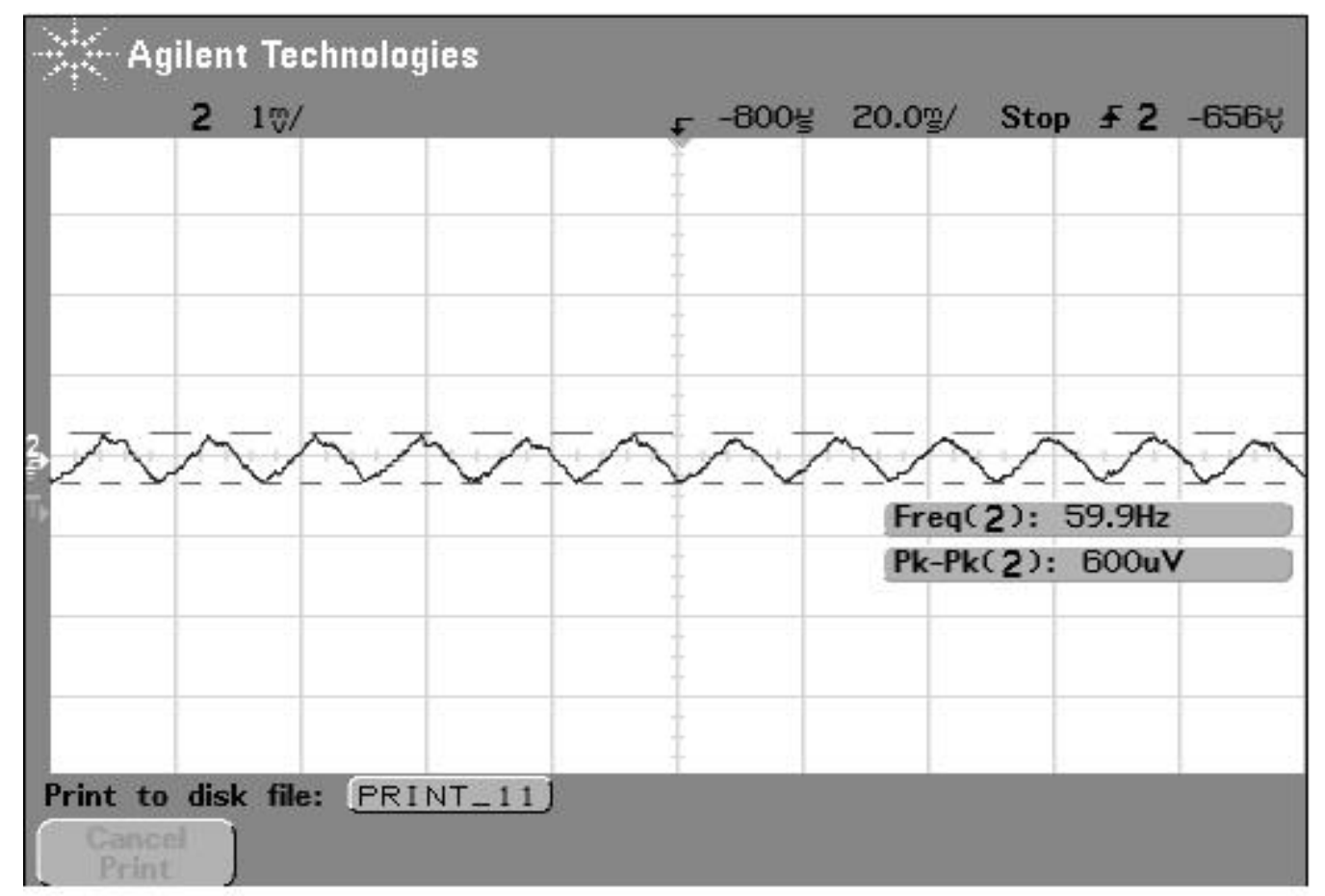

Figura 4.15 - Forma de onda obtida com 34,2 A, terceiro método, filtro e condutor centralizado.

Os resultados mostrados acima foram considerados satisfatórios. Entretanto, a centralização do conjunto de condutores interna a bobina foi feita basicamente manualmente. A título de teste foi decidido que seria interessante criar algum tipo de suporte para uma melhor centralização dos condutores bem como uni-los o máximo possível de maneira a podermos considerá-lo quase como se fosse um único condutor.

Com esses objetivos em mente, passou-se a ensaiar a terceira bobina utilizando o quarto método, porém, os ensaios iniciais foram feitos sem o filtro. Os resultados obtidos seguem na abaixo na Tabela 4.9:

Tabela 4.9 - Valores de tensão obtidos com a terceira bobina e o quarto método

\begin{tabular}{|c|c|c|}
\hline Corrente concatenada em A & Tensão $e_{2}$ esperada em mV & Tensão $e_{2}$ obtida em mV \\
\hline 45,4 & 0,87 & 3,14 \\
\hline 43,0 & 0,83 & 2,93 \\
\hline 40,8 & 0,78 & 2,72 \\
\hline 38,5 & 0,74 & 2,63 \\
\hline 36,3 & 0,67 & 2,4 \\
\hline 34,2 & 0,65 & 2,29 \\
\hline
\end{tabular}


Se compararem-se os resultados obtidos na Tabela 4.9 com os obtidos na Tabela 4.6, pode-se perceber que a simples melhora na técnica de centralizar os fios condutores já se mostrou eficiente. A tensão obtida, mesmo não sendo a ideal, apresentou melhoras em relação à medição anterior (está sendo considerada a medição com condições iguais e sem filtro com a diferença que os novos resultados foram obtidos com o quarto método).

As Figuras 4.16, 4.16 e 4.18 que seguem abaixo mostram as formas de onda capturadas para as correntes de 45,4 A, 38,5 A e 34,2 A respectivamente:

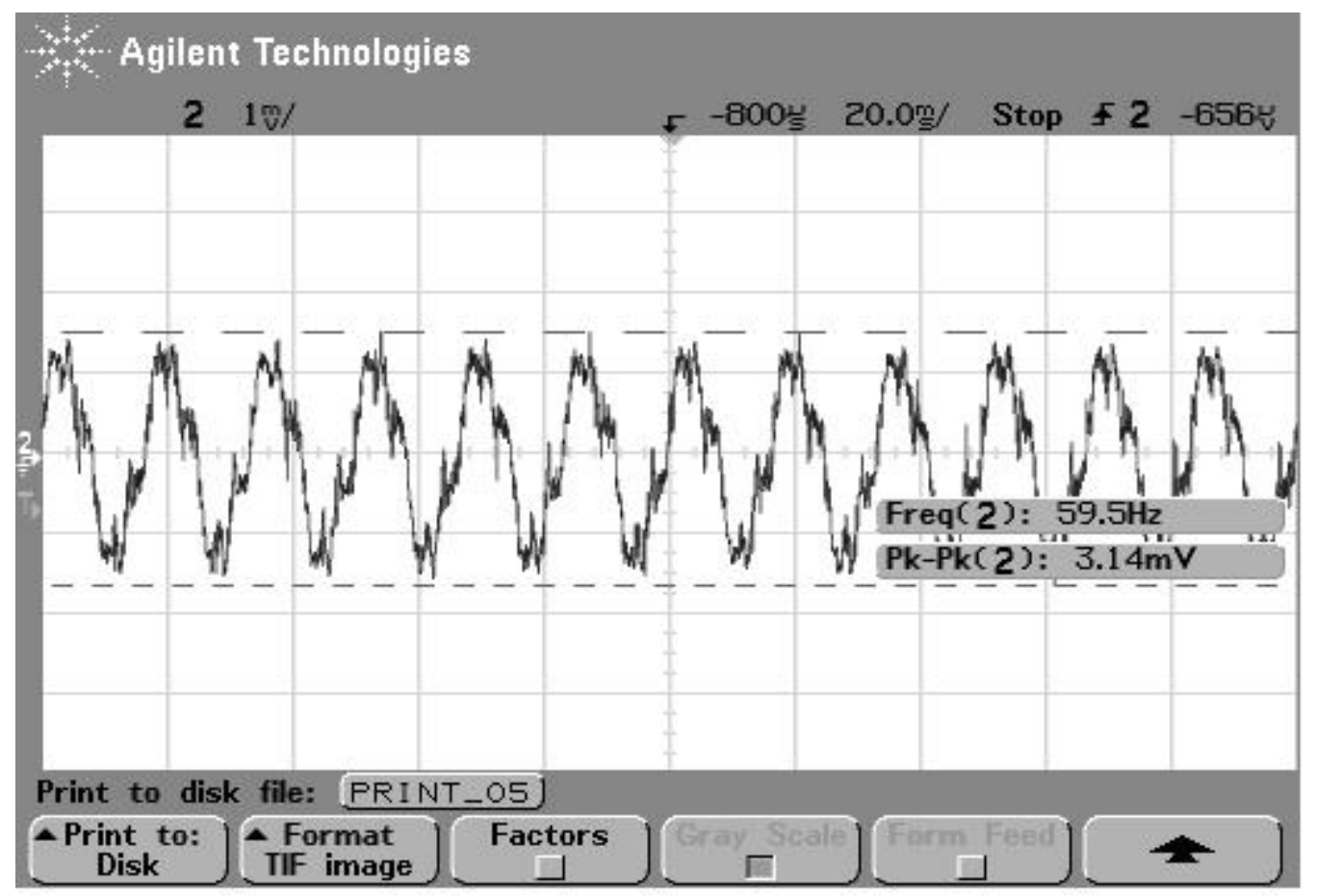

Figura 4.16 - Forma de onda obtida com 45,4 A e o quarto método. 


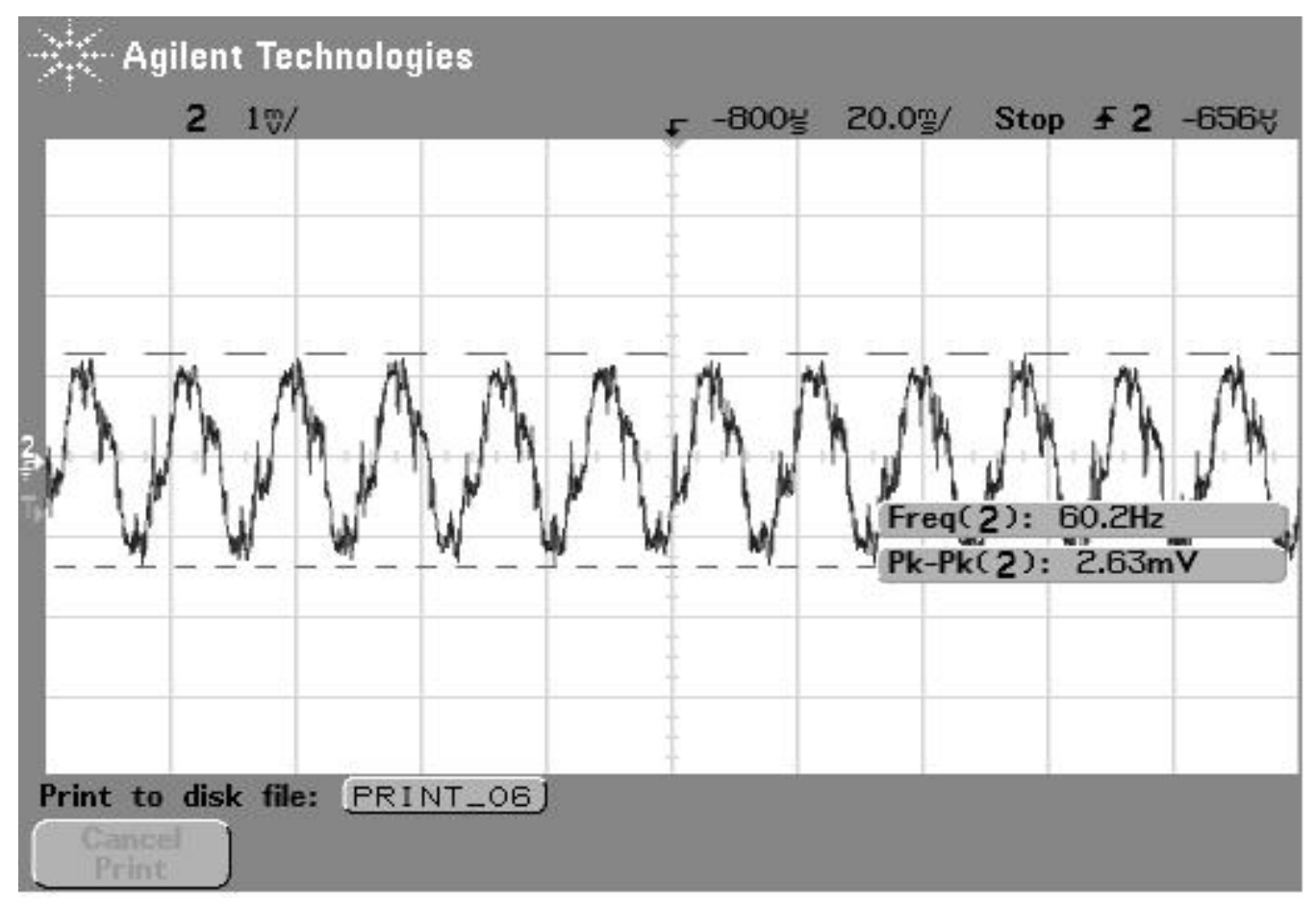

Figura 4.17 - Forma de onda obtida com 38,5 A e o quarto método.

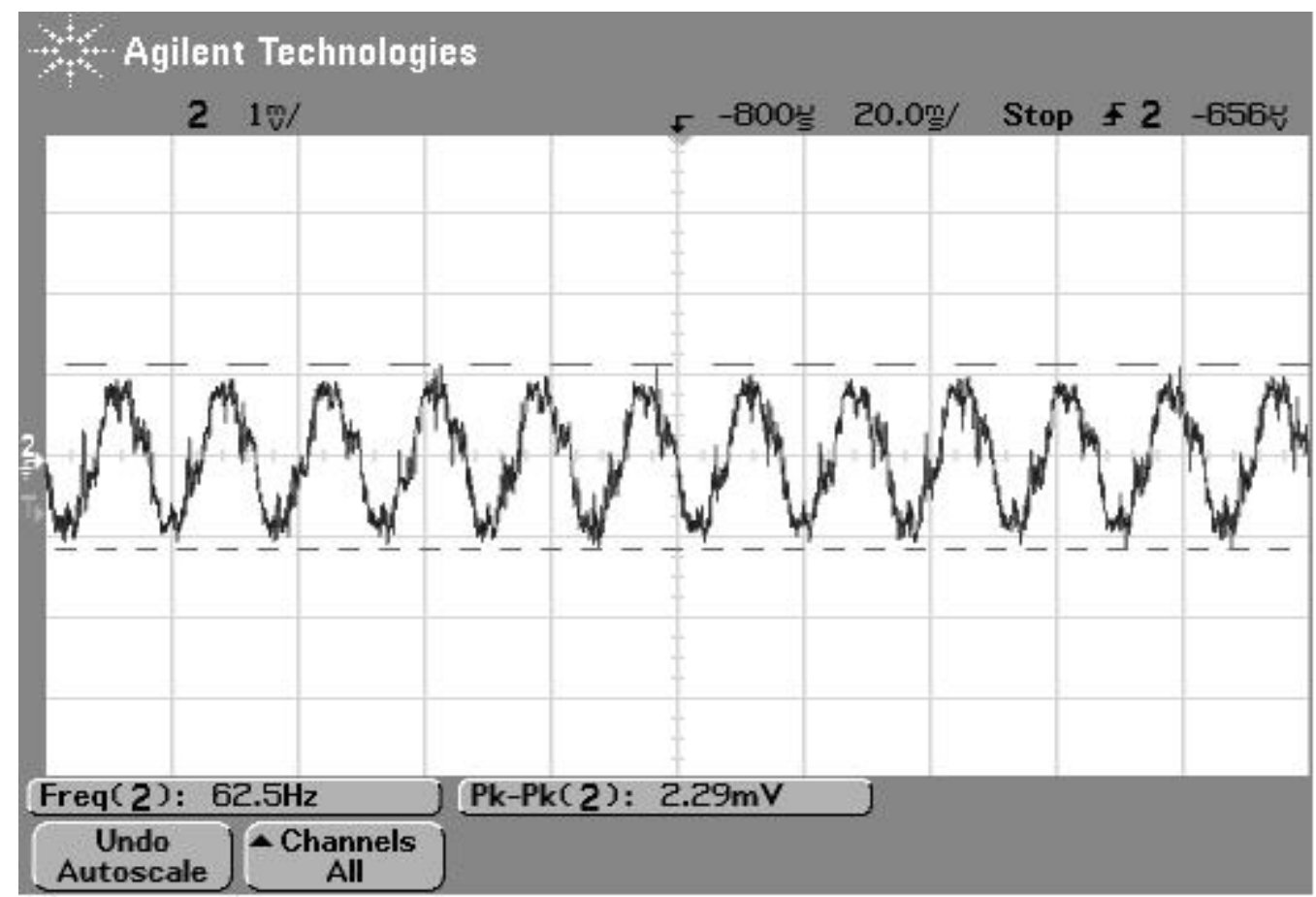

Figura 4.18 - Forma de onda obtida com 34,2 A e o quarto método.

O passo seguinte foi repetir os ensaios da terceira bobina com o quarto método, porém utilizando o filtro passa-baixas. 
Os resultados obtidos seguem abaixo na Tabela 4.10:

Tabela 4.10 - Valores de tensão obtidos com a terceira bobina, o quarto método e filtro.

\begin{tabular}{|c|c|c|}
\hline Corrente concatenada em A & Tensão $e_{2}$ esperada em $\mathrm{mV}$ & Tensão $e_{2}$ obtida em $\mathrm{mV}$ \\
\hline 45,4 & 0,87 & 0,98 \\
\hline 43,0 & 0,83 & 0,92 \\
\hline 40,8 & 0,78 & 0,86 \\
\hline 38,5 & 0,74 & 0,81 \\
\hline 36,3 & 0,67 & 0,73 \\
\hline 34,2 & 0,65 & 0,61 \\
\hline
\end{tabular}

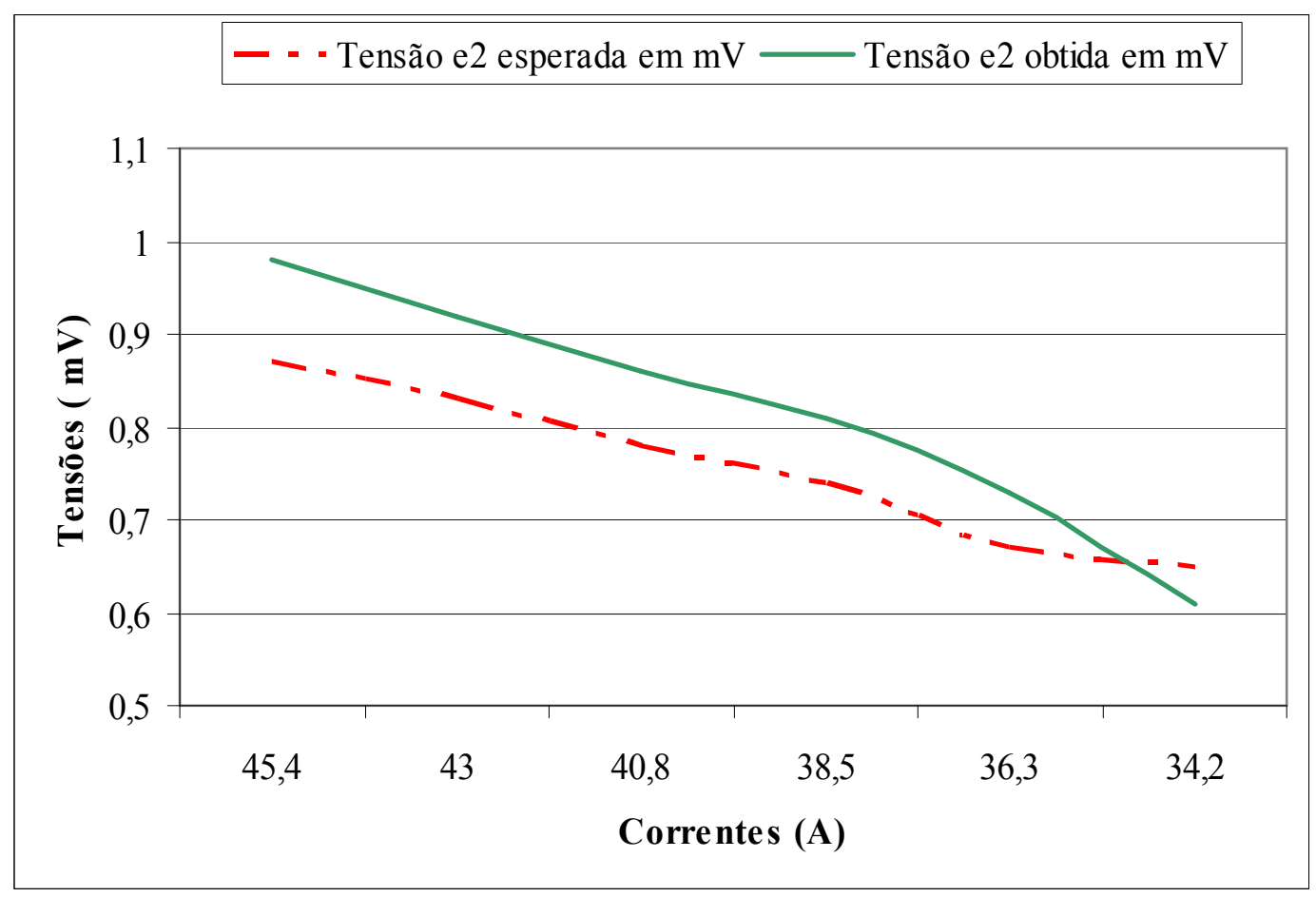

Figura 4.19 - Tensões esperada e medida com a terceira bobina, o quarto método e filtro.

As Figuras 4.20, 4.21 e 4.22 que seguem abaixo mostram as formas de onda capturadas para as correntes de 45,4 A, 38,5 A e 34,2 A respectivamente: 


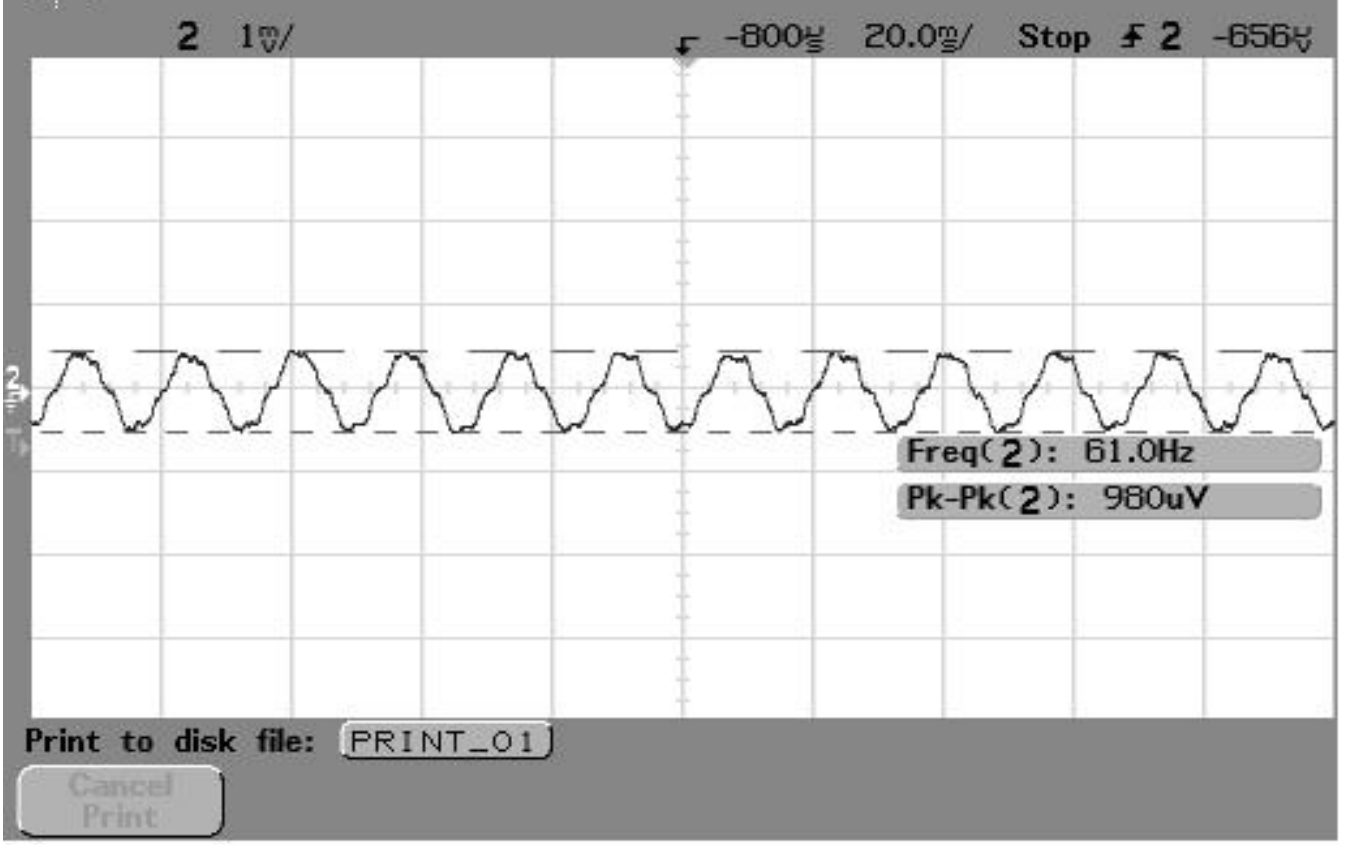

Figura 4.20 - Forma de onda obtida com 45,4 A, o quarto método e filtro.

\section{Agilent Technologies}

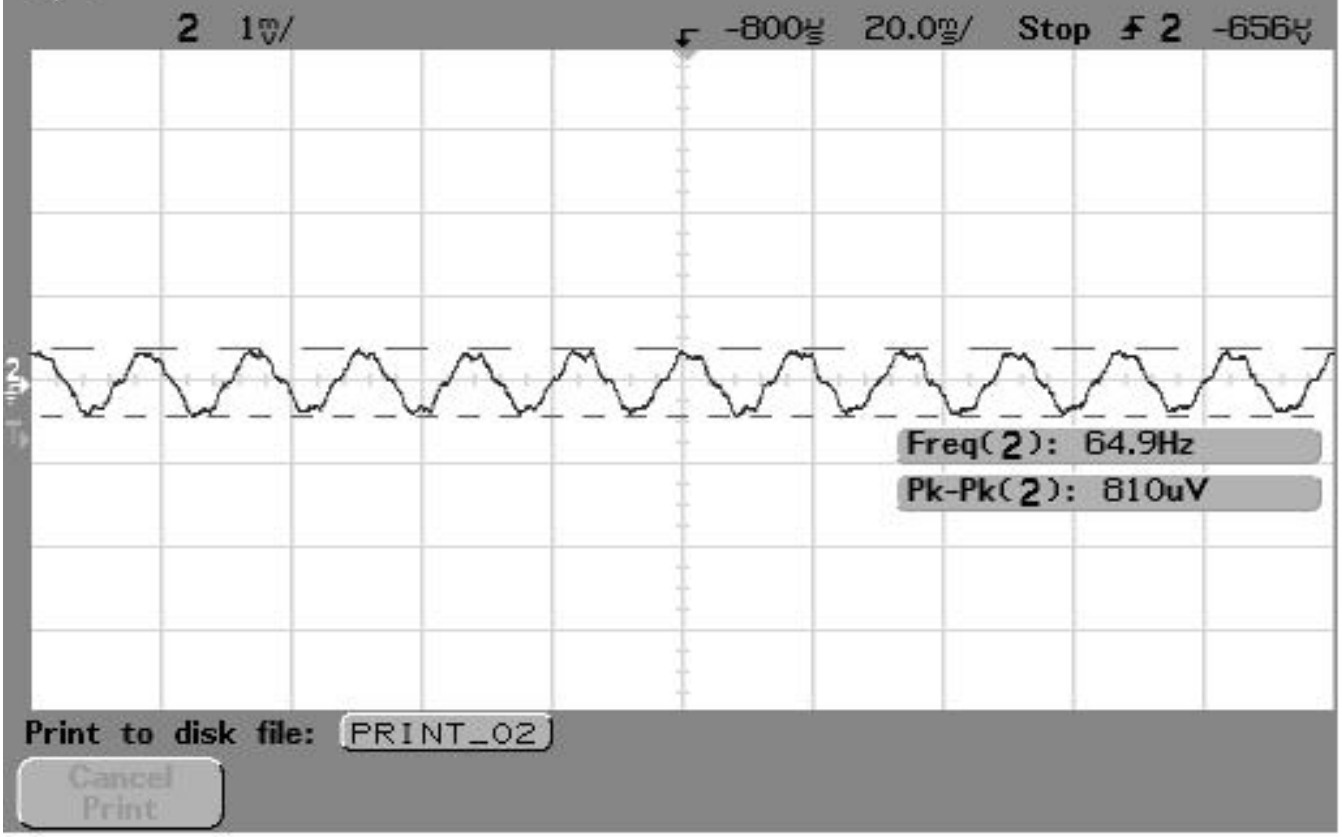

Figura 4.21 - Forma de onda obtida com 38,5 A, quarto método e filtro. 


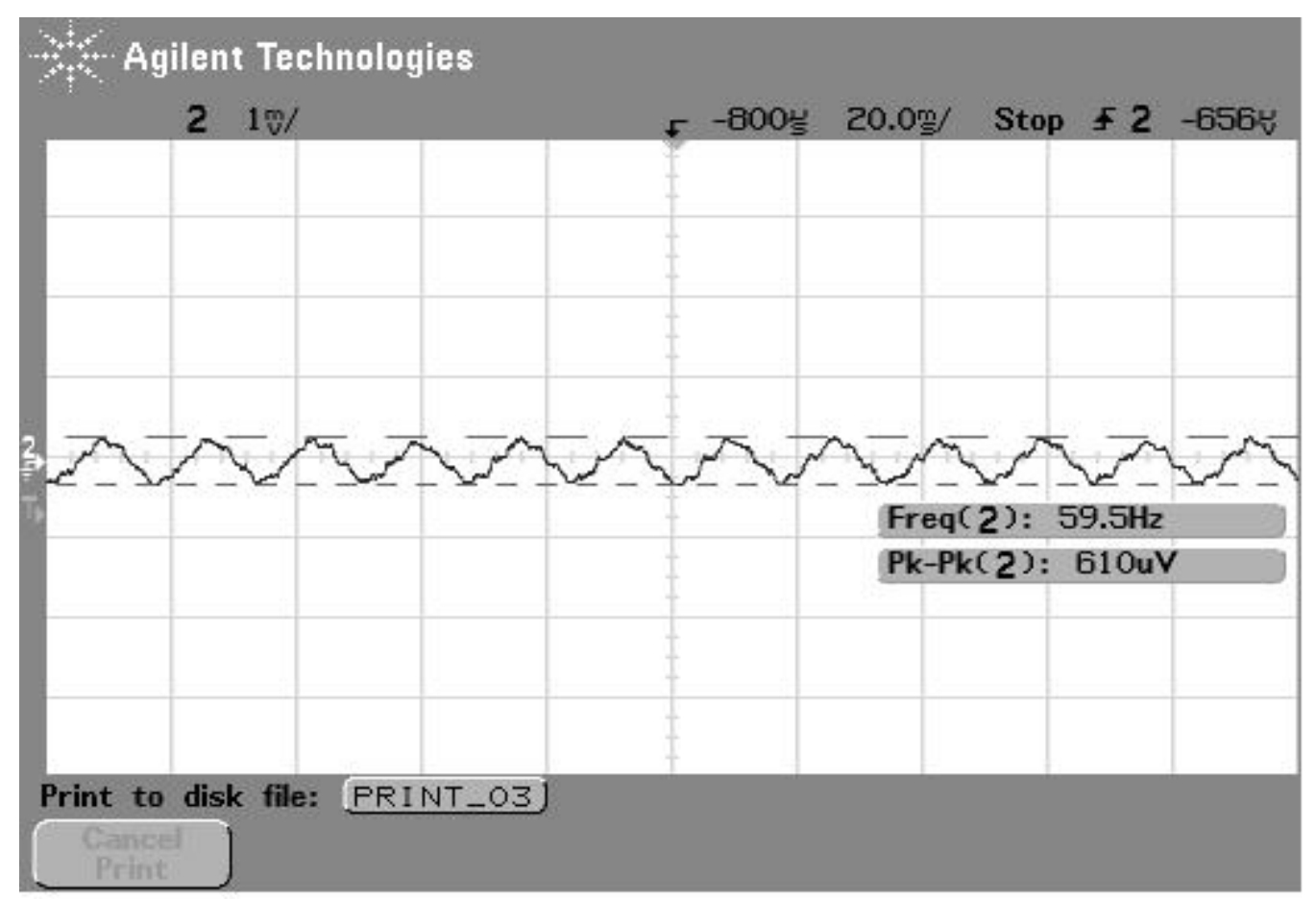

Figura 4.22 - Forma de onda obtida com 34,2 A, quarto método e filtro.

Como se pode verificar, os resultados obtidos ficaram bem próximos dos resultados esperados pela teoria, podendo ser considerados satisfatórios. As pequenas diferenças podem ser decorrentes do fato de nosso protótipo da bobina não possuir formas simetricamente perfeitas e ao fato do conjunto de fios condutores não estarem completamente centralizados.

Vale observar que utilizando a terceira bobina, o quarto método e o filtro, conseguimos os melhores resultados de todo o projeto.

\section{4 - TESTES E RESULTADOS COM CORRENTES MAIORES}

Diante dos últimos resultados obtidos, decidiu-se que seria interessante criar algum outro método que se permitisse utilizar correntes maiores de forma a se verificar o comportamento dos resultados e a validade dos métodos de ensaio empregados diante de um aumento de corrente.

Conseguiu-se encomendar na divisão técnico-laboratorial um cabo que possuísse pelo menos o dobro do comprimento do cabo condutor utilizado em todos os ensaios 
passados. Esse, apesar de apresentar certas desvantagens que serão comentadas mais adiante, foi a melhor solução encontrada para obtermos correntes um pouco maiores.

Para a nova seqüência de ensaios se utilizou, inicialmente, a terceira bobina e o terceiro método, porém, como o fio condutor é bem maior, foram dadas nove voltas por dentro da bobina. Os resultados esperados foram calculados partindo da equação (2.23) da maneira que segue abaixo:

$$
\begin{gathered}
\Phi(t)=1,745 \cdot 10^{-10} \cdot i(t) \cdot\left(\frac{0,6}{\sqrt{\left(\left(\frac{0,6}{2}\right)^{2}+(0,045)^{2}\right)}}\right) \mathrm{Wb} \\
\Phi(t)=1,745 \cdot 10^{-10} . i(t) \cdot 1,988 \mathrm{~Wb} \\
\Phi(t)=3,45 \cdot 10^{-10} . i(t) \mathrm{Wb}
\end{gathered}
$$

Com base nesse resultado o fluxo concatenado será aproximadamente:

$$
\lambda(t)=5,2 \cdot 10^{-8} . i_{1}(t) \text { Wb.espira }
$$

Observe que $I_{l}(t)=81.5 \operatorname{sen}(\omega \mathrm{t})$, onde $\omega=2 \pi f$ e freqüência $f=60 \mathrm{~Hz}$.

Portanto:

$$
\frac{d \lambda(t)}{d t}=1,59 \cos (377 t) \mathrm{Wb}
$$

Logo:

$$
e_{2}(t)=1,59 \cos (377 t) \mathrm{mV}
$$


Os resultados obtidos seguem na Tabela 4.11, lembrando que os resultados esperados para os outros valores de corrente foram calculados utilizando os mesmos métodos. Observa-se que o valor de $l$ utilizado foi maior devido ao fato do número de voltas dentro da bobina ser maior e, conseqüentemente, a corrente e o campo magnético gerado serem maiores.

Tabela 4.11 - Valores de tensão obtidos com a terceira bobina e o terceiro método.

\begin{tabular}{|c|c|c|}
\hline Corrente concatenada em A & Tensão $e_{2}$ esperada em mV & Tensão $e_{2}$ obtida em mV \\
\hline 81,5 & 1,59 & 5,19 \\
\hline 77,5 & 1,51 & 4,94 \\
\hline 73,4 & 1,43 & 4,66 \\
\hline 69,5 & 1,35 & 4,4 \\
\hline 64,9 & 1,26 & 4,27 \\
\hline 61,1 & 1,19 & 4,0 \\
\hline
\end{tabular}

Em seguida, repetimos os testes, porém utilizando o quarto método e o filtro. Os resultados obtidos seguem na Tabela 4.12.

Tabela 4.12 - Valores de tensão obtidos com a terceira bobina, o quarto método e o filtro.

\begin{tabular}{|c|c|c|}
\hline Corrente concatenada em A & Tensão $e_{2}$ esperada em $\mathrm{mV}$ & Tensão $e_{2}$ obtida em $\mathrm{mV}$ \\
\hline 81,5 & 1,59 & 3,8 \\
\hline 77,5 & 1,51 & 3,72 \\
\hline 73,4 & 1,43 & 3,66 \\
\hline 69,5 & 1,35 & 3,56 \\
\hline 64,9 & 1,26 & 3,49 \\
\hline 61,1 & 1,19 & 3,41 \\
\hline
\end{tabular}

Utilizando correntes maiores os resultados se afastaram um pouco dos resultados esperados teoricamente. Uma das prováveis causas para se obter esses resultados foi o fato de agora se estar trabalhando com correntes e campos maiores, o que conseqüentemente, gera uma maior interferência dos campos gerados pelos condutores externos. Devido à impossibilidade de utilizar fios condutores maiores não fomos capazes de realizar ensaios utilizando um espaçamento maior entre a bobina e os fios condutores externos. 


\section{5 - CONCLUSÕES}

\section{1 - CONCLUSÕES GERAIS}

Primeiramente, testamos as quatro Bobinas de Rogowski obtidas no departamento. Foram realizados vários ensaios com essas bobinas, contudo, não conseguimos obter nenhum sinal em regime permanente nem na freqüência da rede de alimentação. Devido ao fato das bobinas serem lacradas, não conhecíamos seus aspectos construtivos. Uma vez que esses aspectos são de fundamental importância para se calcular a tensão no secundário, fomos levados a projetar e construir nossas próprias bobinas.

O projeto foi baseado num modelo matemático desenvolvido a partir dos aspectos construtivos da bobina. Dentre eles, principalmente o fato do enrolamento secundário desta ser mantido em aberto e o da ausência de um núcleo ferromagnético. O projeto também foi fundamentado no princípio de funcionamento da bobina que é baseado na Lei de Faraday-Lenz, ou lei da indução eletromagnética A partir do princípio de funcionamento, apresentou-se um modelo matemático, observando o acoplamento magnético entre seus enrolamentos, para se encontrar a relação entre a tensão no secundário e a corrente elétrica no primário.

O projeto contou basicamente com três etapas principais de mudanças e adaptações da bobina de forma a melhorar cada vez mais os resultados obtidos, aproximando-os cada vez mais dos resultados esperados teoricamente. Foram desenvolvidos métodos de ensaio com objetivo de aperfeiçoar a medição para baixas correntes. A cada etapa de desenvolvimento foram encontradas dificuldades nas formas de medição, todavia, os erros foram identificados e corrigidos.

Como foi possível perceber durante a leitura desse trabalho, houve muitos problemas e enfrentamos muitas dificuldades até conseguirmos obter um sinal que pudesse ser considerado satisfatório. As condições do laboratório são boas para os ensaios que são normalmente realizados nele (laboratório de instalações elétricas), no entanto, devido à natureza desse projeto (um transformador de corrente projetado para medir correntes muito altas), o laboratório não pode ser considerado satisfatório. Logo no inicio já 
sentimos as dificuldades de trabalhar com baixas correntes bem como outras dificuldades citadas em capítulos anteriores. Como ficou evidente no inicio do capítulo quatro, os primeiros resultados obtidos foram muito discrepantes dos valores esperados em teoria, o que causou um grande desânimo no projeto. Porém, com estudo, pesquisa e paciência foi possível desenvolver métodos de ensaio e até mesmo novas bobinas de forma a melhorar os sinais obtidos.

À medida que avançávamos no projeto, cada novo progresso vinha sempre acompanhado de uma nova dificuldade. Aos poucos as dificuldades, dentro das condições possíveis de trabalho, eram sendo superadas até que finalmente conseguimos uma leitura favorável e considerada satisfatória.

Um fato importante que foi observado durante a realização dos ensaios é a influência que a distância entre a bobina e os condutores externos exerce no sinal obtido. Quanto menor à distância, maior o valor de tensão obtido, evidenciando a influência dos campos externos. Outra conseqüência desse fato é que para correntes maiores, como os campos gerados são maiores, a distância entre a bobina e os fios condutores externos deve ser maior de maneira a manter um resultado coerente com a teoria.

É válido ressaltar também a importância de se manter o condutor interno à bobina o mais centralizado possível de maneira a manter certa simetria do campo magnético interno à bobina.

Apesar das dificuldades enfrentadas, podemos afirmar que os objetivos propostos foram alcançados e poderão servir de base para trabalhos futuros que visem analisar com maior profundidade e melhorar o desempenho da bobina de Rogowski para leitura de correntes mais baixas.

\section{2 - SUGESTÕES PARA TRABALHOS FUTUROS}

Ainda há muito trabalho a ser feito no que diz respeito à bobina de Rogowski antes de ser possível afirmar que a teoria e a prática desse tipo de transformador estão completamente esclarecidas. É preciso mais pesquisa e trabalho, antes de podermos prever com certeza absoluta, ou pelo menos com um erro aceitável, os resultados e o 
comportamento dessa bobina, levando em consideração as mais variadas situações de leitura e valores de corrente a que esse tipo de equipamento normalmente é submetido.

É necessário um estudo mais aprofundado sobre os campos magnéticos envolvidos, de maneira a determinar com precisão o grau de influência que os campos externos à bobina exercerão sobre o ensaio. É interessante realizar esse estudo dos campos envolvidos porque através dele será possível determinar com maior segurança o comportamento do campo de acordo com a variação da corrente sendo possível, dependendo do método de ensaio, determinar uma taxa de erro coerente aumentando a aplicabilidade prática do equipamento.

Como os sinais obtidos são muito pequenos é possível que haja outras fontes de campos externos, além dos próprios condutores externos à bobina, que possam causar alterações nos valores medidos.

Sabendo o comportamento dos campos magnéticos envolvidos, pode-se realizar também, um estudo que tivesse como objetivo analisar a possibilidade, e a viabilidade de se projetar e utilizar uma blindagem magnética de forma a atenuar a influência de campos externos indesejáveis. 


\section{REFERÊNCIAS BIBLIOGRAFICAS}

[1] HOMRICH, Roberto Petry; RUPPERT FILHO, Ernesto; FREITAS, Rafael Cassiolato de. Transdutor de Corrente de Tipo Bobina de Rogowski. Science \& Engineering Journal, Edição Especial, p. 101-105, 2003.

[2] RAMBOZ, John D. Machinable Rogowski Coil, Design, and Calibration. IEEE Transactions on Instrumentation and Measurement, vol. 45, № 2 (Abril, 1996), p. 511-515, 1996.

[3] JALEBI, Ehsan Abdi; ROBERTS, Paul; MCMAHON, Richard. Real Time Rotor Bar Current Measurements Using a Rogowski Coil Transmitted Using Wireless Technology.

[4] JINGSHENG, Lao et al. Studies of Rogowski Oil Current Transducer for Low Amplitude Current (100A) Measurement. CCECE 2003 - CCGEI 2003: IEEE, Montréal, 0-7803-7781-8/03 (Mai/2003), p.463-466, 2003.

[5] OATES, C. The Design and Use of Rogowski Coils. [s.1. : s.n.]. [198-].

[6] KRAUS J.D. \& CARVER, K.R.. Eletromagnetismo. Rio de Janeiro : Editora Guanabara. 1978.

[7] PAUL, Clayton R; NASAR, Ayed A.. Introduction to Electromagnetic Fields. New York : Mcraw-Hill International Edition. $2^{\text {nd }}$ ed. 1987

[8] J. D. KRAUS. Eletromagnetismo - . McGraw-Hill. 4a edição. 1992.

[9] HAYT JR., William H., BUCK, John A.. Eletromagnetismo. Rio de janeiro : Livros Técnicos e Científicos Editora SA. 6a edição. 2003.

[10] SEN, P. C. Principles of Eletrric Machines and Power Eletronics. $2^{\text {nd }}$ ed. United States : John Wiley \& Sons, Inc. 1997. 
[11] SWOKOWSKI, Earl W.. Cálculo com Geometria Analítica. - Vol 1. Editora Makron Books. 1995.

[12] SWOKOWSKI, Earl W.. Cálculo com Geometria Analítica. - Vol 2. Editora Makron Books. 1995. 